\title{
Equatorial Guinea Education Sector Diagnostic
}

June 22, 2017 


\section{Acknowledgements}

This report is a result of contributions from Lucy Bassett (Education Specialist, World Bank), Emanuela Di Gropello (Program Leader, World Bank), Jeffery H. Marshall (Consultant), and Julio Alejandro Abril Tabares (Senior Economist, World Bank). 


\section{Table of Contents}

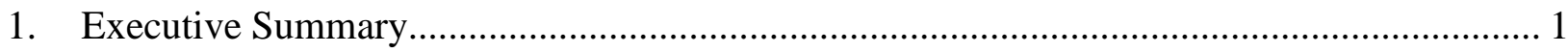

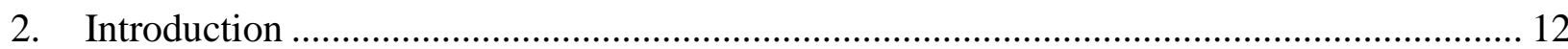

3. Part A. Context, Background and Education Sector Overview............................................. 13

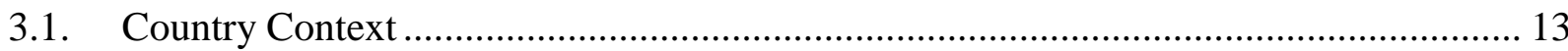

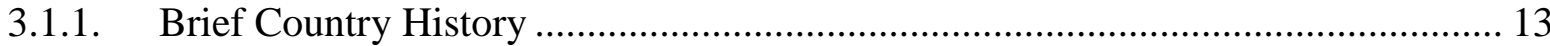

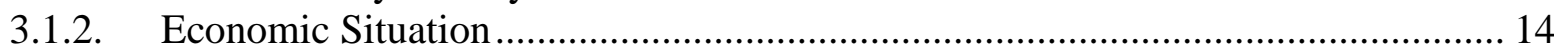

3.1.3. Poverty and Shared Prosperity ............................................................................ 15

3.2. Overview of Education Sector in Equatorial Guinea ................................................ 16

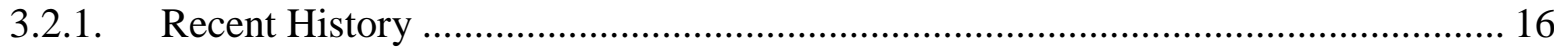

3.2.2. Education Sector Goals and Priorities .............................................................. 17

3.2.3. Education System Structure and Governance..................................................... 19

3.3. Education Sector Indicators, Trends and Comparisons ............................................... 26

3.3.1. Education Indicators and Trends ...................................................................... 26

3.3.2. Equity Comparisons: Gender, Socioeconomic Status (SES), and Location ............ 42

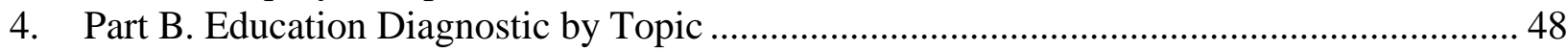

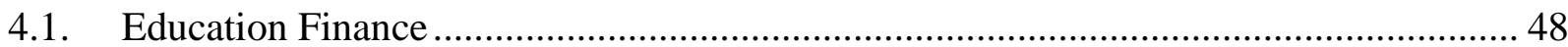

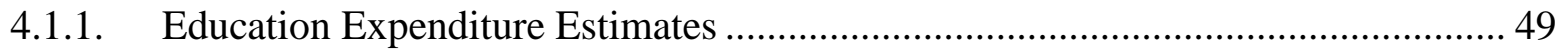

4.1.2. Is Equatorial Guinea Spending Enough and Well on Education? And Why?........ 53

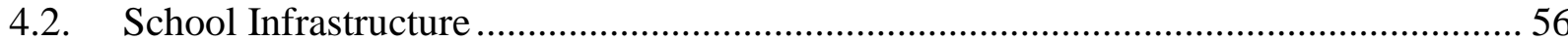

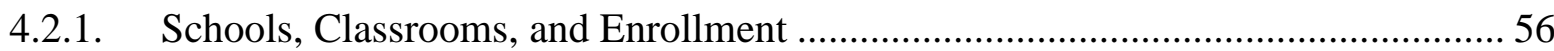

4.2.2. Public Versus Private School Provision ………..................................................... 58

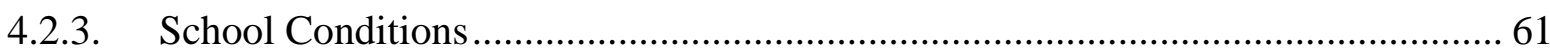

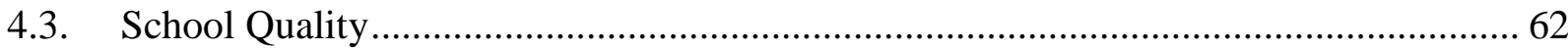

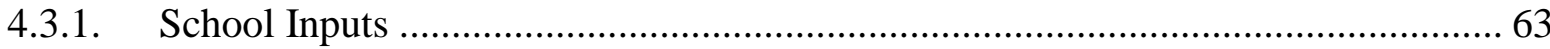

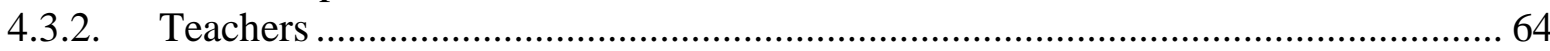

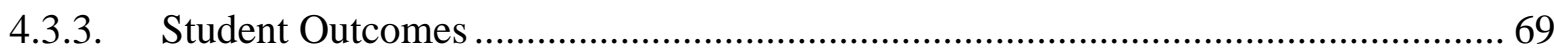

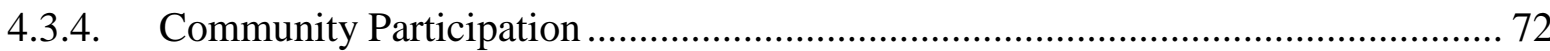

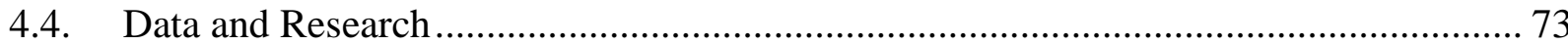

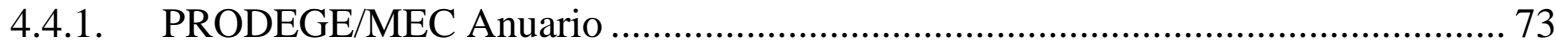

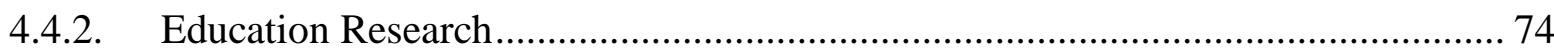

4.5. Spotlight on Higher Education and TVET ………................................................. 74

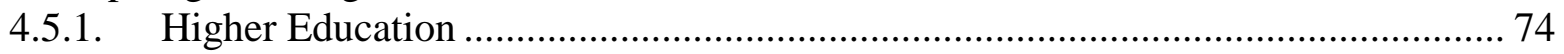

4.5.2. Technical Education (Professional and Vocational Training) ................................. 75

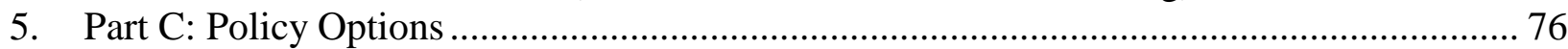

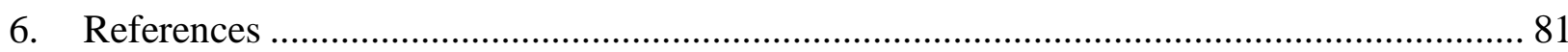




\section{Abbreviations and Acronyms}

ACCEG Association of Catholic Education Center of EQG

ANGE Agencia Nacional Guinea Ecuatorial

DHS Demographic and Health Survey

EDSGE Encuesta Demográfica y de Salud

EFA Education for All

EGMA Early Grade Math Assessment

EGRA Early Grade Reading Assessment

EMIS Education Management Information System

EQG Equatorial Guinea

ESBA Educación Secundaria Básica

GDP Gross Domestic Product

GER Gross Enrollment Ratio

GNI Gross National Income

GoEG Government of Equatorial Guinea

INEGE Instituto Nacional de Estatistica Guinea Ecuatorial (National Statistics Office)

LMD Licenciado, Master y Doctorado (Bachelors, Masters, and PhD)

MEC Ministry of Education and Science (Ministerio de Educación y Ciencia)

MDG Millennium Development Goal

NER Net Enrollment Ratio

NGO Nongovernmental Organization

ODA Official Development Aid

PNDES Plan Nacional de Desarrollo Económico y Social

PER Public Expenditure Review

PIMM Public Investment Management and Monitoring

PRODEGE Programa de Desarrollo Educativo de Guinea Ecuatorial

RAS Reimbursable Advisory Services

SABER Systems Approach for Better Education Results

SDI Service Delivery Indicator

SES Socioeconomic Status

SSA Sub-Saharan Africa

TVET Technical and Vocational Education and Training

UIS UNESCO Institute of Statistics

UNDP United Nations Development Programme

UNGE Universidad Nacional de Guinea Ecuatorial

USAID U.S. Agency for International Development 


\section{Executive Summary}

The Government of Equatorial Guinea (GoEG) requested financial, analytical, and technical support from the World Bank during the country's protracted economic recession. Given the prioritization of education in the country's National Development Plan, the World Bank agreed to undertake an education sector diagnostic study to (a) help the World Bank better understand the education sector, including the main challenges and policy priorities of the government; (b) facilitate dialogue between the World Bank and GoEG in the education sector and suggest options to move forward in the current economic downturn; (c) provide supporting background for a parallel activity that is focusing on public expenditures in the social sector (Public Expenditure Review, PER); (d) support the activities that are planned as part of the National Development Plan's Programa Mayor Educación Para Todos; and (e) provide education sector stakeholders with an updated summary of the sector including a review of recent indicator trends and program activities.

This diagnostic focuses primarily on primary and secondary education, while also providing some information on TVET and higher education, especially where relevant to the other subsectors. It is also intended to update an earlier (2006) World Bank-supported education sector diagnostic.

\section{Data and Methodology}

In addition to the findings from the previous diagnostic, this report relies on a variety of sources of data, including:

1. Interviews conducted with the Ministry of Education and Science (Ministerio de Educación y Ciencia, MEC) officials, international education partners, and other stakeholders about the main challenges and priorities in the sector, as well as detailed data on specific programs and activities

2. Data from statistical annuals (Anuarios), the 2011 Demographic and Health Survey (DHS, Encuesta Demográfica y de Salud, EDSGE-I), and the United Nations Educational, Scientific, and Cultural Organization (UNESCO) Institute of Statistics (UIS)

3. Existing education research ${ }^{1}$

4. Additional qualitative data obtained during field visits to schools and district education offices. Appendix A includes a summary of the field work and interviews that were completed as part of the World Bank mission in June 2016.

5. The most recent (2015) budget execution summary in the Ministry of Finance Budget Law 2016 for education finance information.

All analyses of recent statistics and trends in education (for example, enrollment, repetition, drop-out rates, financing, etc.) are conducted based on this available data. No new data collection

\footnotetext{
${ }^{1}$ For example, Bivini Mangue's (2015) summary of Education For All (EFA) and various studies carried out by the Programa de Desarrollo Educativo de Guinea Ecuatorial (for example, PRODEGE 2009, 2011).
} 
was conducted for this study. Given data limitations, the diagnostic is not able to provide additional information on the determinants of learning and characteristics of the quality assurance framework and all the required details on the private schooling sector, or undertake cost-effectiveness comparisons across public and private school systems. Additional information and analysis on education financing will be possible under an upcoming Public Expenditure Review (PER).

\section{Organization of the Report}

The diagnostic first provides country context and an overview of the education sector. It then describes recent trends in education (for example, enrollment, repetition), both within the country and compared to other countries in the region and GDP peers, ${ }^{2}$ and highlights key challenges in areas such as education finance, quality, and learning outcomes. The report concludes with possible policy actions to support the government's education goals, framed within the current economic crisis that the country is facing.

\section{Country Context and Education Sector Overview}

\section{Country Context}

Equatorial Guinea (EQG), a small country on the west coast of Sub-Saharan Africa (SSA), is considered to be one of the least free countries in the world. It benefitted from significant economic growth owing to the discovery of oil in the mid-1990s; however, since late 2012, fiscal constraints, investment cuts, and reduced revenue from oil sales resulted in a contraction of the gross domestic product (GDP). With little prospect of an upturn in growth, this economic crisis in EQG poses significant risks to the country, but could also offer an opportunity for needed reforms.

Data on poverty are limited and do not provide a sense of trends over time; however, there are sharp differences in basic welfare indicators between the mainland relative to the islands and among individuals with lower levels of education and wealth.

\section{Education Sector Overview}

The education system is made up of four main levels: preschool, primary, secondary, and higher education (see Table 1.1), with preschool and primary considered mandatory. Complementary education modalities include Permanent Training and Adult Literacy Education, Long Distance Education, and Special Needs Education. The general management of the entire education system is assigned to the Ministry of Education and Science (MEC). Its principal functions include proposing education policies and programs; approving curricular programs; creating and managing public education centers and approving and regulating private centers; coordinating and stimulating different social and economic stakeholder efforts; and issuing and accrediting diplomas and certifications.

\footnotetext{
${ }^{2}$ GDP peers were selected as those with GDP per capita within US $\$ 1,000$ below or above EQG's GDP per capita (or within 10 percent of EQG's per capita GDP), using 2015 figures from the World Development Indicators (WDI) http://data.worldbank.org/indicator/NY.GDP.PCAP.CD
} 
Table 1.1. Education Levels, Modalities, and Enrollment Figures (2014-15)

\begin{tabular}{|c|c|c|c|c|}
\hline Level & Enrollment & \multicolumn{2}{|c|}{ Modality } & Age \\
\hline \multirow{3}{*}{ Higher Education } & $\mathrm{n} / \mathrm{a}$ & \multicolumn{2}{|c|}{ PhD (3 years) } & $\mathrm{n} / \mathrm{a}$ \\
\hline & $\mathrm{n} / \mathrm{a}$ & \multicolumn{2}{|c|}{ Master's (2 years) } & $\mathrm{n} / \mathrm{a}$ \\
\hline & 7,971 & \multicolumn{2}{|c|}{ Licenciado (4 years) } & $\mathrm{n} / \mathrm{a}$ \\
\hline \multirow{3}{*}{ Secondary Education } & $\mathrm{n} / \mathrm{a}$ & $\begin{array}{l}\text { University orientation } \\
\text { course (1 year) }\end{array}$ & $\begin{array}{l}\text { Advanced technical and } \\
\text { professional training ( } 2 \text { years) }\end{array}$ & $18-19$ \\
\hline & $\begin{array}{c}7,941 \\
\text { (Bachillerato) }\end{array}$ & Bachillerato (2 years) & $\begin{array}{l}\text { Basic technical and professional } \\
\text { training ( } 2 \text { years) }\end{array}$ & $17-18$ \\
\hline & 27,027 & \multicolumn{2}{|c|}{ Basic secondary education (4 years) } & $13-16$ \\
\hline \multirow{2}{*}{ Primary Education } & 36,481 & \multicolumn{2}{|c|}{ 2nd cycle: grades 4-6 (3 years) } & $10-12$ \\
\hline & 56,915 & \multicolumn{2}{|c|}{ 1st cycle: grades $1-3$ (3 years) } & $7-9$ \\
\hline \multirow{2}{*}{ Preschool Education } & 39,596 & \multicolumn{2}{|c|}{ Preschool (3 years) } & $4-6$ \\
\hline & 2,512 & \multicolumn{2}{|c|}{ Childcare (3 years) } & $1-3$ \\
\hline
\end{tabular}

Source: Programa de Desarrollo Educativo de Guinea Ecuatorial (PRODEGE)/MEC Anuario (2015-16); Ley General de Educación No. 5/2007.

Education centers can be public or private and despite having more public than private centers, the actual number of students enrolled in preschool, primary, and secondary education shows that education in EGQ is mainly privately delivered.

\section{Key Issues and Challenges}

\section{Poor Educational Outcomes}

EQG trails in education development given its substantial GDP per capita and could do more to convert its oil wealth into human wealth.

According to available data, both learning outcomes and quality of schooling are poor. In 2011, more than 70 percent of grade 1 students were classified as Low Achievement (based on the test scoring categorization) in non-reading test components and at the end of grade 1: few students were able to write more than five words. The results in mathematics were also low, as fewer than 10 percent of grade 1 students achieved a High Achievement level. There are no national assessments, making it difficult to track learning outcomes and know how to improve them.

Several factors contribute to poor education quality, including low teacher qualifications, lack of learning materials, and poor physical conditions. While teacher training is improving, there are still low rates of qualified teachers ( 5 percent in preschool, 54 percent in primary school, and 69 percent in secondary school) and no mechanisms to hire or promote teachers based on performance. Moreover, classes tend to be teacher-dominated, with a heavy reliance on dictation and copying, and limited use of problem solving and student-initiated dialogue. Learning materials, such as textbooks, are often lacking. For example, in most primary grades, the ratio of students to textbooks is above 3, and in some cases this ratio is much higher. Evidence shows little improvement in school infrastructure, both physical conditions and 
maintenance, between 2008 and 2015. Community and parent participation seems to be low, suggesting weak linkages between parents and schools.

High quality support and monitoring is lacking. One of the greatest challenges facing the education system in EQG is to create an effective monitoring system that guarantees high-quality education in all schools. While inspectors or supervisors are in place, there is no system capable of addressing school needs on an individual basis, across very different contexts and realities. Information is a critical input in this process, but these systems also require a very strong institutional commitment to monitoring, and a strengthening of local education offices and the role they play in the system.

Repetition and dropout rates are very high in EQG, resulting in low learning outcomes. Large numbers of students are repeating the earliest grades, often multiple times, before eventually dropping out. As of 2015, grade 1 students outnumbered grade 6 students by more than two to one. Although repetition rates for grade 1 have decreased over the past decade, still a quarter (25 percent) of all first-graders repeat the grade (in 2014-15) and repetition rates for grades 2-5 remain at 10-20 percent. These figures are high compared to other African countries as well as countries with similar GDP per capita (see Figure 1.1 and Figure 1.2).

Figure 1.1. Repetition Rate in Primary Compared to Selected African Countries

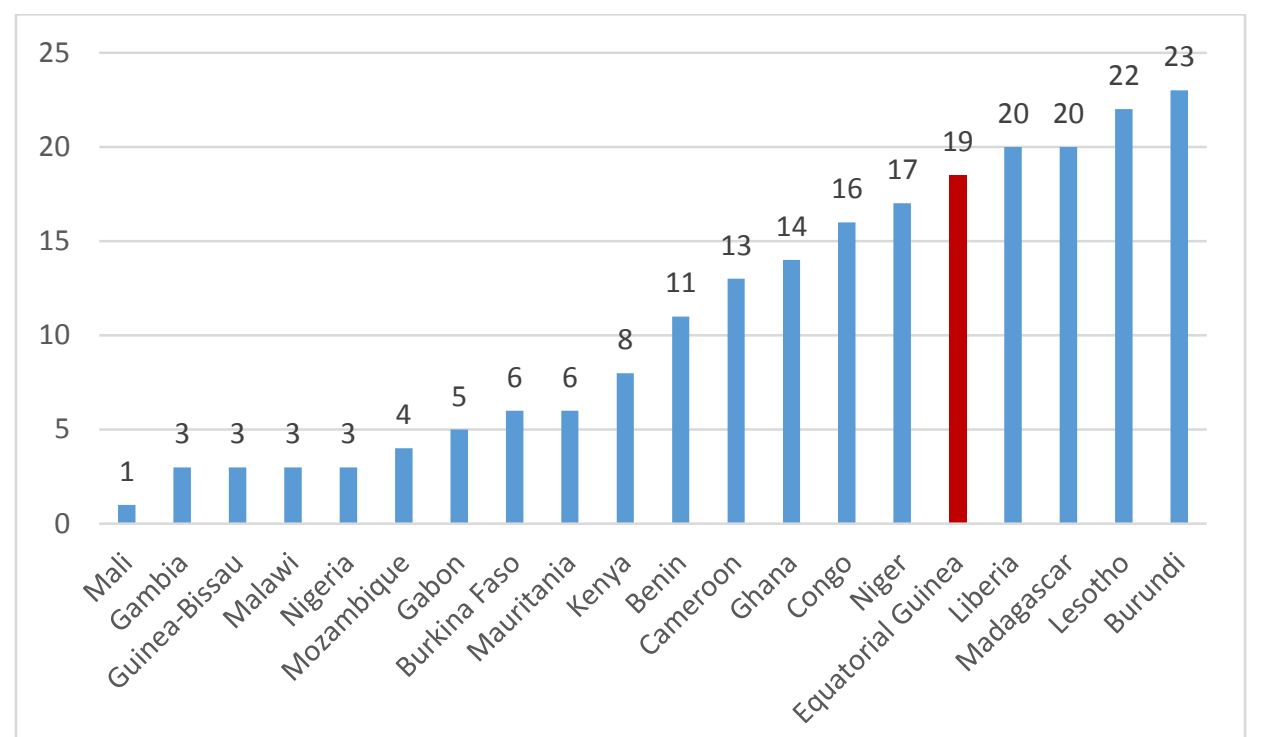

Source: United Nations Educational, Scientific, and Cultural Organization (UNESCO) Institute for Statistics (UIS), latest available data. 
Figure 1.2. Repetition Rate in Primary Compared to GDP Peers

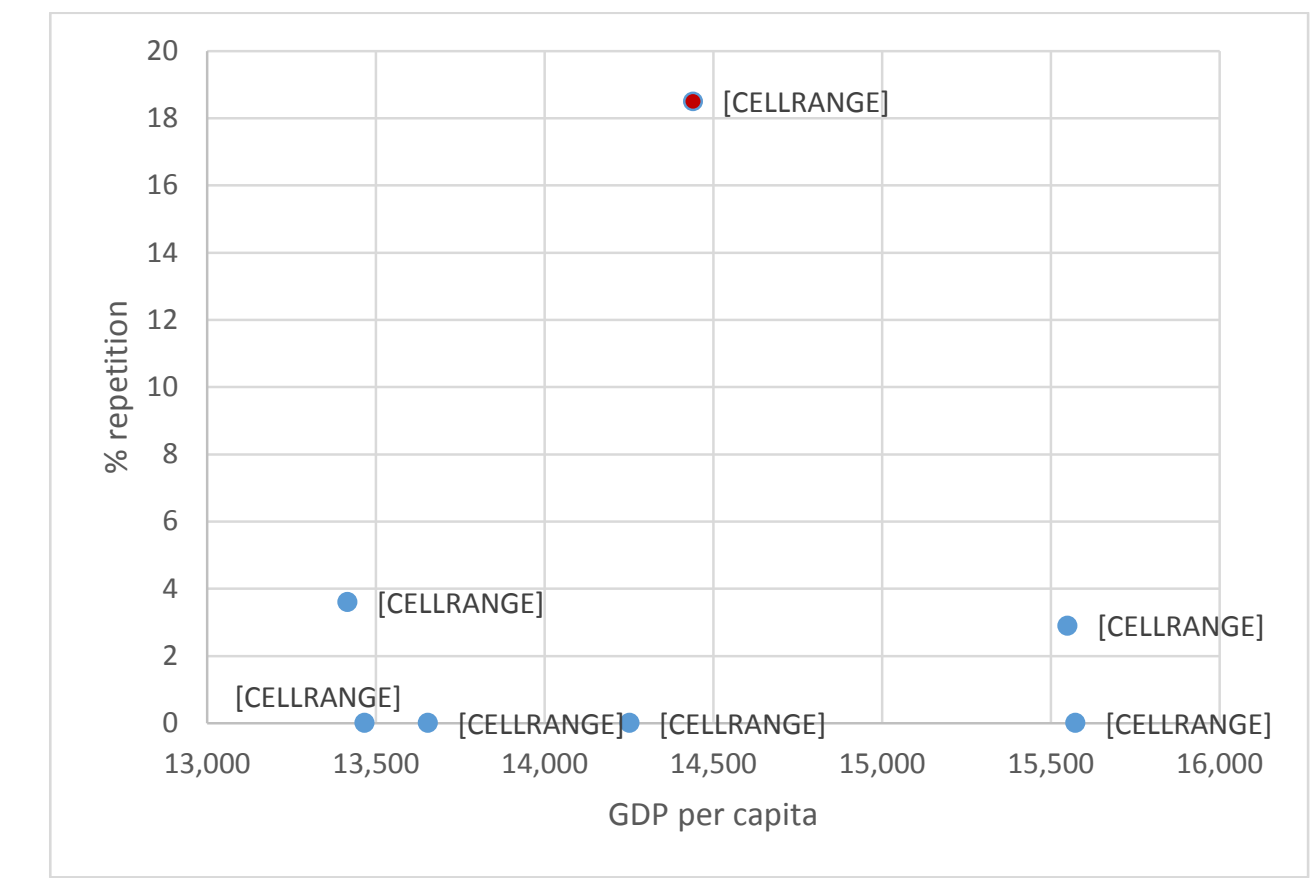

Source: UIS (for repetition rates); WDI (for GDP per capita 2015).

Research shows negative consequences to high repetition rates, including faster dropout and less learning. Several options exist to address the problem of high repetition rates. One option is ensuring access to quality preschool, which prepares young people for primary school, and should, in turn, reduce repetition and dropout rates. Options for children already in the primary system include remedial education and automatic grade progression. However, automatic grade progression comes with a risk that children will not learn in the next grade unless teacher training is based on differentiated teaching.

Inequitable Access

Preschool net enrollment in 2015 was 42 percent, but this is concentrated largely in urban areas (with $\mathbf{7 5}$ percent of preschool enrollment), suggesting that rates are very low in rural areas. Preschool enrollment is similar amongst girls and boys.

Access to primary education is relatively high in EQG, with net enrollment ratios between 6086 percent, depending on the data source used. However, when compared to other African countries and considering its income level, both primary gross and net enrollment rates are relatively low. Given that the country is facing an economic crisis, enrollment is likely to fall because families have less money available to pay for school or related expenses (school supplies, transportation, clothes, and so on). High gross enrollment ratios indicate significant overage enrollment in EQG, at a rate higher than GDP peers. School enrollment rates in primary school are roughly equal across income quintiles (89 percent for the riches quintile vs. 83 percent for the poorest quintile) and amongst boys and girls. 
Access to secondary education is much lower and inequalities based on gender, income, and geographical area are clear at this level. The latest available net enrollment ratio ${ }^{3}$ is 43.6 percent in secondary school. Enrollment is nearly 4 times higher in the richest quintile (63 percent) compared to the poorest quintile (15 percent). Disparities in enrollment are stark between urban and rural areas, with enrollment nearly double in urban areas. Although girls' enrollment is higher overall in secondary school than boys (46 vs. 41 percent, respectively), at age 16 boys' enrollment surpasses that of girls. For the 17-21 age range the average male advantage in attendance is slightly more than 10 percent.

Higher education is limited. The higher education system in EQG is still relatively new, and mainly consists of the offerings at the Universidad Nacional de Guinea Ecuatorial (UNGE). Between 2006 and 2015 there was a steep decline of the enrollment in the education school, which affects the pool of potential trained teachers. In EQG there is very little original research in education conducted in EQG to draw on, but more is needed to learn more about the education system, especially qualitative data that focuses on schooling processes.

Professional and technical education is concentrated in the capital and vocational training programs do not seem to be well matched with economic opportunities. Very few programs aim to develop skills for agriculture and fishery, two of the sectors the government has identified as potential engines of the economy to help balance with the oil sector. Also, skills are not abundant in the construction sector, which makes it difficult to meet the demands of the secondlargest source of GDP growth during the past years.

\section{Insufficient Financing}

Compared to other Africa countries and countries with similar GDP, EQG spends significantly less on education. As a reference, African countries devoted 4.8 percent of their GDP and 17.2 percent of their total government expenditure to education in $2015,{ }^{4}$ while OECD countries spend an average of 5.2 percent of their GDP on education and 11.3 percent of their total public spending. ${ }^{5}$ Spending only 2.3 percent of their GDP (see Figure 1.3) and 5.2 percent of their total government expenditure on education, EQG lags behind.

\footnotetext{
${ }^{3}$ DHS 2011.

${ }^{4}$ UNESCO Institute for Statistics, most recent year available.

${ }^{5}$ OECD 2016.
} 
Figure 1.3. Public Spending on Education as a Percentage of GDP (selected African countries)

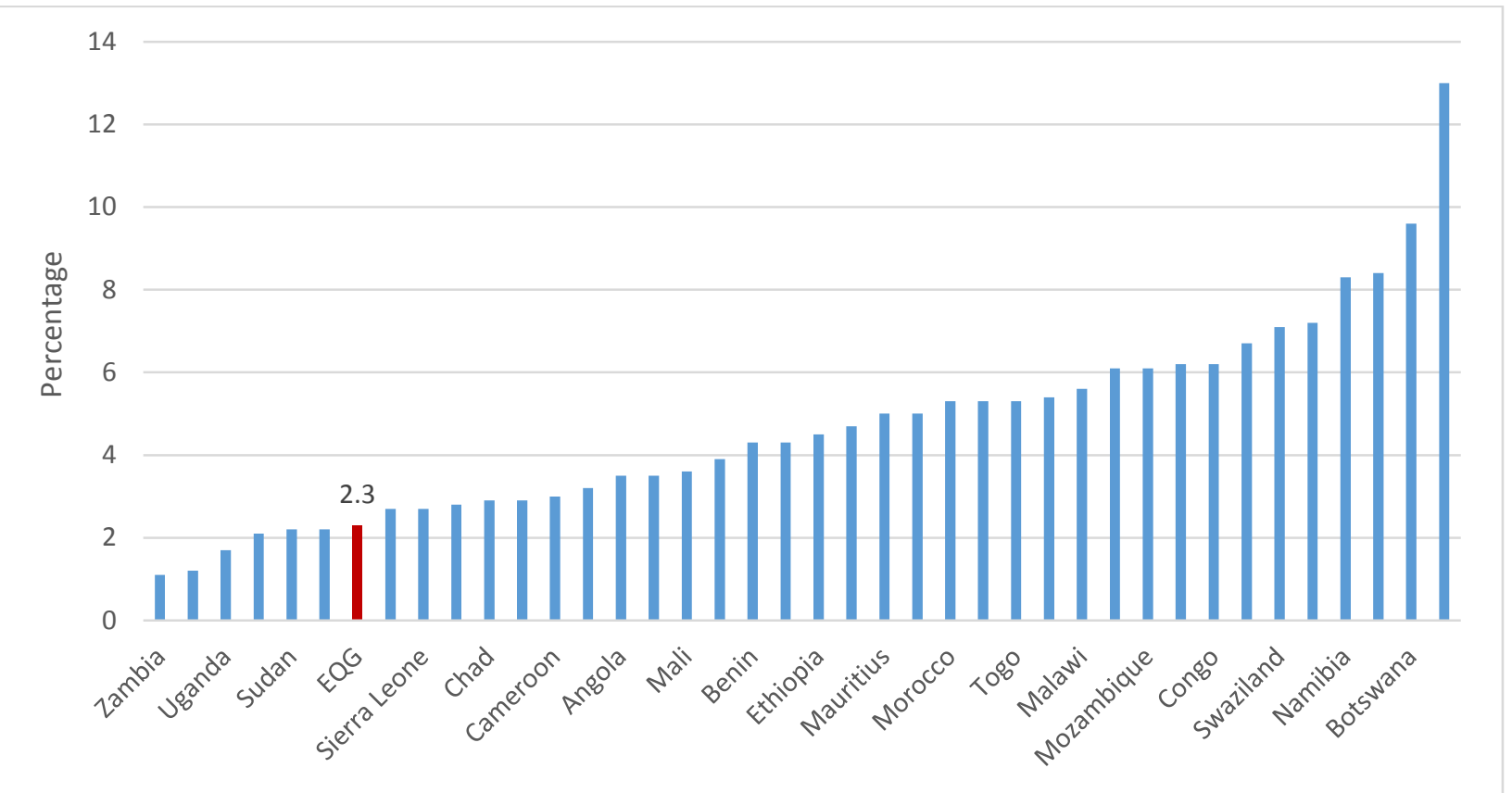

Source: UIS database.

Furthermore, spending on education is not well prioritized and budgets are poorly managed. Financial resources for education have increased over the last 15 years and in 2015 the MEC had the fourth-highest expenditures of all 26 ministries. Nevertheless, the share of total government spending devoted to education appears to be low, and, financing has often been concentrated in areas that are not the most cost-effective and/or equitable, such as infrastructure and higher education, with limited emphasis on quality inputs. There are also signs of upcoming vulnerability of education (and other social sectors) spending to variations in oil prices with risks to pro-poor spending. The education sector is also characterized by a lack of detailed action plans that clearly spell out budget needs by activity, as well as links with outcome indicators for monitoring progress. There are substantial risks associated with poor budget management, including ineffective spending, corruption, and falling short of government spending targets (that is, unused money).

Given that both primary and secondary education are becoming more urban and more private, it would be important to gather more information on private education and monitor and evaluate the subsidies provided to private schools. These subsidies may be able to have a greater impact if the funding is tied to better measurement of outcomes and requirements/incentives of the private schools.

\section{Policy Options}

The GoEG has articulated clear goals for education. These include (a) ensuring universal coverage in preschool and primary education, and a 98 percent gross enrollment rate in secondary education; (b) improving the quality of education, including adequate teacher preparation; (c) eliminating gender discrepancies at all levels; and (d) improved and expanded 
professional, technical, and higher education adapted to the necessities of the labor market. These goals are well focused on the key target groups and strategic areas in the country.

The following policy recommendations provide options to reach the government's four goals as well as an additional goal of improved education financing, taking into consideration the current economic crisis in the country. The recommendations attempt to reflect promising solutions to maintain access to education and basic school functioning, especially for poor children, while improving school quality and systems data.

\section{Increasing enrollment in preschool, primary, and secondary education}

\section{Demand-side interventions to prevent dropout and keep poor children in school}

The main reasons for dropout during the school year were identified as child sickness, lack of a teacher, and lack of money to pay for studies. In a situation of economic crisis, where enrollment may already be decreasing, the ability to pay for school or related expenses (school supplies, transportation, clothes, etc.) is likely to diminish. Some options to reduce dropout and keep poor children in school include cash transfers (either unconditional or conditioned on school attendance), school feeding, and transportation subsidies. According to the information in this diagnostic there is no such program in EQG so it could be difficult to begin to implement such an intervention, unless started on a small scale with a focus on children most at risk. Adolescent girls could be a target of these transfers to maintain their attendance in secondary school.

\section{Comprehensive approach to reduce grade repetition}

Addressing the problem of high repetition rates in primary school requires a comprehensive approach. This would consist of several aspects: (i) expansion of pre-primary, (ii) enforcement of age requirements in primary; and (iii) a clear threshold for repetition rates coupled with personalized attention to the weakest students.

Ensuring access to quality preschool is the best way to prepare young people for primary school, which in turn can reduce repetition and dropout rates. There is a significant geographic disparity in preschool access in EQG with 75 percent of preschool enrollment in urban areas. Access in rural areas could be expanded through the creation of community-based preschools, expansion of public provision, or the addition of private preschools, provided there is sufficient monitoring and oversight by the MEC.

Early entry into primary, before the official entry age of seven, is fairly common. According to the 2014-15 Anuarios, nearly one-third of grade 1 entrants in 2014-15 were below seven years of age at the national level and 42 percent in the Insular zone. Enforcement of entry age requirements in primary would prevent younger children from joining too early, thereby allowing teachers to focus on ensuring learning and grade progression for the age-appropriate students in the class.

A clear threshold for repetition rates, coupled with personalized attention to the weakest students could allow the MEC to better limit repetition rates. For example, a threshold of 10 percent repetition could be held, with the rest of the children automatically progressing with additional attention for the weakest students to ensure they can learn and perform in the subsequent grade. 


\section{Improving the quality of education}

\section{School grants to improve basic school conditions}

Learning materials (such as textbooks) and infrastructure deficiencies, including poorly resourced and dilapidated schools and classrooms, have been identified as key constraints limiting the country's ability to achieve a basic set of quality conditions for students to learn in EQG. One solution to these problems is the provision of school grants, that is, cash grants that are disbursed to schools to address priorities as defined by the school and local community. Activities like purchasing textbooks and other learning materials as well as improving physical conditions (and school maintenance) are commonly supported by school grants. The overarching goals of school grant programs are to improve school conditions for learning while also using the planning and execution process to improve school management capacity as well as strengthen the interface with parents and the community. School grants therefore have a lot of potential to address a range of needs in EQG schools, with the added advantage that the grant does not have to be a 'one size fits all' intervention. Grants can also be targeted to the regions and schools with greatest need and be made conditional on the achievement of simple education outcome/output indicators to increase school accountability for results.

\section{Teacher sector reform}

In the context of economic crisis in EQG, there is a risk of increased teacher absenteeism (for example, if teachers do not receive regular payment from the Government or seek other work to earn enough money) and diminished investment in teacher training due to limited financial resources. In such a situation, it is critical to ensure first, that teachers continue to show up at schools to teach children and, second, that the quality of teaching is as high as possible. According to a series of workshops conducted by PRODEGE in 2016, it was identified that neither school principals nor academic department coordinators are supervising the issue of absenteeism. It would be important, then, to ensure that such monitoring takes place. that public school teachers receive consistent payment, especially those working in areas most affected by the crisis, and that mechanisms are in place to replace teachers that are not showing up.

To ensure high quality teacher training, there is a need to ensure sufficient Government resources are allocated to pre- and in-service training. Indeed, training must be strengthened to better orient teachers to effective pedagogies (for example, child-centered rather than teacher-dominated) and classroom techniques. There is a particular need to ensure improved training of preschool teachers, who are currently the least trained, since research shows that quality preschool education can contribute to reducing grade 1 repetition, a significant problem in the country. An alternative teacher training program, such as a shorter condensed program, particularly for teachers in rural areas, could be developed to expand the number of teachers in the short term, with a path to certification planned over time.

Improving data collection, data quality, and analysis to improve the evidence-based policy planning process 
Improving data collection, data quality, and analysis can be supported by three specific policy actions. First, a Service Delivery Indicator (SDI) study would be useful as a way to obtain more data on service delivery in EQG, especially given the lack of data and the potential effect of the economic crisis. A Service Delivery Indicator (SDI) study uses a set of education indicators to examine the effort and ability of staff and the availability of key inputs and resources that contribute to a functioning school. The surveys measure the performance and quality of education services using cutting-edge methodologies and a high degree of quality assurance and generate nationally representative indicators, disaggregated by rural and urban location, and public and private provider type. The survey instrument is nimble allowing for relatively rapid fieldwork and data analysis, making it more useful for decision making and policy discussions. This would provide data to shape policy decisions regarding teachers, learning materials, and other inputs needed to ensure school quality. Ideally, some of the key questions could eventually be integrated into the EMIS.

Second, learning assessment can provide up-to-date information on student achievement levels in different grades (and subjects), and also help create a 'culture of assessment' in the country, which can in turn facilitate more expansive quality monitoring and support activities later on. To fill the gap in learning assessment data in EQG, it is recommended that sample-based assessments take place at different grade levels to determine how well students in specific grades are able to answer questions taken from the official curriculum. For example, the Early Grade Reading Assessment (EGRA) and Early Grade Math Assessment (EGMA) could provide insight into how well the youngest children are learning while there is still time to adjust teaching methods and ensure they learn in subsequent years. Results can be used to inform and adapt the teacher training system improvements noted earlier.

Third, high quality support and monitoring is needed. Having a strong Education Management Information System (EMIS) in place provides a foundation for an effective overall monitoring system, with the added advantage of making schools comfortable with a system where data is collected on an annual basis. The Anuario process that was implemented as part of PRODEGE has served a critical function in a data-constrained environment and should be strengthened to guarantee that it continues to provide at least a minimum amount of annual information on all schools. The ultimate goal is a strong, two-way flow of information where schools are being constantly monitored to define their needs, this information is then processed at different levels, and then information flows back to the schools in the form of support intended to address their specific needs.

\section{Eliminating gender discrepancies in enrollment}

\section{Support for adolescent girls and early childhood development}

The critical period for girls' enrollment is in late adolescence. The main reasons for girls leaving school at this time are likely related to pregnancy and starting their own families, work demands at home to take care of other family members, or a household aversion to continuing the educational investment for girls, especially as the direct and indirect costs increase by educational level. To address this increase in girls' dropout rates in late adolescence in EQG, the most at-risk adolescent girls should be targeted with comprehensive programs including 
mentorship, financial assistance, childcare support, and sexual and reproductive health services. This would require collaboration across ministries of health, education, and so on. It would also be beneficial to remove the ban on pregnant teenage girls staying in school, if it is still in place. Children of teenage mothers are at higher risk of illness, poor nutrition, and mortality than children of older mothers. At the same time, adolescent mothers are less likely to take preventive measures to ensure their children's health and nutrition, which can adversely affect cognitive and socioemotional development and learning and put children of teenage mothers at higher risk of poor development outcomes. Therefore, early childhood development support for these children is critical. This could be parenting counseling for adolescent mothers and other caregivers (perhaps delivered through the health system), subsidized access to childcare (ideally near the adolescent mother's school), and financial support.

\section{Education financing}

\section{Identification of priority spending needs and plans for execution}

To guarantee the necessary inputs for a quality education system, education financing must be of sufficient size and prioritized according to the greatest needs-rather than the current bias toward infrastructure and higher education. For example, there is the consistently low spending on preschool in EQG and yet preschool is critical for building the foundation of children's learning and preparing them to be successful in primary school. Given the conditions of economic crisis in EQG, it is essential to identify the most important budget lines to maintain basic education functioning and then ensure that the available money is actually disbursed. This requires identifying spending needs and laying out detailed plans for how these will be executed, with specific goals and targets.

Improved monitoring and evaluation of private schools and support for Strengthening Public Private Partnerships (PPPs)

Given that both primary and secondary education is becoming more private in EQG, it would be important to better monitor and evaluate the supply, quality, and cost of private education. Based on this information, there could be opportunities to strengthen Public Private Partnerships (PPPs), including, for example, better design of the subsidies provided by Government to private schools, such as tying the funding to specific process and performance results for private schools. 


\section{Introduction}

The World Bank seeks to support the Government of Equatorial Guinea (GoEG)'s objectives to shield the poorest from the worst effects of the economic downturn and invest in building the country's human capital. Since 2013, the World Bank Group has supported the GoEG through a limited program of Reimbursable Advisory Services (RAS), which has enabled small, but important improvements in economic management. The government has since requested financial, analytical, and technical support to help during the country's protracted economic recession. Given the prioritization of education in the country's National Development Plan, the World Bank agreed to undertake an education sector diagnostic study to (a) help the World Bank better understand the education sector, including the main challenges and policy priorities of the government; (b) facilitate dialogue between the World Bank and GoEG in the education sector and suggest options to protect children, especially the poor and vulnerable, during the current economic downturn; (c) provide supporting background for a parallel activity that is focusing on public expenditures in the social sector (Public Expenditure Review, PER); (d) support the activities that are planned as part of the National Development Plan's Programa Mayor Educación Para Todos; and (e) provide education sector stakeholders with an updated summary of the sector including a review of recent indicator trends and program activities.

This diagnostic focuses primarily on primary and secondary education, while also providing some information TVET and higher education, especially where relevant to the other sub-sectors. It is also intended to update a 2006 World Bank-supported education sector diagnostic. When possible, comparisons are made between current and previous education indicators to provide an extended trend summary that goes beyond what is available in the statistical annuals (called Anuarios, available since 2007-08).

\section{Data and Methodology}

In addition to the findings from the previous diagnostic, this report relies on a variety of sources of data, including:

6. Interviews conducted with the Ministry of Education and Science (Ministerio de Educación y Ciencia, MEC) officials, international education partners, and other stakeholders about the main challenges and priorities in the sector, as well as detailed data on specific programs and activities

7. Data from statistical annuals (Anuarios), the 2011 Demographic and Health Survey (DHS, Encuesta Demográfica y de Salud, EDSGE-I), and the United Nations Educational, Scientific, and Cultural Organization (UNESCO) Institute of Statistics (UIS)

8. Existing education research ${ }^{6}$

\footnotetext{
${ }^{6}$ For example, Bivini Mangue's (2015) summary of Education For All (EFA) and various studies carried out by the Programa de Desarrollo Educativo de Guinea Ecuatorial (for example, PRODEGE 2009, 2011).
} 
9. Additional qualitative data obtained during field visits to schools and district education offices. Appendix A includes a summary of the field work and interviews that were completed as part of the World Bank mission in June 2016.

10. The most recent (2015) budget execution summary in the Ministry of Finance Budget Law 2016 for education finance information.

All analyses of recent statistics and trends in education (for example, enrollment, repetition, drop-out rates, financing, etc.) are conducted based on this available data. No new data collection was conducted for this study. Given data limitations, the diagnostic is not able to provide additional information on the determinants of learning and characteristics of the quality assurance framework and all the required details on the private schooling sector, or undertake cost-effectiveness comparisons across public and private school systems. Additional information and analysis on education financing will be possible under an upcoming Public Expenditure Review (PER).

\section{Organization of the Report}

The diagnostic is divided into three main parts. Part A focuses on country context, background on the education sector, and recent trends in education (for example, enrollment, and repetition). Part B then moves into the education sector diagnostic by topic, focusing on the main challenges in areas such as education finance, quality, and learning outcomes. Part $\mathrm{C}$ introduces possible policy actions, framed with the current crisis context, that address some of the main issues identified in Part B.

\section{Part A. Context, Background and Education Sector Overview}

\subsection{Country Context}

\subsubsection{Brief Country History}

Equatorial Guinea (EQG) is a small country located in the Gulf of Guinea on the west coast of Sub-Saharan Africa (SSA), bordering Gabon and Cameroon and several islands. The country consists of a mainland area, comprising 90 percent of the total land area and housing 75 percent of the total population, and five inhabited islands. The population is approximately 1.2 million. ${ }^{7}$ There was a dramatic population decline during the chaotic period of the 1970s, followed by a large increase in population in the 1980s. In the last 25 years the population growth rate has steadied at just under three percent per year, which is consistent with the sub-Saharan Africa average. However, it is important to note that there is no consistent agreement on growth projections going forward. (See Appendix B for more on population dynamics.)

Formerly a Spanish colony, EQG gained its full independence in 1968. Prior to its independence, EQG was ranked as one of the countries with highest per capita income in Africa. ${ }^{8}$ The years

\footnotetext{
${ }^{7}$ This data is from the 2015 census. The 1.22 million estimate for 2015 represents an increase of approximately 50 percent relative to previous estimates.

${ }^{8}$ U.S. Department of State. Bureau of African Affairs, 2005.
} 
following independence were characterized by a worsening economy, high levels of social and political conflict, and significant human rights abuses. President Francisco Macias Nguema's 'reign of terror' involved a violent crackdown on the opposition, resulting in thousands of prisoners, murders, injuries, and 160,000 exiles. ${ }^{9}$ Many of the plantations controlled by foreigners were closed and foreign investment declined. The country's infrastructure (electricity, water, roads, transportation, and health) fell into ruin and the agricultural sector could not recover from the economic crisis that followed independence. Schools were also closed during this period.

In 1979, Teodoro Obiang Nguema, a senior military officer, overthrew his uncle-and he remains president today. He lifted some of the restrictions of the previous regime (for example, reestablishing diplomatic ties with Spain, returning exiles), but also maintained many of the repressive policies and corruption. The present situation has been characterized as 'restricted democracy', since despite the democratic structure, real opportunities for the development of an opposition are limited or nonexistent. ${ }^{10}$ According to Freedom House's 2017 annual global survey, ${ }^{11}$ on a scale from 1 (most free country) to 7 (least free country), EQG received a score of 7 for both political rights and civil liberties. While a new constitution was introduced in 1982, President Obiang and his clan continued in power.

\subsubsection{Economic Situation}

Prior to the discovery of oil in the mid-1990s, the economy was dominated by the agriculture (cocoa) and forest (wood) sectors. Agriculture experienced an extended period of decline in the post-colonial period, driven in part by the expulsion of foreign settlers and the withdrawal of Nigerian labor. ${ }^{12}$ The forestry sector has also encountered difficulties, due to a depletion of timber in forests for production, and the country has been forced to resort to import timber to meet local market needs. ${ }^{13}$

The most significant recent development in the economy is the growth of the hydrocarbon extraction industry beginning in the mid-1990s, which led to an extended period of economic growth and recovery of macroeconomic indicators. The oil industry has transformed the economy in terms of composition, overall size, and growth rates. For example, in 2002 EQG ranked first in the world in terms of the growth rate of gross domestic product (GDP) per capita. ${ }^{14}$

Figure 3.1 highlights the transformative effect of the extraction industry on the economy. In 1995 the non-oil sector was responsible for nearly the entire production of a much smaller overall economy. In contrast, by the early 2000s the economy had grown by a multiple of ten, and the oil sector made up more than 80 percent of total production. In 2011, less than ten percent of the male workforce was in agriculture and the largest work categories were skilled and

\footnotetext{
${ }^{9}$ Razquin 2006.

${ }^{10}$ Razquin 2006

${ }^{11}$ Freedom House 2017

${ }^{12}$ Bolobo Ekobo 2001

${ }^{13}$ Razquin 2006

${ }^{14}$ World Bank 2004
} 
un-skilled manual labor, followed by professional-technical. About half of women reported current employment, compared with over 70 percent of men; for younger men (and women) the rates of unemployment were much higher. (Appendix $\mathrm{C}$ provides more information on the labor market.)

Figure 3.1. Evolution of GDP by Sector, 1994-2004

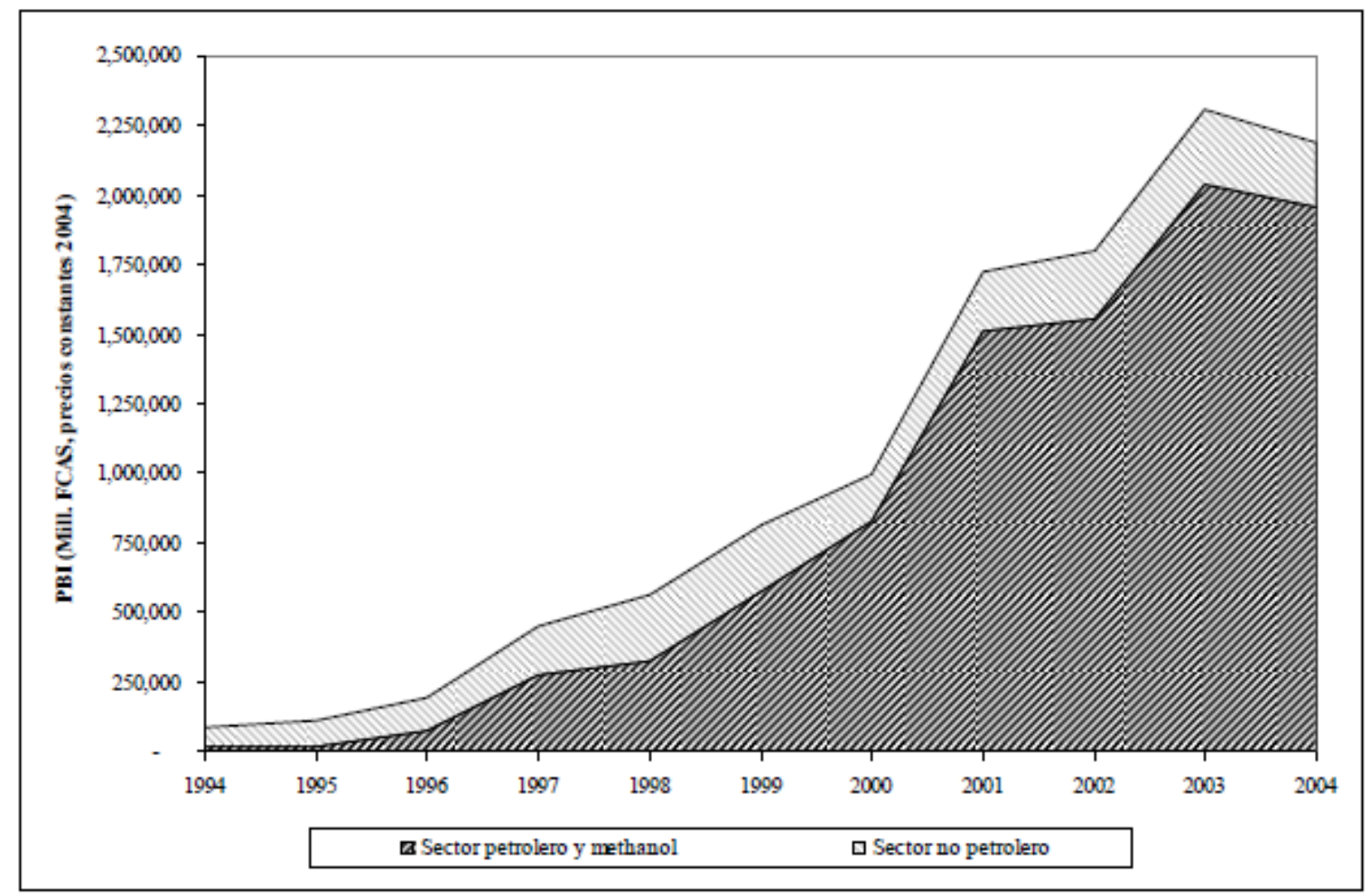

Source: Razquin 2006.

Note: Shaded section is the petroleum sector; non-shaded area is non-petroleum sector.

However, since late 2012, fiscal constraints, investment cuts, and continued falls in revenue from sales of hydrocarbons resulted in a 30 percent contraction in per capita GDP. EQG's economic contraction has accelerated since 2014: overall GDP declined by 7.4 percent during 2015 and the estimated growth rate for 2016 is -10 percent. With little prospect of an upturn in growth, this economic crisis in EQG makes the near-term outlook in EQG very challenging.

\subsubsection{Poverty and Shared Prosperity}

Data on poverty are limited and do not provide a sense of trends over time. The 2011 DHS (EDSGE-I) does not include any estimations of poverty based on a poverty line, but instead relies on quintile-based comparisons of households. The only reference to poverty levels is from World Bank indicators, that refer to a poverty headcount ratio (that is, percentage living below poverty line) of 76.8 percent in 2006.

Average income levels have certainly increased in the last 20 years as a result of the growth of the extraction sector, but it is not clear to what degree the new economic reality has benefited the larger population. In fact, per-capita income measures can be quite misleading 
about the real economy, especially when they have increased dramatically in a short period of time (as is often the case with the discovery of oil). This question can only be answered with detailed comparisons of poverty and income levels at different points in time, which is handicapped by the lack of survey (and other) data.

The 2006 poverty figure from the World Bank (76.8 percent) is a reminder of the challenges of significantly reducing poverty in developing countries, even with huge injections of resources into the economy. Difficult living conditions that are prevalent in rural areas (see Table 3.1) are also evident from 2011 data. For example, more than half of rural households lack access to electricity, compared to only 7 percent of urban dwellings and 42 percent of rural households have dirt floors in their homes, and over 70 percent report using wood for cooking

Table 3.1. Basic Welfare Indicators in Equatorial Guinea (2011)

$\begin{array}{lrr}\text { \% households with: } & \text { Rural } & \text { Urban } \\ \text { no access to electricity } & 57.0 & 6.9 \\ \text { flooring made of earth/sand } & 41.9 & 7.1 \\ \text { using firewood for cooking } & 72.2 & 7.3 \\ \text { 3 or more per bedroom } & 71.2 & 49.2 \\ \text { Gini coefficient } & 0.3 & 0.17\end{array}$

Source: Ministries of Health and Social Welfare and Economy, Planning and Public Investment with ICF International, Maryland, United States (November 2012).

Sharp differences in basic welfare indicators exist between the mainland relative to the islands and among individuals with lower levels of education and wealth. The share of mothers receiving postnatal care in the two days following birth, for example, is 69 percent on the islands but only 37 percent on the mainland; 30 percent in the lowest wealth quintile compared with 53 percent in the highest quintile; and 21 percent among mothers with no education compared with 64 percent among those with higher education. There are similar stark differences between households with respect to the share of young children receiving vaccinations and in female literacy rates. (See Appendix D for more information on health.)

\subsection{Overview of Education Sector in Equatorial Guinea}

\subsubsection{Recent History}

There is limited documentation on the history of the education sector in EQG. ${ }^{15}$ During the colonial era, which ended in 1968, only primary and secondary levels were available. During 1968-1979, a period marked by considerable civil conflict, the education system suffered with public and private (Catholic) schools closing, and education focusing mainly on 'patriotic education. ${ }^{16}$ Teachers and school administrators were also targeted for repression in this period. $^{17}$

\footnotetext{
${ }^{15}$ See Razquin (2006) for a more detailed overview, pieced together from a few sources.

${ }^{16}$ Dyombe 2009.

${ }^{17}$ Razquin 2006.
} 
The situation stabilized substantially with the installation of the current president, Teodoro Obiang Nguema Mbasogo, in 1979. The education system was a point of emphasis in his new regime, as teachers were brought back into the system, new staff was hired, older schools were rehabilitated, and new ones were built. A significant step was realized in 1981 with the passing of the country's first education law (Decreto Ley $N^{o} 11$ de Aprobación de la Ley General de Educación).

In the period from 1979 through the mid-1990s there was considerable donor support in the social sectors. By the late 1980s, official development aid (ODA) reached more than 50 percent of gross national income (GNI). ${ }^{18}$ In education, bilateral (Spanish, French) and multilateral (United Nations Development Programme - UNDP, UNESCO) partnerships helped create learning materials, provide school furniture, and train teachers. A new curriculum was also approved in 1985, which served as a base curriculum for future additions.

With the discovery of oil and subsequent increase in national income from petroleum exports, the donor presence (as a percentage of the overall economy) declined precipitously in the 1990s. During this period, another significant milestone in the development of the education system was the new education law passed in 1995 (La Ley de Educación no. 14/1995). This created a five-level system, including: preschool (3 years and older), primary grades 1-5, secondary school consisting of seven grades ('cursos') and exams at different stages (including an entrance exam for higher education), a two-grade professional education program, and higher education. The national university (Universidad Nacional de Guinea Ecuatorial - UNGE) was created in 1995 as a result of the new law.

The current system is governed by the 2007 Education Law (Ley General de Educación no. 5/2007), which introduced two fundamental changes in the education system. First, the 2007 law codified education as a fundamental right for all citizens. And second, the law created a new system modeled on international standards. The present system has four levels: preschool, primary, secondary, and higher education. The main innovations and reforms introduced by the new law include: a mandate for free preschool education in public education centers, the extension of primary education from five to six grades; the introduction of the fourgrade basic secondary education and the two-grade Bachillerato (high school) with four different branches of specialization; and the introduction of technical and professional training to address higher standards of job training.

The education system in EQG is quite young. There have been fewer than 10 years to institutionalize the updated features and accompanying goals of the 2007 law (summarized below).

\subsubsection{Education Sector Goals and Priorities}

Discussions of goals and priorities in the education system begin with EFA, which is part of the larger Millennium Development Goals (MDG). As described in Bivini Mangue's (2015) summary of the education component of the MDGs, EQG was the first country in Central Africa to develop a National Plan for Education for All, which was approved by

\footnotetext{
${ }^{18}$ Maroto Blanco 2014.
} 
presidential decree in 2003. The overarching goal of EFA is to have universal primary education completion by 2015.

To meet the EFA universal primary goal, the government has implemented a number of reforms. These include guaranteeing that every community (and Consejo de Poblado) in the country has access to a primary school, and creating a department within the MEC that focuses on special education (Dirección General de la Educación Especial).

Education also occupies an important place in the National Agenda for Diversified Sources of Economic Growth (Agenda Nacional para la Diversificación de las Fuentes de Crecimiento), commonly referred to as Guinea Ecuatorial Horizonte 2020. The Horizonte 2020 Programa Mayor Educación Para Todos provides a good overview of system-wide priorities and needs in education, in addition to defining areas that are to be addressed through government actions and partnerships. ${ }^{19}$ These goals include:

- Universal coverage in preschool and primary education, and a 98 percent gross enrollment rate in secondary education;

- Improve the quality of education by insuring adequate teacher preparation, with a focus on the primary level;

- Eliminate gender discrepancies by reducing dropout rates among girls in primary and secondary education, and improving higher education completion rates for young women;

- Adapt professional, technical, and higher education to the necessities of the labor market, expand professional training to seven provincial capitals, and increase literacy rates to above 75 percent among adults.

Efforts to attain EFA and Horizonte 2020 goals have been aided by a number of partnerships with international organizations (United Nations), bilateral donors (U.S. Agency for International Development - USAID, Spanish Government) and the private sector. These activities have helped the government organize and coordinate different interventions, as well as monitor changes, and have also addressed specific areas of need, such as preschool education and teacher training.

One of the largest initiatives has been funded by the Hess Corporation, the Programa de Desarrollo Educativo de Guinea Ecuatorial (PRODEGE) has operated in the country since 2006 (and will continue through 2019). PRODEGE is summarized in more detail later in the diagnostic, but it is important to note that one of the priorities of PRODEGE was to improve the measurement and monitoring of education indicators in the country. This is particularly relevant in relation to sector goals, since these can only be assessed on the basis of specific indicators. The annual reports (Anuarios) produced by a PRODEGE-government partnership have helped address this need, although more information is needed.

\footnotetext{
${ }^{19}$ Equatorial Guinea National Agency - ANGE, 2016.
} 
In addition to EFA and Horizonte 2020 documents that detail specific system goals, information on priorities was also gathered as part of the diagnostic in interviews with the MEC and other government officials. Two priorities stand out. The first is cross-sectoral, and refers to the importance of improving public administration of budgets. Achieving goals in sectors like education is complicated by the lack of detailed action plans that clearly spell out budget needs by activity, and are linked with outcome indicators for monitoring progress. There are substantial risks associated with poor budget management, including ineffective spending, corruption, and falling short of government spending targets (that is, unused money).

The second priority is related to education quality. There is a general recognition on the part of education officials that much work remains to improve quality in the country. As discussed in more detail in later sections, references to quality tend to focus on teacher credentials and infrastructure indicators, as opposed to processes and student achievement outcomes. Nevertheless, the better quality 'message' was clearly present in almost all discussions with government officials, in central and district offices.

Overall, the GoEG goals and priorities in education are similar to those in many countries, and revolve mainly around the joint challenges of expanding access (to attain goals like EFA and higher enrollment rates in secondary) while also improving quality. It is easy to view these as competing priorities that are vying for the same budget resources. But they are better viewed as complementary actions, since research from around the globe has demonstrated that one way to improve participation - and decrease things like school dropout rates - is to improve quality. This in turn highlights the importance of budget management and the effective articulation of system goals, and accompanying action plans, to maximize the utility of the resources that are available. GoEG recognition of the importance of quality and coverage, and budget management capacity, is therefore a critical step for moving forward.

These aspects are all the more important in the current context of economic crisis, which is likely already having some impact on education outcomes while also putting downward pressure on public resources for education and therefore running the risk of further exacerbating education outcomes. In this context, it will be critical to protect and better prioritize scarce public resources to maintain and improve education outcomes. This will also require an effective formulation of education sector goals and reforms moving forward.

\subsubsection{Education System Structure and Governance}

\section{Education Levels}

There are four basic levels of the education in the system.

Preschool education is considered mandatory and free of charge in public centers, has its own basic curricular structure and ranges from one to six years old divided into two phases: infant education from one to three years old, and preschool education ranging from four to six years. 
Primary education, also considered mandatory and, under the new law, delivered free of charge in public centers, has its own basic curricular structure and ranges from six to twelve years old divided into two cycles: from six to nine years old entails grades 1,2 , and 3; and from ten to twelve years old entails grades 4, 5, and 6. After completion of the primary education a test is conducted to grant a Certification of Primary Studies upon approval, also allowing the student to pursue secondary education. Alternatively, students not passing this test can opt for technical and professional training.

Secondary education is considered voluntary and covers six years in total. It is divided into two modalities, beginning with general secondary education that in turn contains two cycles:

- Basic Secondary Education known as ESBA (Educación Secundaria Básica) is four years in duration and intended to be delivered from 13 to 16 years old. After successful completion of ESBA, students will obtain a graduate certificate to continue on to either Bachillerato (Bach) or to technical and professional training.

- Bachillerato (Bach), has a two-year duration and is intended for 16-18-year-olds comprising four different branches of specialization that students can opt for Science, Humanities, Technology, and Arts. Upon successful completion of Bach, a certificate is granted for graduates of general secondary education allowing them to continue on to higher education in the National University, or access the advanced cycle of technical and professional training.

To certify conditions to access the National University, students must also have orientation courses and take a selectivity test (formerly called maturity test) that, if approved, enables them to enroll in a university program.

The second modality is technical and professional training, which is intended to deliver job training to students of up to 19 years of age. Programs for these modalities will be designed by the MEC in collaboration with other sectorial ministries and specialized private institutions. In practical terms this inter-ministerial collaboration and coordination is relatively low. It contains two cycles:

- A basic two-year cycle for obtaining the diploma on Auxiliary Technician, intended for students who completed ESBA.

- An advanced two-year cycle offering a diploma in Officer Technician, offered to students who either completed the first basic two-year cycle or Bachillerato, but not the selectivity test. This modality of secondary education is intended to be delivered for students up to 19 years of age and is offered in National Institutes of Professional Education.

Currently there are two professional training centers delivering programs in Malabo and Bata under the scope of the Ministry of Labor and Social Security, with an estimated 2,400 persons graduated in 2015. There are plans underway to enlarge this offer creating one National Institute in all province capitals. 
Higher education is currently delivered exclusively in the National University of Equatorial Guinea (UNGE) to students who passed the selectivity test, and students who passed the advanced two-year cycle of technical and professional training. The higher education system introduced in the 2007 law considers a pedagogic architecture of three levels: Bachelor's, Master's, and $\mathrm{PhD}$ known locally as the LMD system for its initials in Spanish (Licenciado, Master y Doctorado).

Following this LMD structure, higher education contains three cycles: an initial four-year cycle aiming at obtaining a Bachelor's degree (known locally as Licenciatura; faculty of medicine entails a five-year program); a second cycle of two additional years aiming at specializing professionals obtaining Master's degrees; and a third cycle of three more years, intended to prepare a body of professors and advanced researchers, obtaining $\mathrm{PhD}$ degrees. Currently, there is no offering of Master's and $\mathrm{PhD}$ programs. ${ }^{20}$

Table 3.2 summarizes the education levels and modalities and includes current enrollment figures for each level, based on the statistical yearbook for the 2014-15 school year.

Table 3.2. Education Levels, Modalities, and Enrollment Figures (2014-15)

\begin{tabular}{|c|c|c|c|c|}
\hline Level & Enrollment & \multicolumn{2}{|c|}{ Modality } & Age \\
\hline \multirow{3}{*}{ Higher Education } & $\mathrm{n} / \mathrm{a}$ & \multicolumn{2}{|c|}{$\mathrm{PhD}$ (3 years) } & $\mathrm{n} / \mathrm{a}$ \\
\hline & $\mathrm{n} / \mathrm{a}$ & \multicolumn{2}{|c|}{ Masters ( 2 years $)$} & $\mathrm{n} / \mathrm{a}$ \\
\hline & 7,971 & \multicolumn{2}{|c|}{ Licenciado (4 years) } & $\mathrm{n} / \mathrm{a}$ \\
\hline \multirow{3}{*}{$\begin{array}{l}\text { Secondary } \\
\text { Education }\end{array}$} & $\mathrm{n} / \mathrm{a}$ & $\begin{array}{l}\text { University orientation } \\
\text { course (1 year) }\end{array}$ & $\begin{array}{l}\text { Advanced technical and } \\
\text { professional training ( } 2 \text { years) }\end{array}$ & $18-19$ \\
\hline & $\begin{array}{c}7,941 \\
\text { (Bachillerato) }\end{array}$ & Bachillerato (2 years) & $\begin{array}{l}\text { Basic technical and } \\
\text { professional training ( } 2 \text { years) }\end{array}$ & $17-18$ \\
\hline & 27,027 & \multicolumn{2}{|c|}{ Basic secondary education (4 years) } & $13-16$ \\
\hline \multirow{2}{*}{ Primary Education } & 36,481 & \multicolumn{2}{|c|}{ 2nd cycle: grades 4-6 (3 years) } & $10-12$ \\
\hline & 56,915 & \multicolumn{2}{|c|}{ 1st cycle: grades $1-3$ (3 years) } & $7-9$ \\
\hline \multirow{2}{*}{ Preschool Education } & 39,596 & \multicolumn{2}{|c|}{ Preschool (3 years) } & $4-6$ \\
\hline & 2,512 & \multicolumn{2}{|c|}{ Childcare (3 years) } & $1-3$ \\
\hline
\end{tabular}

Source: Programa de Desarrollo Educativo de Guinea Ecuatorial (PRODEGE)/MEC Anuario (2015-16); Ley General de Educación No. 5/2007.

\section{Complementary Education Modalities}

In addition to preschool, primary, secondary, and higher education, other modalities are considered in the Education Law, including: Permanent Training and Adult Literacy Education, Long Distance Education, and Special Needs Education. In practical terms these programs are not systematically coordinated and conducted, are delivered by a multiplicity of public and private institutions, and are not regulated by a central authority (although there is limited information available to provide a more detailed assessment).

\footnotetext{
${ }^{20}$ Title two of the new law establishes the requirements and procedures to register and accredit (homologar) foreign diplomas assigning to students the initiative in presenting the request to the MEC. A special commission has been created to study each case and validate it accordingly.
} 
Permanent Training and Adult Literacy includes job training oriented toward the improvement of job skills and studies equivalent to primary and secondary education for adults. The MEC is responsible for the approval and supervision of all programs related with this modality, however its implementation can be considered as decentralized in the sense that the 2007 law empowers a variety of institutions - public, private, nongovernmental organizations (NGOs), and non-profit organizations - to implement these programs. Currently, adult literacy programs are entirely undertaken by the Ministry of Social Affairs and Gender Equality (MASIG for its initials in Spanish) and framed under the Education for All (EFA) policy framework. Recipients of permanent training and education for adults programs are mainly young people left behind by the formal system; teachers of preschool, primary, and secondary levels specifically trained for these purpose; unemployed adults; and specific industries' and institutions' employees.

The Long Distance Education modality follows every aspect of the four basic levels of regular education, but is specifically designed for people unable to participate in a regular education center in regular conditions. This type of education is targeted mainly in dispersed and rural communities. ${ }^{21}$

Finally, Special Needs Education is intended for students that are not able to attend a regular education center or follow the regular schedules because of a physical or cognitive disability, and as a result are unable to achieve the common objectives of each of the basic education levels. Currently the approach for developing this type of education is to train a specific body of teachers to reach out to students with special needs once they are identified and targeted by a given education center. A 2015 UNESCO study found that $0.4,0.5$, and 0.1 percent of the primary enrollment reported visual, auditory, and motor difficulties, respectively.

\section{System Governance}

The general management of the entire education system is assigned to the MEC. Its principal functions include: propose education policies and programs; approve curricular programs; create and manage public education centers and approve and regulate private centers; coordinate and stimulate different social and economic stakeholder efforts; and issue and accredit diplomas and certifications. The organization chart of the ministry features a highly centralized system: ${ }^{22}$

- Government Members: Minister, Deputy Minister, Secretary of State

- Technical Bodies: Office of the General Secretary; General Directorate of Preschool and Primary Education, General Directorate of Secondary Education, General Directorate of Higher Education, General Directorate of Technical and Professional Education; General Directorate of Planning and Education Development; General Directorate of Education for All; Office of the General Inspector

\footnotetext{
${ }^{21}$ Razquin 2006.

${ }^{22}$ World Bank 2010.
} 
- Consultative Body: Administrative Council

- Autonomous Entities: National Commission for Cooperation (UNESCO), National Commission for Diplomas and Certification Authentication, National University of Equatorial Guinea - UNGE

Education centers can be public or private. According to the most recent statistical yearbook (2014-15), there are 761 preschool centers, 802 primary education centers, and 137 secondary education centers. Despite having more public than private centers, the actual number of students enrolled in preschool, primary and secondary education shows that education in EQG is mainly privately delivered (Table 3.3).

Table 3.3. Education Centers and Students - School Year 2014-15

\begin{tabular}{|l|c|c|c|c|c|c|}
\cline { 2 - 5 } \multicolumn{1}{c|}{} & \multicolumn{2}{c|}{ Public } & \multicolumn{2}{c|}{ Private } & TOTAL & TOTAL \\
\cline { 2 - 5 } \multicolumn{1}{c|}{} & CENTERS & Students & CENTERS & Students & CENTERS & STUDENTS \\
\hline SECONDARY EDUCATION & 37 & $\mathbf{1 2 , 4 5 9}$ & 100 & $\mathbf{2 2 , 5 0 9}$ & 137 & 34,968 \\
PRIMARY EDUCATION & 556 & $\mathbf{3 8 , 6 0 4}$ & 246 & 54,792 & 802 & 93,396 \\
\cline { 1 - 1 } PREESCHOOL EDUCATION & 547 & $\mathbf{1 7 , 5 8 8}$ & 214 & $\mathbf{2 4 , 5 2 0}$ & $\mathbf{7 6 1}$ & $\mathbf{4 2 , 1 0 8}$ \\
\hline
\end{tabular}

Source: PRODEGE/MEC Anuario 2014-15.

Education center management involves both individual and collegiate bodies (see Figure 3.2). School councils, made up of students, teachers, parents, administrative staff, and representatives from the local political authority, guarantee the participation of the communities served by the centers. Steering councils are composed of the managerial staff plus a teacher representative. Discipline councils, made up of managerial staff in charge of discipline matters, plus students and teachers, are keepers of the school environment and are responsible for stakeholder relations. Finally, education departments are technical organs aimed at unifying and coordinating criteria and action of given teaching areas. 
Figure 3.2. General Structure of Management Bodies of Education Centers

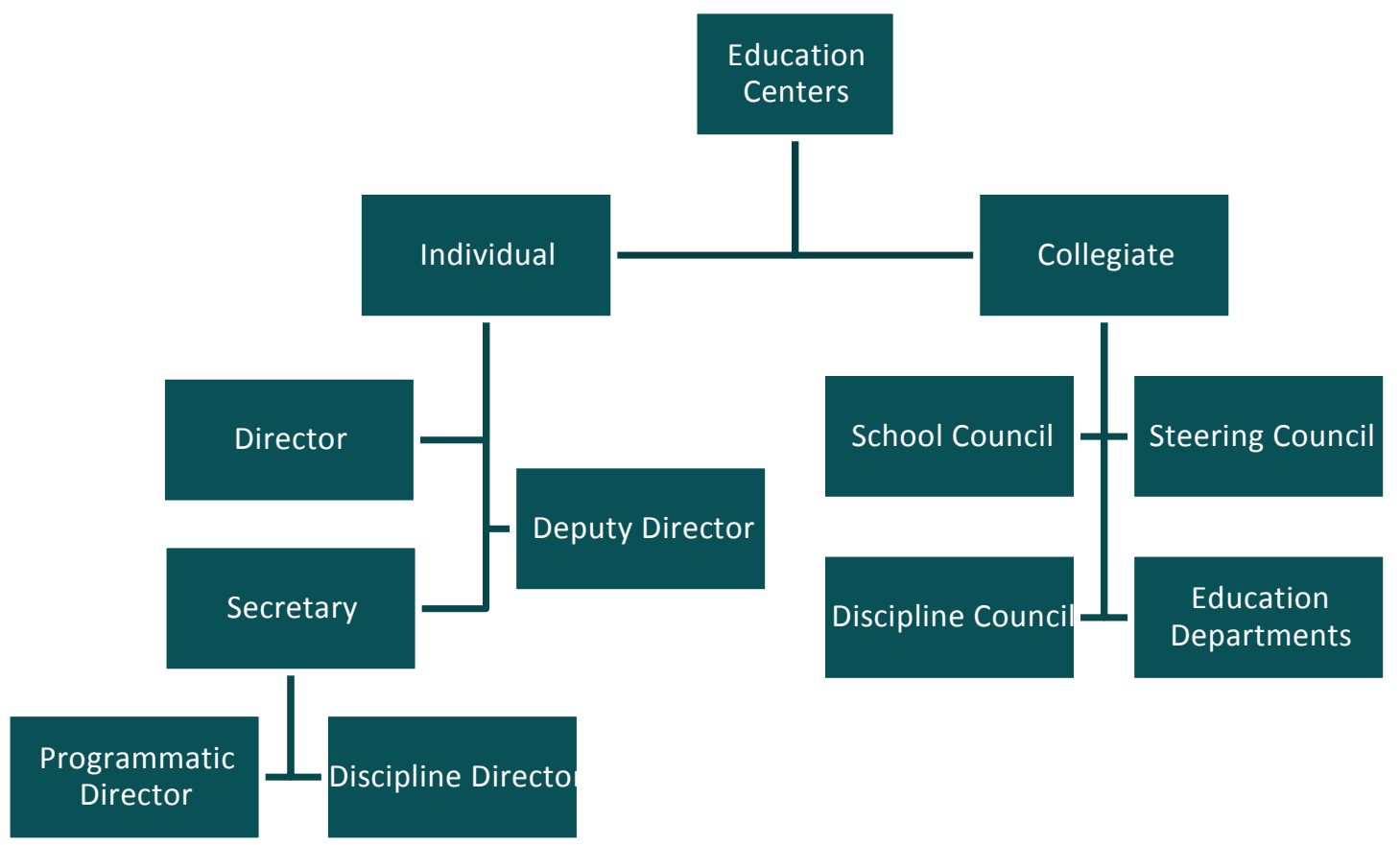

Source: Ley General de Educación No. 5/2007.

At the primary level, public centers are entirely under the jurisdiction of the MEC, with supervision conducted through the body of inspectors. Public centers cover the four basic levels of education in all its modalities. Centers delivering primary education are in three categories depending on size: unitary schools, currently 134 centers, delivering grades 1 and 2; graduated schools, currently 225 centers, delivering grades 1, 2, and 3; and national schools, currently 443 centers, delivering the six grades.

Public secondary centers are divided into three categories depending on the modality of education they deliver: National Institutes of secondary education are responsible for ESBA and Bach; National Institutes of Technical and Professional Training are responsible for delivering job training to students not pursuing a university program; and special education centers.

The only public higher education center is the National University of Equatorial Guinea UNGE. The law gives UNGE higher levels of autonomy to define its own methods, evaluation mechanisms, and management arrangements, adopted on a singular and particular body of statues that must be formulated and approved with the concurrence of the MEC. As for the higher education centers, the Dean and Deputy Dean are the highest authorities appointed directly by the President of EQG, accompanied by an administrative manager appointed by the Minister of Education and Science. Also the university can create a social council to enable and channel the participation of society.

Private centers are more independent from MEC in the sense that they have pedagogic autonomy to adopt and implement programs, methodologies, and management systems; 
however, private education institutions must comply with approval, supervision, and control from the MEC. The law authorizes transfers from the public budget to private institutions by request. In practical terms there are several annual transfers and investment projects to private centers. As an example, almost all Catholic private centers are integrated in the Association of Catholic Education Center of EQG (ACCEG as known in Spanish), which is a clerical organism with a long-standing tradition in the country. These centers are partially funded with a regular transfer from the public budget and cooperate with the ministry and other donors. The transfer approved in the 2016 budget law to ACCEG is of CFAF 2,000 million.

\section{Teaching Staff}

Minimum standards for teaching staff are based on the following criteria:

- Preschool and primary school teachers: Certificate of a diploma degree course in preschool or primary education from UNGE (or equivalent)

- ESBA teachers: Certificate of a diploma degree course from UNGE

- Bach teachers: Certificate of a university program degree in the level of Licenciatura

- Higher education teachers: Certificate of a university program degree in the level of Licenciatura, Master's, or PhD

Historically, the total number of teachers at each level has been insufficient to cover the demand, especially considering the construction of new infrastructure, and the implementation of free (and mandatory) education since 1985. As a countermeasure, the government has recruited young volunteers without any standardized or minimum training, which in turn requires new in-service training programs. In part to attend to this new group, UNGE created two different modalities of specialization, primary and preschool diploma programs, in the Faculty of Education.

Teacher qualification levels are low, especially in preschool and primary. According to the latest statistical yearbook (2014-15), there are 2,140 preschool teachers, of which 5.8 percent have the minimum or above the required standard; 4,021 primary teachers, of which 54 percent reach the minimum or above the required standard; and 2,119 secondary teachers, of which 69 percent acquired a university program degree and 16 percent a certificate of diploma degree. Of the high education 731 teachers, 19 percent have Master's degrees level or above (see Table 3.4). 
Table 3.4. Total Number of Teachers by Level and Education Level, (2014-15)

\begin{tabular}{|c|c|c|c|c|c|c|c|c|}
\hline & Preeschool & $\%$ & Primary & $\%$ & Secondary & $\%$ & Higher & $\%$ \\
\hline PhD & & & & & & & 44 & $6 \%$ \\
\hline Master & & & & & & & 95 & $13 \%$ \\
\hline Graduate & 29 & $1.4 \%$ & 456 & $11 \%$ & 1,454 & $69 \%$ & 546 & $75 \%$ \\
\hline Diploma & 96 & $4.5 \%$ & 1,703 & $42 \%$ & 335 & $16 \%$ & 46 & $6 \%$ \\
\hline Other & 2,015 & $94.2 \%$ & 1,862 & $46 \%$ & 330 & $16 \%$ & & \\
\hline Total & 2,140 & & 4,021 & & 2,119 & & 731 & \\
\hline
\end{tabular}

Source: PRODEGE/MEC Anuario 2014-15; Ley General de Educación No. 5/2007, and

http://unge.education/main/.

The teaching staff include a mix of public official and external contractors. The latter group is widely used by education centers; however, there is a notable lack of details about this sector. According to information from structured interviews (July 2016), it is a common practice that both staff and contractors are appointed at the same time to technical positions in a given ministry or autonomous entity, which can complicate the delivery of timely and complete educational programs. It is also common practice to have substitute teachers back up formally hired ('official') teachers based on less formal arrangements with the MEC, its regulations and supervising institutions.

The MEC is responsible for hiring, evaluating, and promoting the teaching staff according to the systems established. The system lacks a systematic assessment instrument (other than the inspectorate) and directors of public education centers have no mechanisms to hire, evaluate, and promote the teaching staff based on performance. This institutional architecture leaves a quality 'vacuum' and the lack of autonomy and accountability regarding teacher management is part of a more general set of concerns about quality in the country.

\section{Auditing System}

Technical inspectors housed in the MEC are responsible for assessing standards and performance of the public school centers. The bureaucracy of this technical inspection allows it to reach virtually every education center in the country.

\subsection{Education Sector Indicators, Trends and Comparisons}

One of the purposes of this diagnostic is to provide an update of available education data, which includes the 2014-15 Anuario and the 2011 Equatorial Guinea DHS (EDSGE-I). The most recent indicators are useful for assessing the current state of education in the country, including any effects of the crisis, while the updated trends analysis makes it possible to track progress going back to the beginning of the Anuarios (2007-08), and in some cases farther back. Comparisons with countries in the region and/or with similar GDP provide additional information.

\subsubsection{Education Indicators and Trends}


One key positive feature of the basic education system is that very few young people in EQG have never entered $\operatorname{school}^{23}$ and most are remaining in the school system for 10 years or more. This is not always the case in the developing world, as many systems struggle with problems such as children who never enter school or begin leaving school at age 12 (or earlier). ${ }^{24}$ What this means is that Equatorial Guinean children are able to devote a significant amount of time to their educational development.

However, high repetition rates contribute to severe imbalances in enrollment across grade levels. As of 2015, grade 1 students outnumbered grade 6 students by more than two to one. Although repetition rates for grade 1 have decreased over the past decade, still a full quarter (25 percent) of all first graders repeat the grade (in 2014-15) and repetition rates for grades 2-5 remain at 10-20 percent. The total enrollment in grades 1-3 of the primary cycle is nearly equal to the total enrollment of the entire basic education system after grade 3 . When dropout rates are fairly low, this kind of imbalance is only possible if large numbers of students are repeating multiple times, but remaining in school.

The underlying problem with basic education is therefore easily summarized: an extremely low efficiency rate in primary education. This is hardly a new finding, as PRODEGE focused on reducing high repetition rates as part of its original (PRODEGE I) plan of action. The consequences of low efficiency are multiple: high gross enrollment rates in primary grades, low net enrollment rates in secondary, and severe imbalances in enrollment across grade levels, which potentially complicates teacher staffing and development. And unfortunately, the high net enrollment rate in primary is somewhat misleading, since relatively few of these children are in the correct grade for their age.

\section{Gross and Net Enrollment Ratios (GER, NER)}

Gross and net enrollment ratios are critical data points for evaluating systemic performance, defining priorities, and preparing plans for the future. The annual statistical summaries in EQG provide, in theory, up-to-date information on enrollment by school level, in addition to agespecific breakdowns. These are necessary pieces to construct GERs and NERs by level. However, the Anuarios have no way of estimating total populations of school-age persons, which can only be obtained definitively through a census.

\section{Gross enrollment ratio (GER)}

The number of children enrolled in a level (primary or secondary), regardless of age, divided by the population of the age group that officially corresponds to the same level.

\section{Net enrollment ratio (NER)}

The number of children enrolled in a specific level of school who belong to the age group that officially corresponds to that level, divided by the total population of the same age group.

Preschool net enrollment in 2015 was 42 percent, $^{25}$ but this is concentrated largely in urban areas, suggesting that rates are very low in rural areas.

\footnotetext{
${ }^{23}$ At the time of the 2011 DHS.

${ }^{24}$ See recent research on Out-of-School Children; UNICEF and UNESCO 2015.

${ }^{25}$ UIS, 2015.
} 
Primary GERs and NERs declined after 2002, with little change between 2008 and $2015,{ }^{26}$ but the figures differ by data source (Box 3.1 addresses the discrepancies in GER and NER estimations in Figure 3.3). According to the 2011 DHS, GER and NER (see box within Figure 3.3) are much higher: the primary GER in 2011-12 was nearly 140, while the NER was 86.8.

Figure 3.3. Summary of Primary NER and GER, 2000-2015

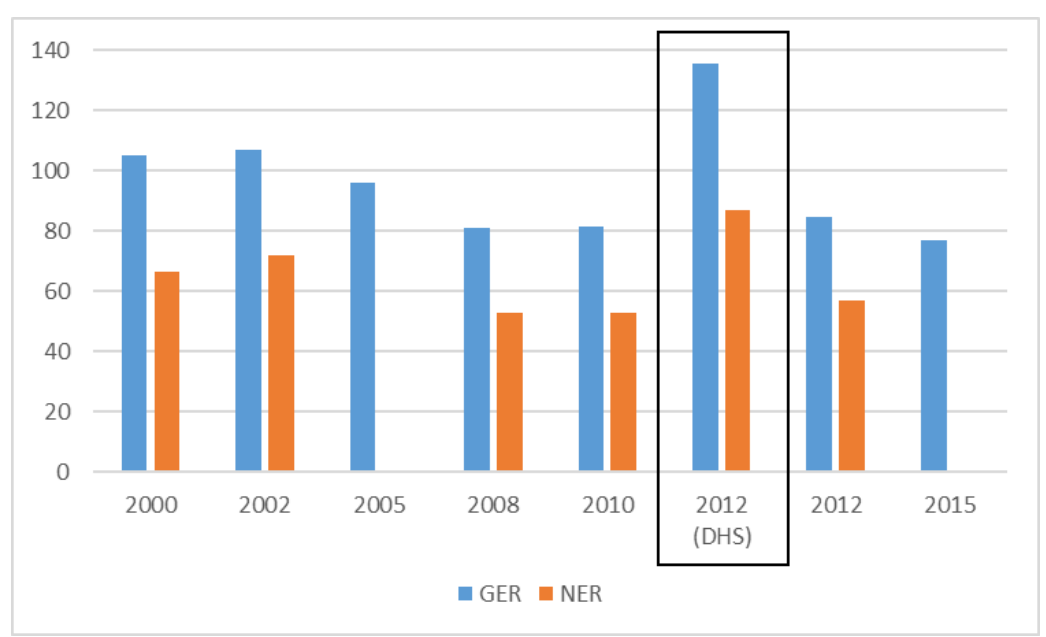

Source: UIS, various years; EDSGE-I (DHS), 2011.

\section{Box 3.1 NER, GER and Data Accuracy}

What explains the discrepancies in GER and NER estimations in Figure 3.3? The problem is the population numbers for 7-12-year-olds that are used to construct these measures. The UNESCO (UIS) website includes population figures for primary- and secondary-age children by year, which were last available as part of the 2001 census. Assuming that the education enrollment figures are correct in 2000 and 2002, the GER and NER for those years will be very reliable. But in the years after 2002 the enrollment ratios can only be calculated on the basis of population projections forward from the 2001 census, and given the decline in GER and NER rates after 2002, it seems likely that there are some problems with the population denominators used in the calculations. As a result, the GER and NER numbers based on 'official' data sources (that is, Anuario enrollments compared against projected populations) appear to significantly understate education coverage, especially since 2002 .

How accurate are GER and NERs based on the 2011 DHS (EDSGE-I)? In general, household survey data sources are considered to be reliable for measuring GERs and NERs. In the case of the 2011 DHS, the sample was based on clusters of households (5,000 in total) drawn from 200 of the roughly 1,000 communities in the country; this is a very large sample in relation to the entire population. Therefore, the 2011 DHS estimations are the best, most recent estimations available for GER and NER. What is less clear is how these 'current' (as of 2011) rates compare with earlier periods, since the data sources are not consistent.

EQG has some of the lowest gross and net enrollment ratios compared to other countries in SSA (see Figure 3.4 and Figure 3.5).

\footnotetext{
${ }^{26}$ The figures for primary gross and net enrollment rates are obtained from the s UIS webpage, with one exception: for the 2011-12 school year the GER and NER based on the DHS data are also shown.
} 
Figure 3.4. Comparison of Primary School GER

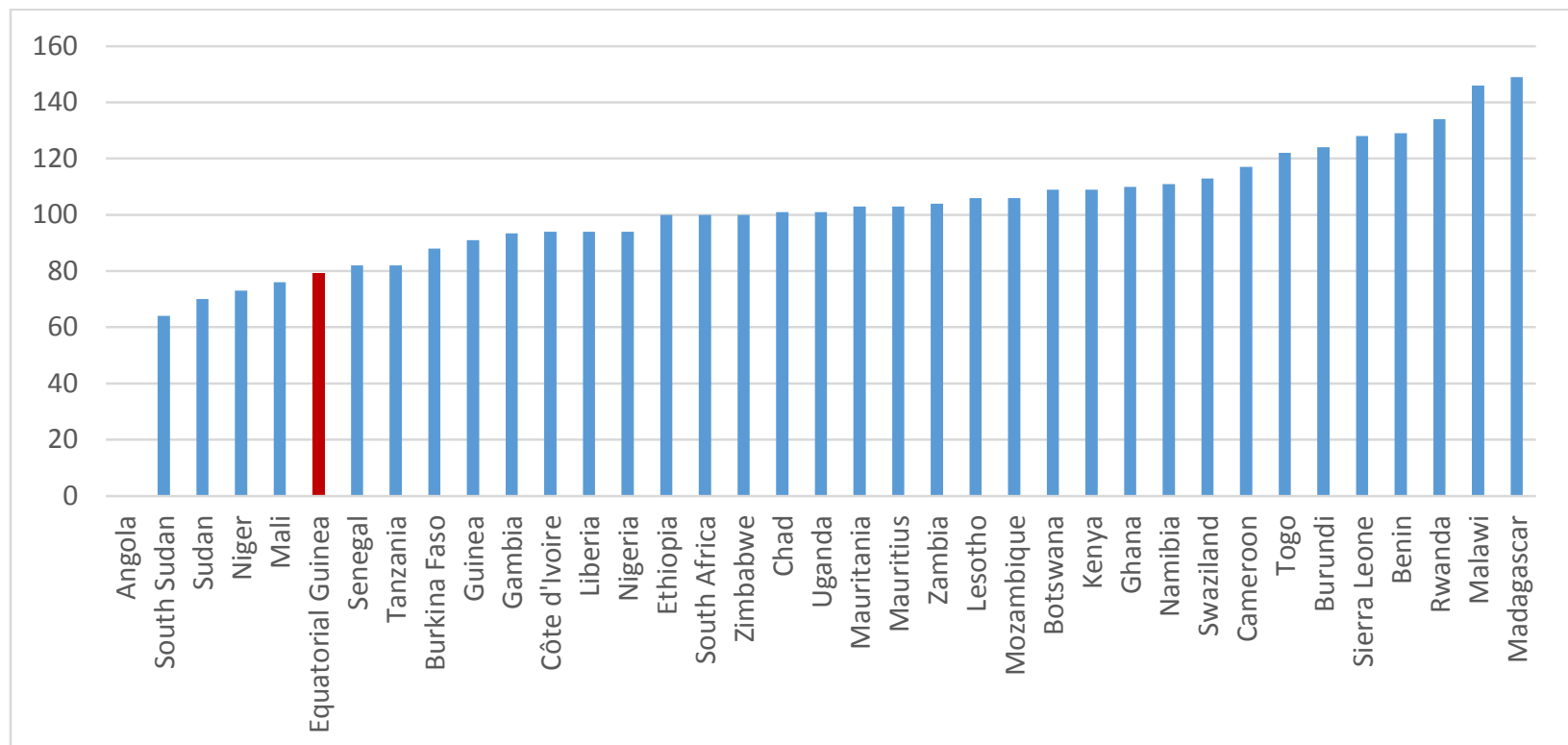

Source: UIS.

Figure 3.5. Comparison of Primary School NER

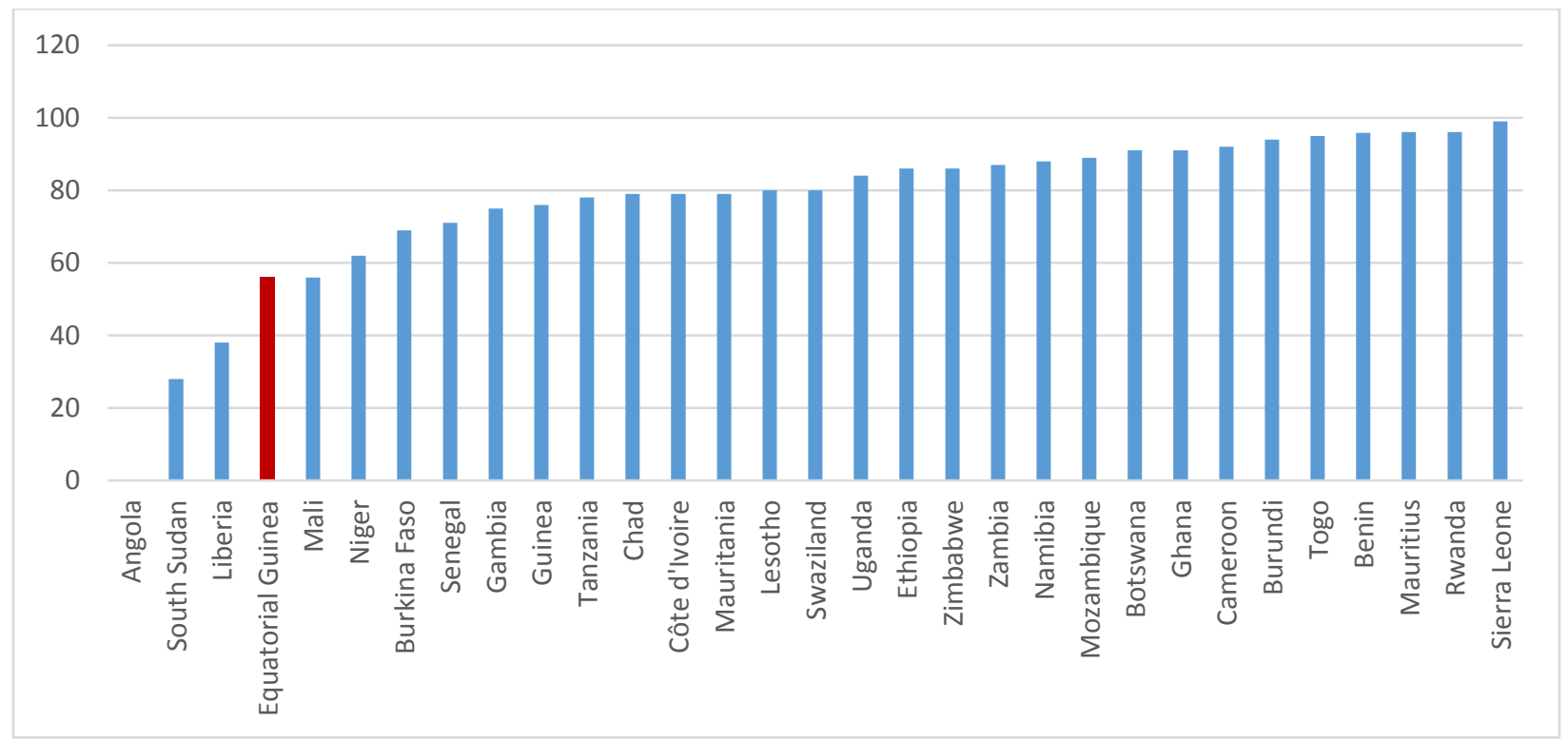

Source: UIS.

EQG also shows a low NER given its GDP per capita. Its NER is significantly lower than countries with similar GDP per capita and some others with lower GDP per capita (see Figure 3.6). 
Figure 3.6. NER by GDP Per Capita

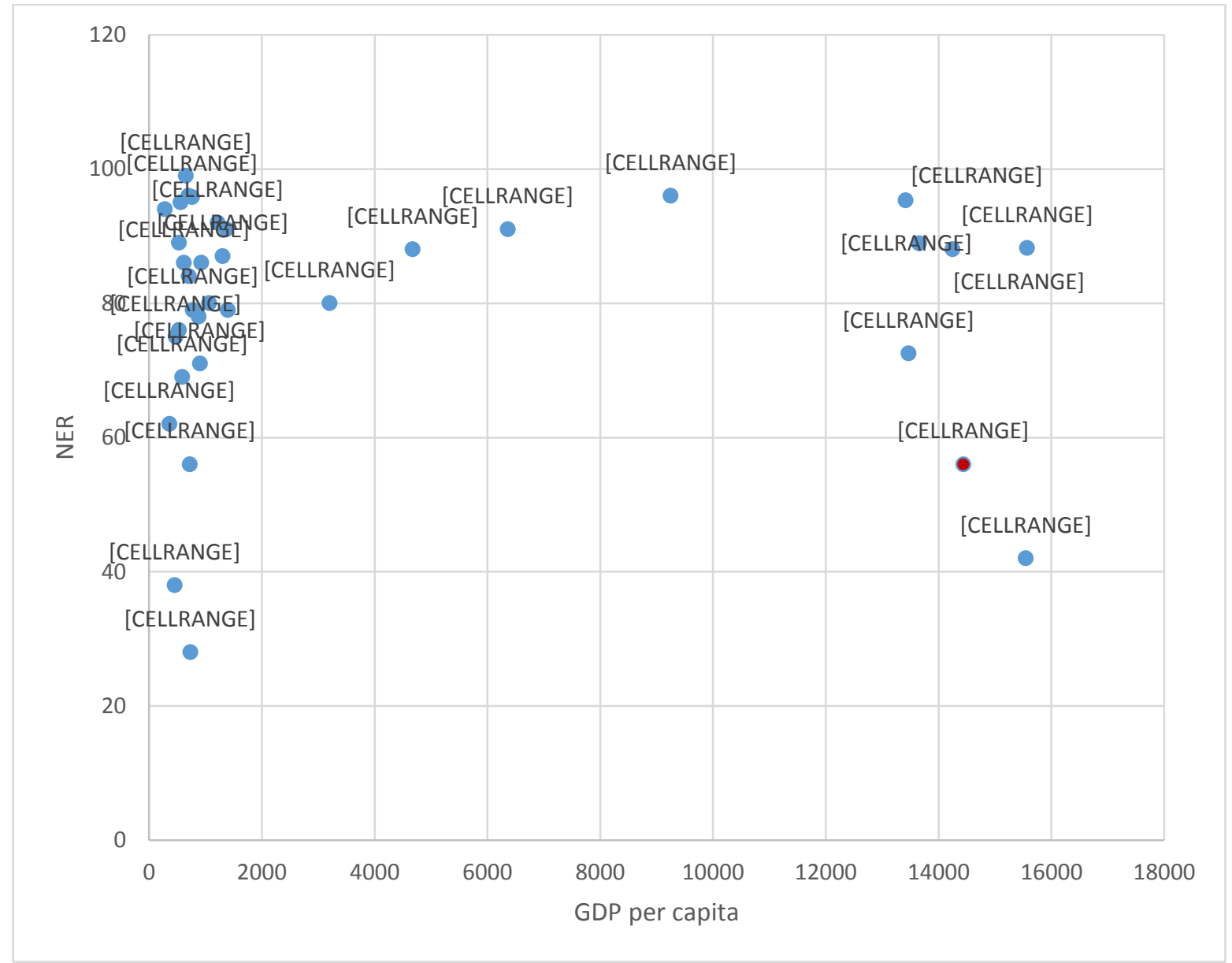

Source: UIS (for NER); World Development Indicators (for GDP per capita).

At the preschool level, all 18 districts in the country report preschool enrollment, with a large proportion (35 percent) in Malabo, followed by Bata district (20 percent). Seventy-five percent of preschool enrollment is urban, although this is again affected especially by Bata district, which is entirely urban.

At the primary level there are high GERs across all four strata. The highest GER (in 2011) is found in the rural zones of the Insular region (nearly 150 percent). Primary NERs are between 60 and 86 percent, depending on the data source used, with a relatively low NER in rural areas of the continent. In secondary school (ESBA), GERs and NERs diverge considerably: the average GER is about 88 percent, compared with only 35 percent NER. Unlike in primary, there is also a lot of variation between strata at this level, which likely reflects the limited access to ESBA in rural areas (see Figure 3.7). 
Figure 3.7. NERs and GERs by School Level and Strata, DHS 2011

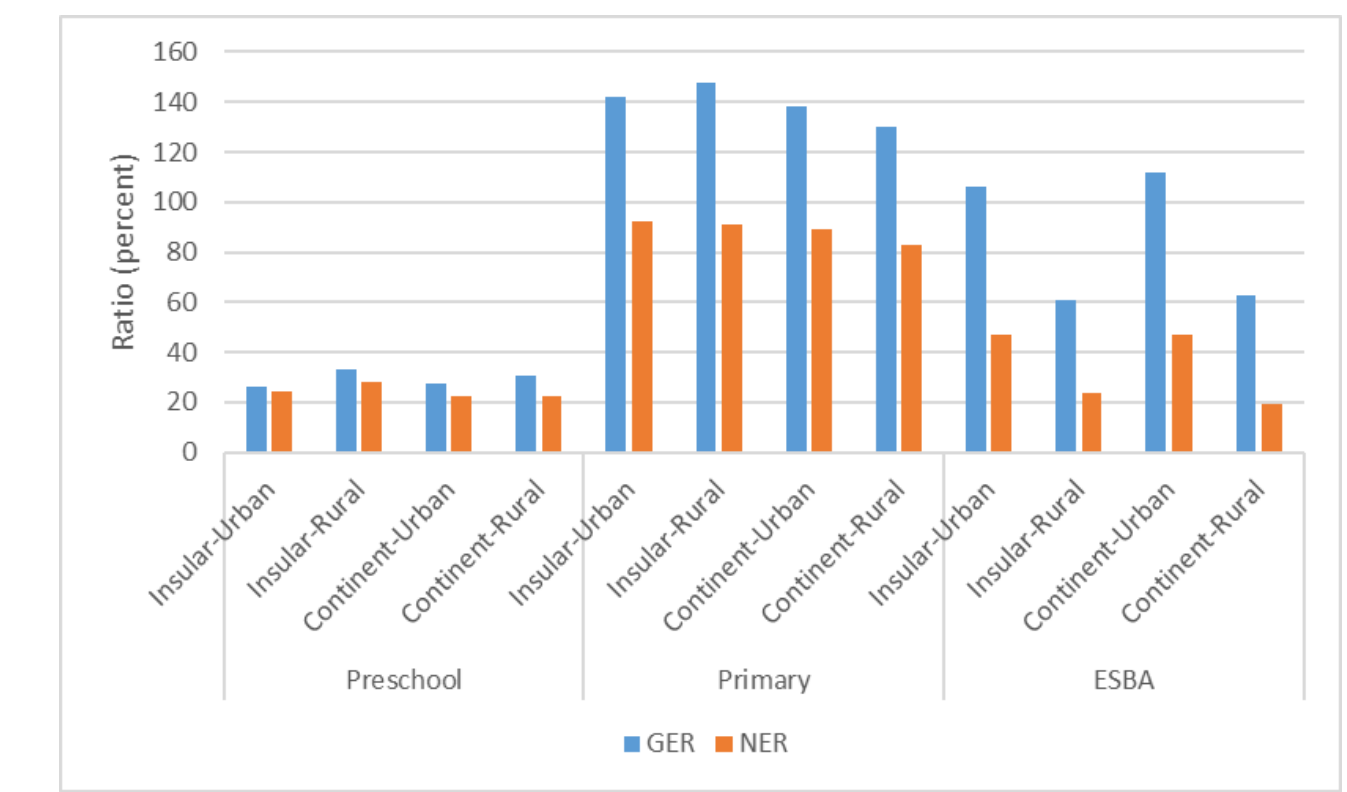

Source: EDSGE-I (DHS), 2011.

Main findings:

1. The very high GERs in primary and urban ESBA strata likely mean that a large number of overage children are enrolled in these levels. There are two main sources of overage children: late entry into primary school, and grade repetition.

2. The relatively high net enrollment rate in primary school is encouraging, and is likely a result of new infrastructure investments, and sector-wide education improvement programs such as PRODEGE. However, it is likely that many of these children in primary are not in the correct grade for their age.

3. There is work that remains to improve participation in preschool and secondary levels, as well as reduce the gaps between urban and rural areas in post-primary schooling. These are common challenges in basic education throughout the developing world, and the government and education partners are well aware of them.

The results in this section highlight two pressing needs going forward. First, the national census data from 2015 are needed to update the gross and net enrollment calculations using the most recent Anuarios from 2014-15 and 2015-16 (when complete). Also, it may be possible to interpolate between the 2001 and 2015 census numbers to obtain new projections by age group that could then be used with previous Anuario summaries to update the GER and NER estimations across the entire 2008-2015 period. However, as of this date, these population estimates have not been released. 
The second critical input is accurate data via the Anuario data generation process. ${ }^{27}$ As is generally the case with administrative data (often referred to as Education Management Information System, or EMIS), there are some potential issues with quality. PRODEGE-MEC staff working on the Anuarios indicated in interviews that their main problem is obtaining complete information from all schools. They are confident that virtually all of the schools in the country are returning the information sheets, but not all of the information fields are complete. This then requires following up with the schools, which can be difficult. This issue is returned to later on in the review of the Anuario data collection system. ${ }^{28}$

\section{Enrollment Trends}

Trends in enrollment over time provide another way of assessing overall system performance. Figure 3.8 shows a summary of preprimary, primary, and secondary enrollment totals between 1999 and 2015. For 2008-15, the data are taken from the corresponding statistical Anuarios, while the pre-2005 data are obtained from the UIS webpage. Also, the Anuarios only report secondary-level data in the 2011 and 2015 reports, so the trend analysis at this level is fairly limited.

Figure 3.8. Preprimary, Primary, and Secondary Enrollment Totals, 1999-2015

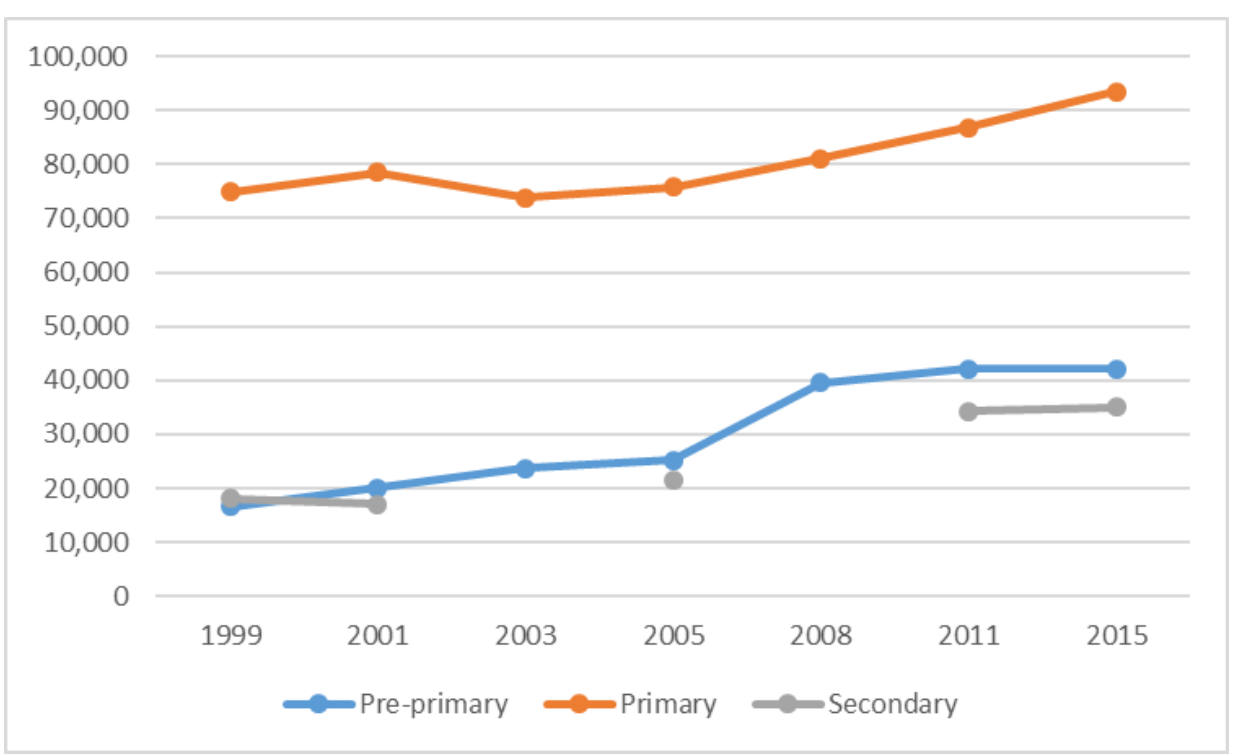

Source: UIS; PRODEGE/MEC Anuarios, various years.

\footnotetext{
${ }^{27}$ The best way to assess administrative data accuracy is to compare official numbers of enrolled children against other data sources, including household survey data. Unfortunately, no such comparisons are currently possible. The 2011 DHS (EDSGE-I) uses normalized weights, which means that it is not possible (with existing data files) to obtain raw numbers of children who are reported as being enrolled in school, which in turn rules out comparing raw numbers in DHS versus enrollment numbers in the Anuario for the 2011-12 school year. Furthermore, even if it were possible to obtain raw numbers of children by age from the DHS 2011, these numbers would presumably be based on much earlier population projections, which may no longer be accurate. These issues with normalized weights and uncertain underlying population projections are not unusual in DHS (and other household survey) analyses in developing countries.

${ }^{28}$ Rodriguez 2012.
} 
Primary and preprimary enrollments have been steadily growing since 2003; for secondary the trend is not as complete, but there has clearly been some expansion since 1999. Preprimary enrollments experienced a particularly rapid period of growth between 2005 and 2008, which corresponds to the PRODEGE I period, although in recent years they have leveled off. Secondary enrollment data are only available since the 2010-11 school year Anuario, and at the time of the 2014-15 Anuario the total secondary enrollment (ESBA and Bachillerato) was about 34,000 students.

The generally upward enrollment trends are encouraging in the sense that they suggest that the system is growing, notwithstanding the recent crisis, which is important since the population of young people is growing as well. However, enrollment in primary school does not appear to have steadily increased over the last 25+ years. In fact, there was a small decrease between 2012 and 2015 (see Figure 3.3), which, given the increase in population of children, may indicate that the crisis is having some impact on school enrollment.

Primary enrollment is concentrated in the two largest provinces (Litoral and Bioko Norte), home to the largest cities in EQG. Figure 3.9 summarizes primary enrollment totals by province according to the 2008-09 and 2013-15 Anuarios. Enrollment in these two provinces at the time of the 2014-15 Anuario represented nearly 75 percent of the entire primary system. Also, these are the only two provinces where substantial increases in primary enrollment took place between the 2008-09 and 2014-15 school years. Wele-Nzas also recorded a somewhat small increase, but in the other four provinces the total enrollment actually declined. We cannot rule out that the crisis had stronger effects outside of Litoral and Bioko Norte leading to lower enrollment.

Figure 3.9. Primary Enrollment by Province, 2009-15

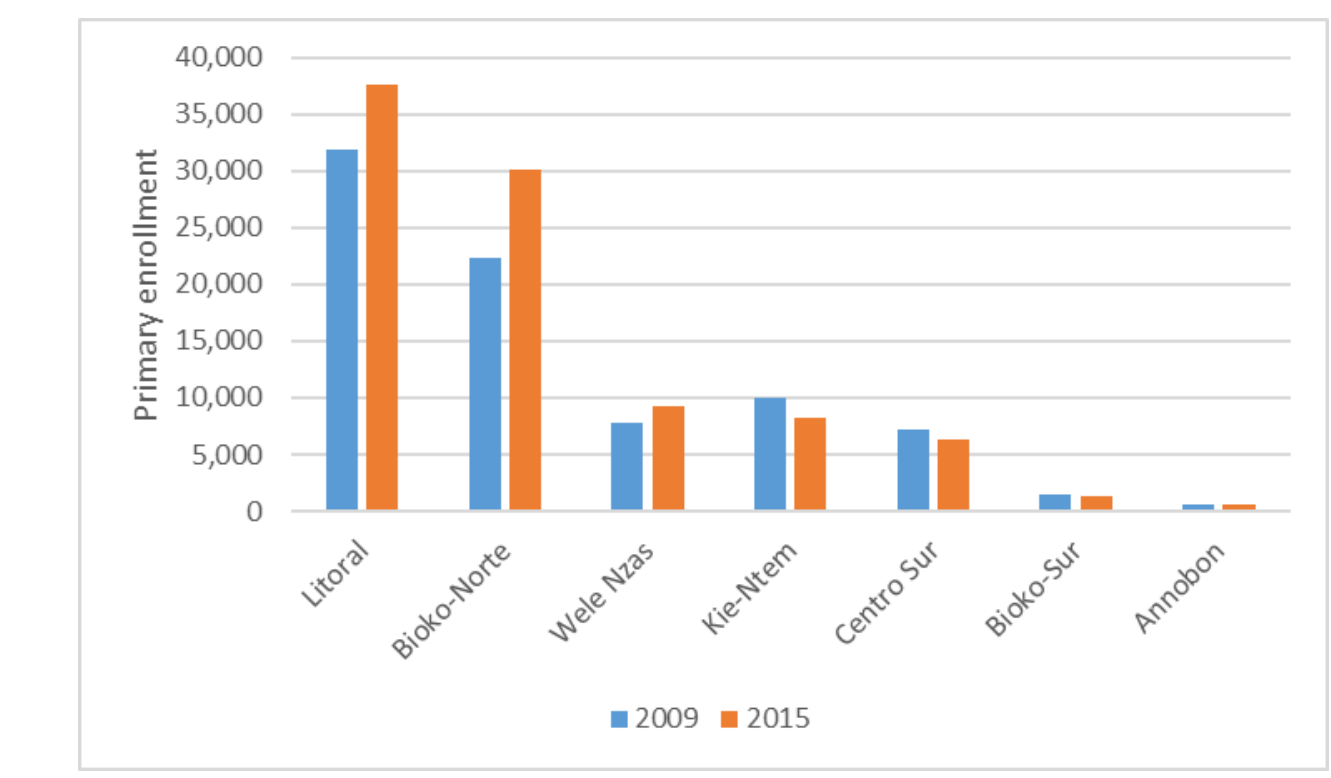

Source: PRODEGE/MEC Anuarios, various years.

Since 2000, there has been a large decline in enrollment between grades $\mathbf{1}$ and 6; as of 2015, grade 1 students outnumbered grade 5 students by more than two to one. However, this gap has 
been shrinking as the number of grade 1 students remains steady, while enrollments are increasing in all other grades (see Figure 3.10). There is still the problem of 'bunching up' in grade 1, which appears to be mainly a result of grade repetition. Furthermore, in comparison with the pre-PRODEGE period data from 2000, the primary enrollment profile has improved considerably (that is, it has become more equal across grades). For example, in 2000 the grade 1 enrollment accounted for roughly 50 percent of the entire primary enrollment, whereas by 2015 this proportion had fallen to about 25 percent.

Figure 3.10. Primary Enrollment by Grade 2000-15

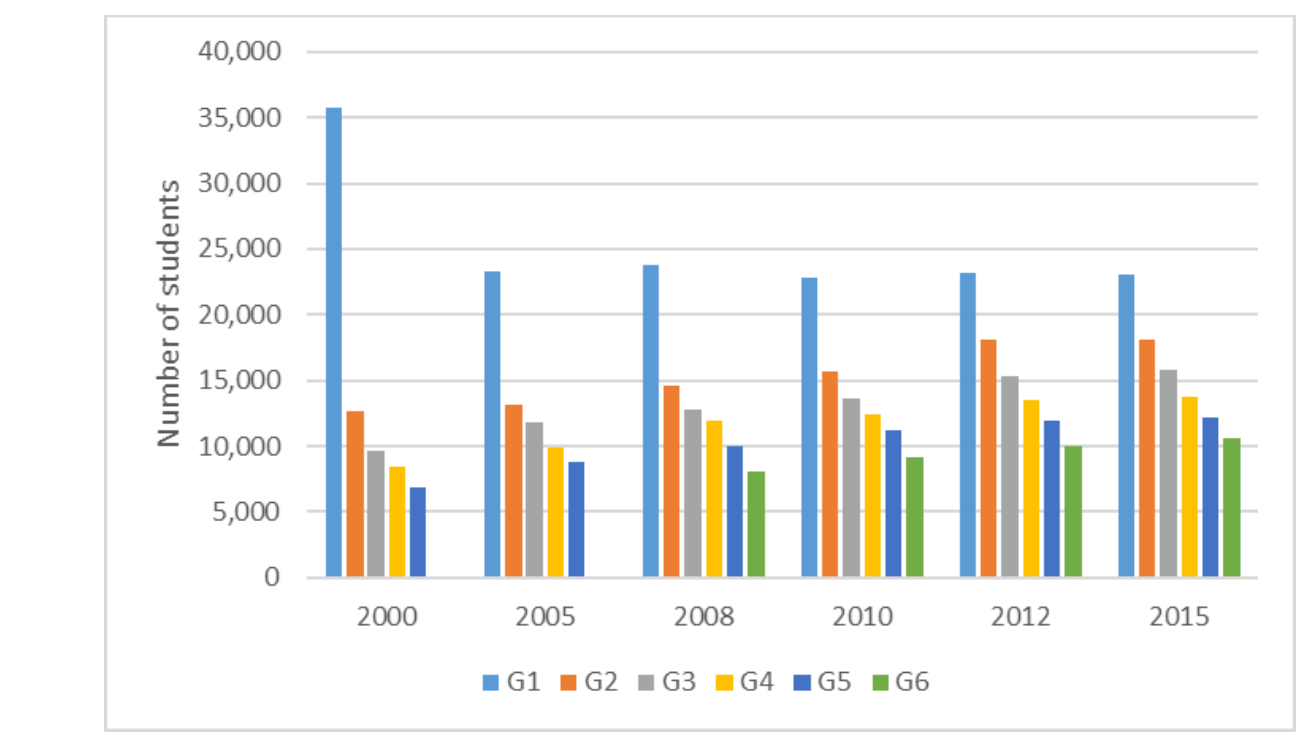

Source: PRODEGE/MEC Anuarios, various years; UIS.

These enrollment distributions indicate the challenges facing the system. Despite steady improvement, the imbalance in enrollment between the earliest primary grades and later primary and secondary grades is notable. Ideally, the goal of the system should be enrollment summaries that are relatively flat from the earliest grades through the highest and across boys and girls.

The steady growth in preschool participation is a positive development for the entire sector, however it is critical that this level of schooling provides quality preparation for young people. Quality preschool is the best way to prepare young people for primary school, which in turn should reduce repetition and dropout rates. However, based on the education profiles of the preschool teachers, there are reasons to be concerned about quality. This has also been addressed as part of PRODEGE, and is a point of emphasis for the MEC.

\section{Age Profiles and Age at Entry}

Very few young people in EQG - at the time of the 2011 DHS — had never entered school. For example, among 10-year-olds, less than 3 percent had never attended school, and this figure was even lower among 9-year-olds (see Figure 3.11). This shows that the education system has achieved a near-universal opportunity to learn, as measured by having a primary school to enroll in, a critical first step in achieving EFA goals. 
Figure 3.11. School Attendance Status by Age (6-10), 2011 DHS

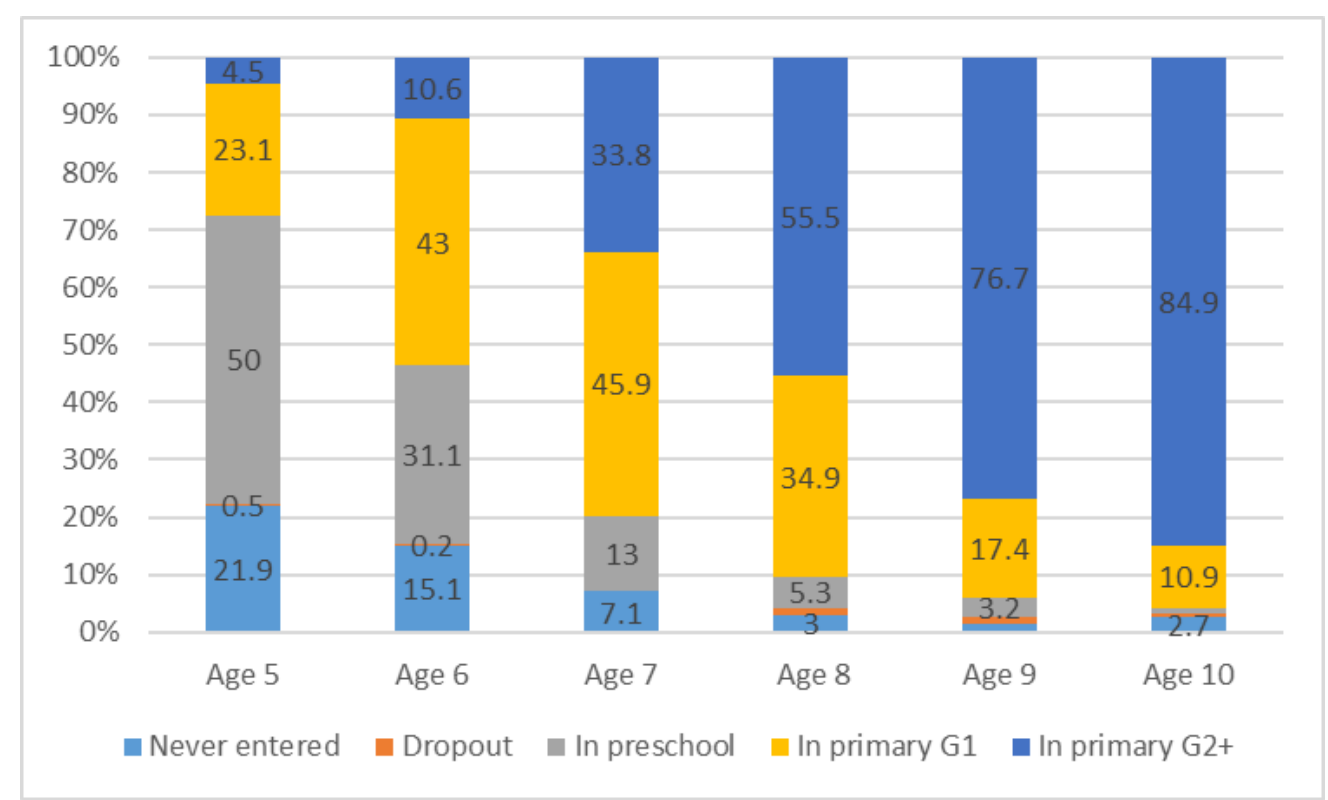

Source: EDSGE-I (DHS), 2011.

Note: The status variable includes five categories: 1) never attended school; 2) attended school but has dropped out; 3) currently in preschool; 4) currently in primary grade 1; and 5) current in primary grade 2 or higher. Never attending school is not directly measured in the 2011 DHS with a question such as "Has the person ever attended school?" Instead, never attended school is derived by combining the variables that measure grade attainment and current attendance. When the person has "No education", and is not currently attending school, they are classified as "Never attended." For young people this is likely to be accurate, but for older individuals it may miss people who have entered school but never completed first grade.

Most children begin their primary education on time (or earlier). There is little overage enrollment in preschool; only 13 percent of seven-year-olds and 5.3 percent of eight-year-olds reported being in preschool at the time of the 2011 DHS. Furthermore, early entry into primary is quite common. One-third (32.5 percent) of grade 1 entrants in 2014-15 were below seven years of age, while only about 15 percent were older than eight years (see Figure 3.12). Early entry is even more common in the Insular zone: 41.8 percent of grade 1 entrants in 2014-15 were under seven. 
Figure 3.12. Age of Primary Grade 1 New Entrants by Zone, 2014-15

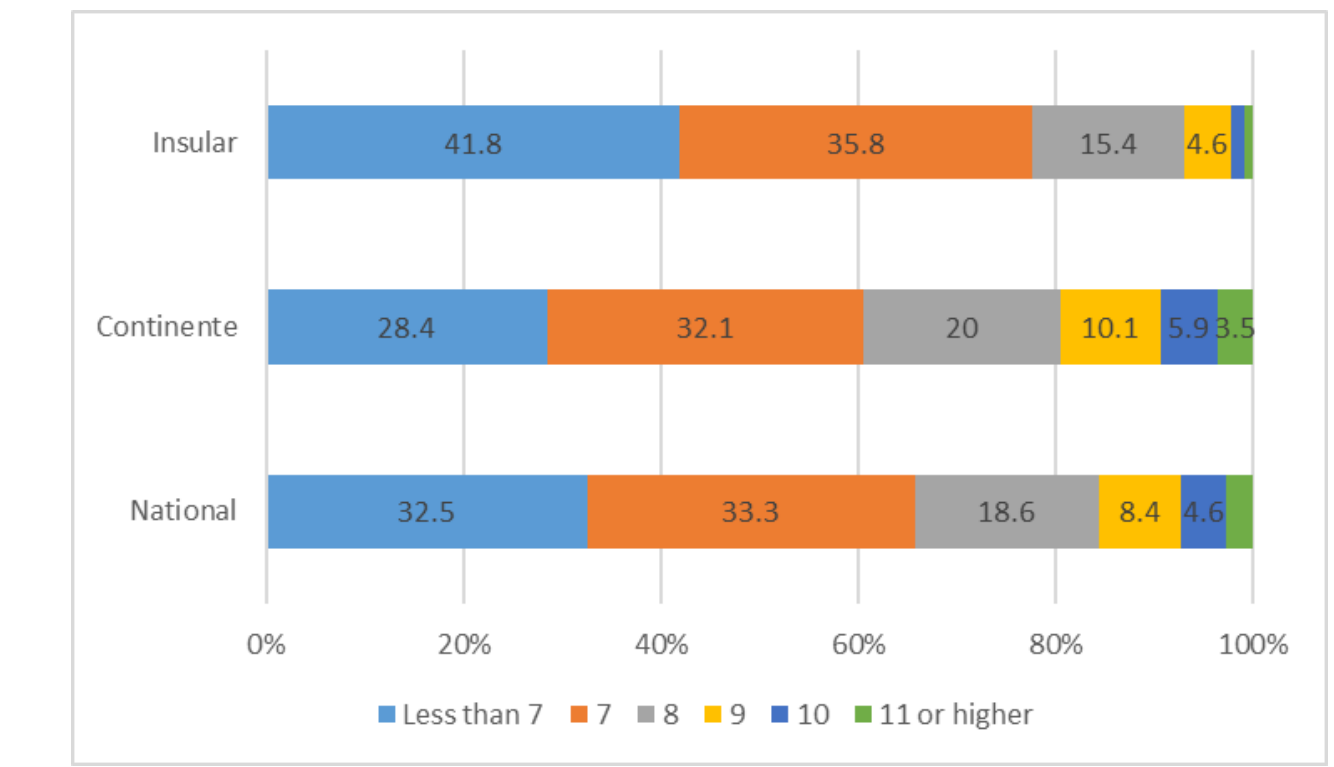

Source: PRODEGE/MEC Anuario, 2014-15.

This helps explain the high GER in primary at the time of the 2011 DHS: a large number of children who are below the official primary school age were enrolled in primary school, which increases the gross enrollment figure. EQG's official grade 1 entrance age of seven years (rather than 6) means this is more likely. Under-age enrollment could contribute to repetition in grade 1 because children are not ready for school, contributing to inefficiency in the system and higher fiscal costs.

There are many overage children in primary school. At the time of the 2014-15 annual report, a majority of children in grades 3 and 6 were overage, including nearly 75 percent in grade 6 (see Figure 3.13). For example, in 2008 only 39 percent of grade 1 students were at or below the correct age (7). In 2014-15 this proportion had increased to nearly 60 percent. This, too, causes inefficiency. 
Figure 3.13. Student Age Categories in Primary Grades 1, 3, and 6, 2008-15

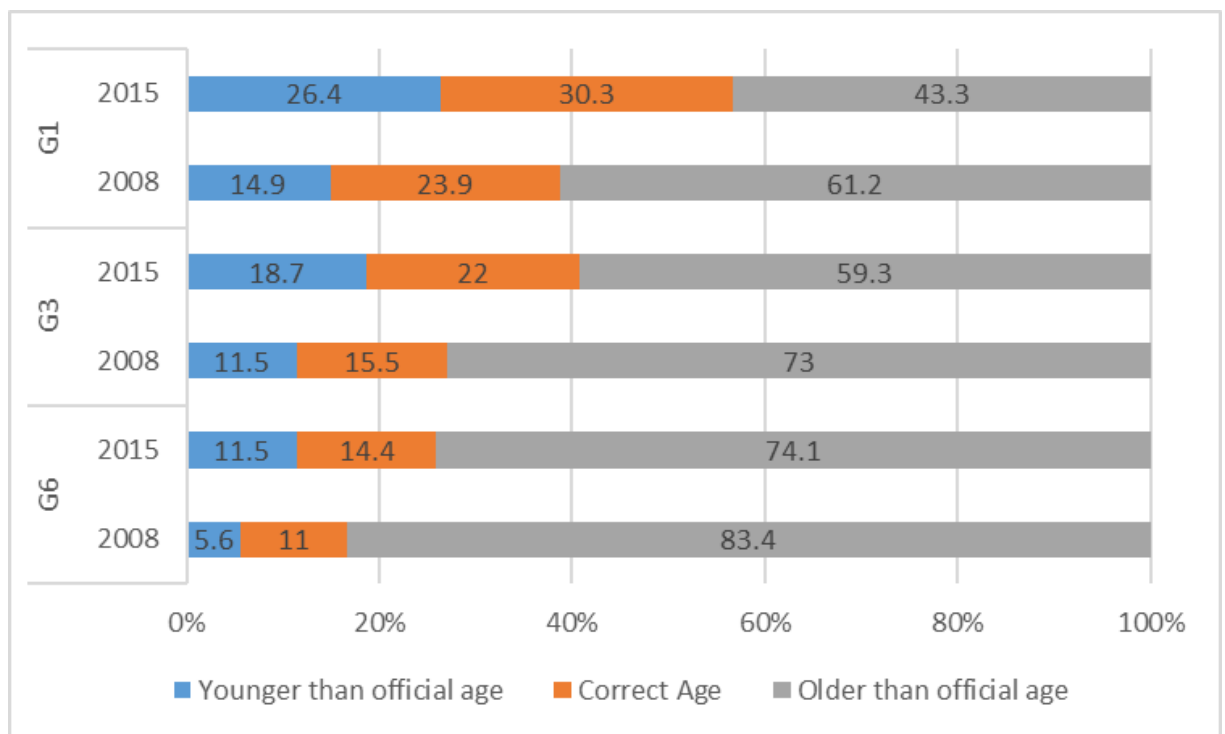

Source: PRODEGE/MEC Anuario, 2014-15.

Note: The overage enrollment rates are high compared to countries with similar per capita GDP (see Figure 3.14 and Figure 3.15) and other countries in SSA. This is particularly notable when looking at the percentage of children who are at least two years overage for their current grade (see Figure 3.16 and Figure 3.17).

Figure 3.14. Overage Enrollment in Primary Compared to GDP Peers

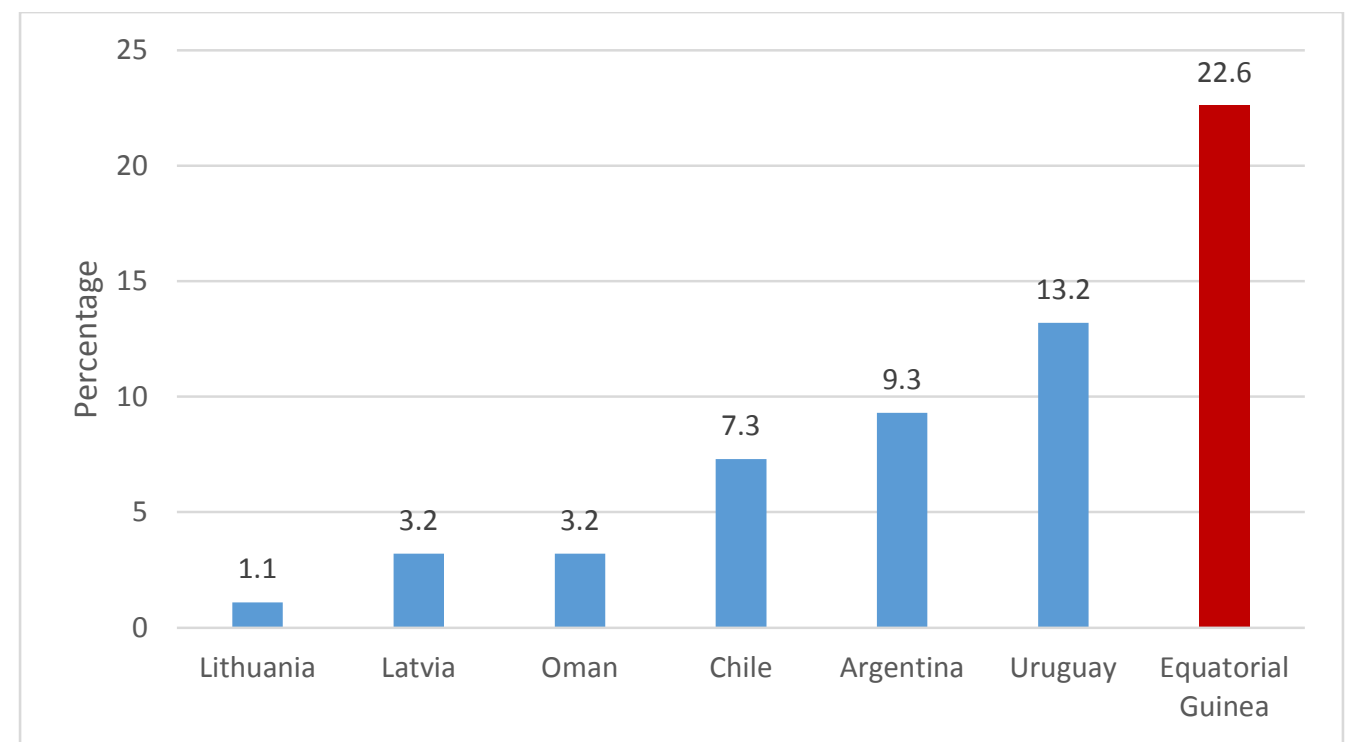

Source: UIS, latest available data. 
Figure 3.15. Overage Enrollment in Primary Compared to SSA Countries

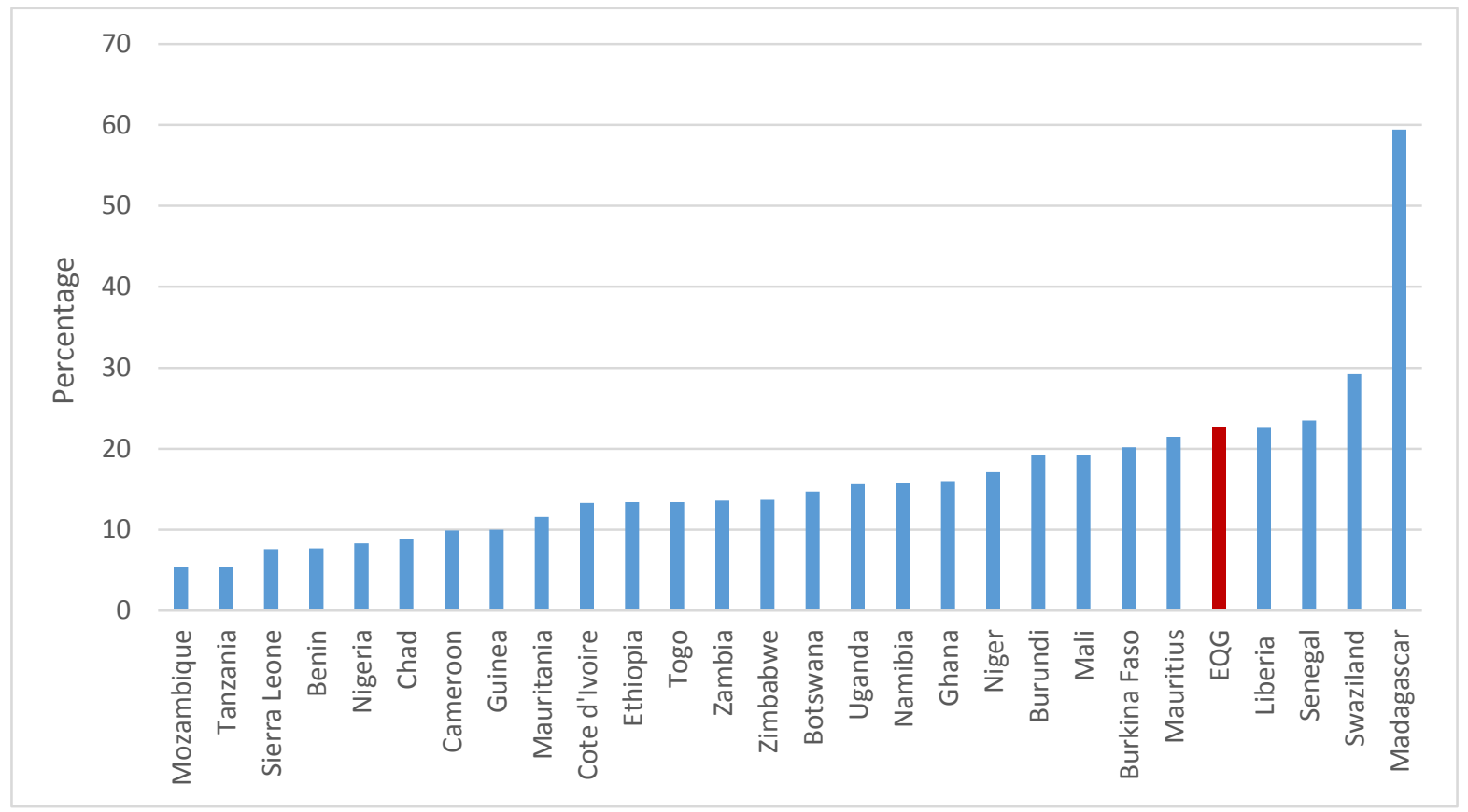

Source: UIS, latest available data.

Figure 3.16. At Least Two Years Overage for Current Grade in Primary, Compared to GDP Peers

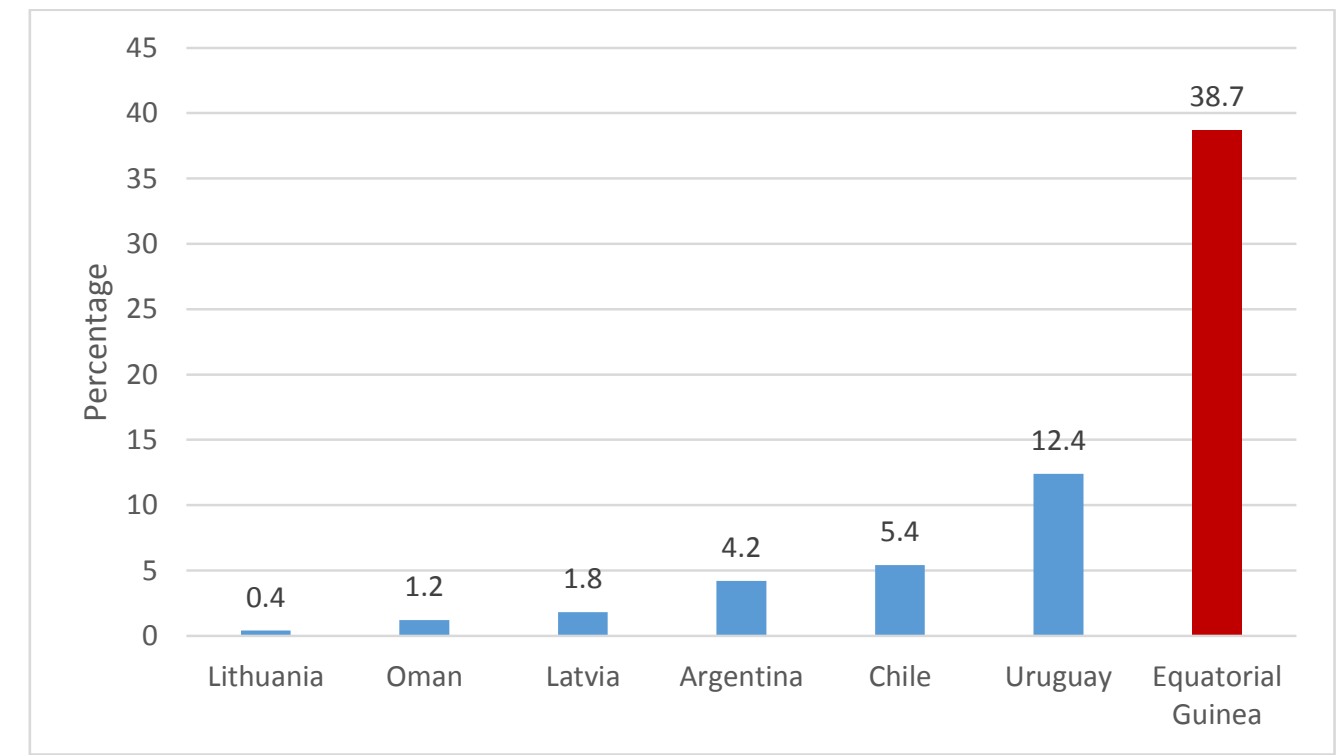

Source: UIS, latest available data. 
Figure 3.17. At Least Two Years Overage for Current Grade in Primary, Compared to SSA Countries

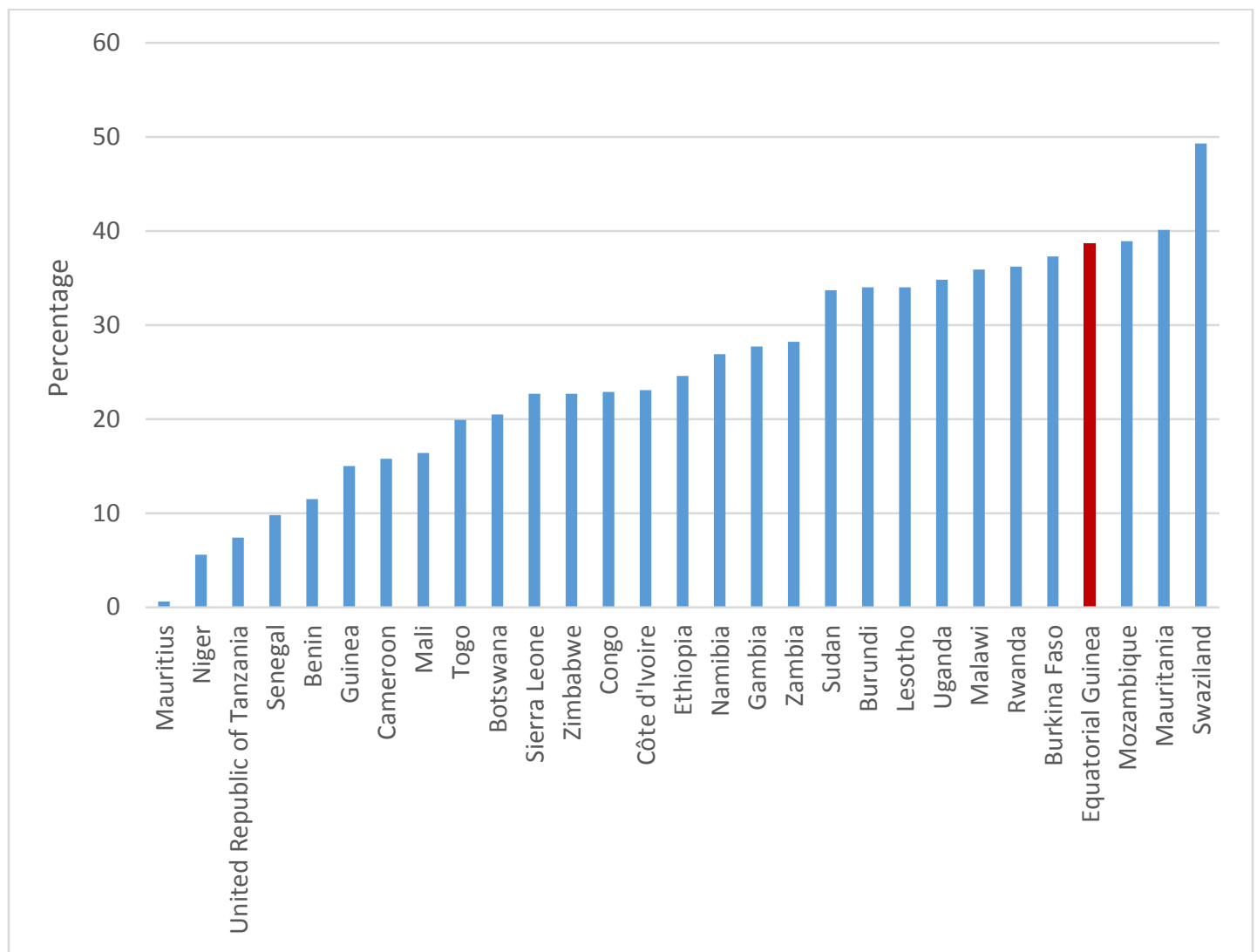

Source: UIS, latest available data.

\section{Grade Repetition and Dropout}

High repetition rates are a well-known problem in EQG, as demonstrated in the statistical Anuarios and in the goals of educational programs like PRODEGE. The very high averages in grade 1 stand out, although it is important to note that they have come down from 35 percent in 2002 to just under 25 percent in 2014-15 (see Figure 3.18). PRODEGE focused on reducing grade 1 repetition, primarily through improved training of grade 1 teachers, focusing on appropriate pedagogy to teach reading, writing, and math and support mechanisms to teachers to help them implement new strategies. It is encouraging to see the decline in grade 1 repetition between 2008 and 2011; nevertheless, roughly one-quarter of grade 1 students were still repeating the grade in 2014-15. And the repetition problem is not only a problem in grade 1, as the averages are in the 10-20 percent range in grades $2-5$ of primary, with only some improvement in recent years. The repetition rate in EQG is also high compared to countries with similar GDP and other African countries (see Figure 3.19 and Figure 3.20). 
Figure 3.18. Primary Repetition Rates by Grade, 2002-15

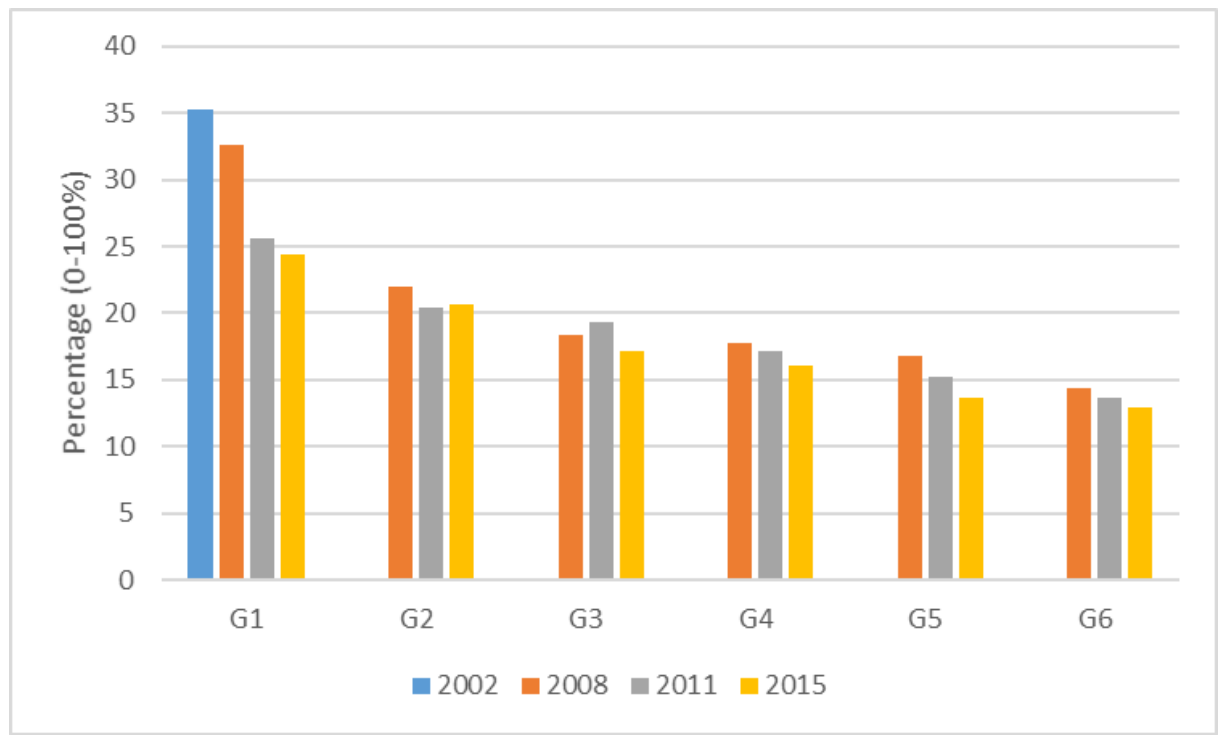

Source: PRODEGE/MEC Anuarios, various years; UIS.

Figure 3.19. Repetition Rate in Primary Compared to GDP Peers

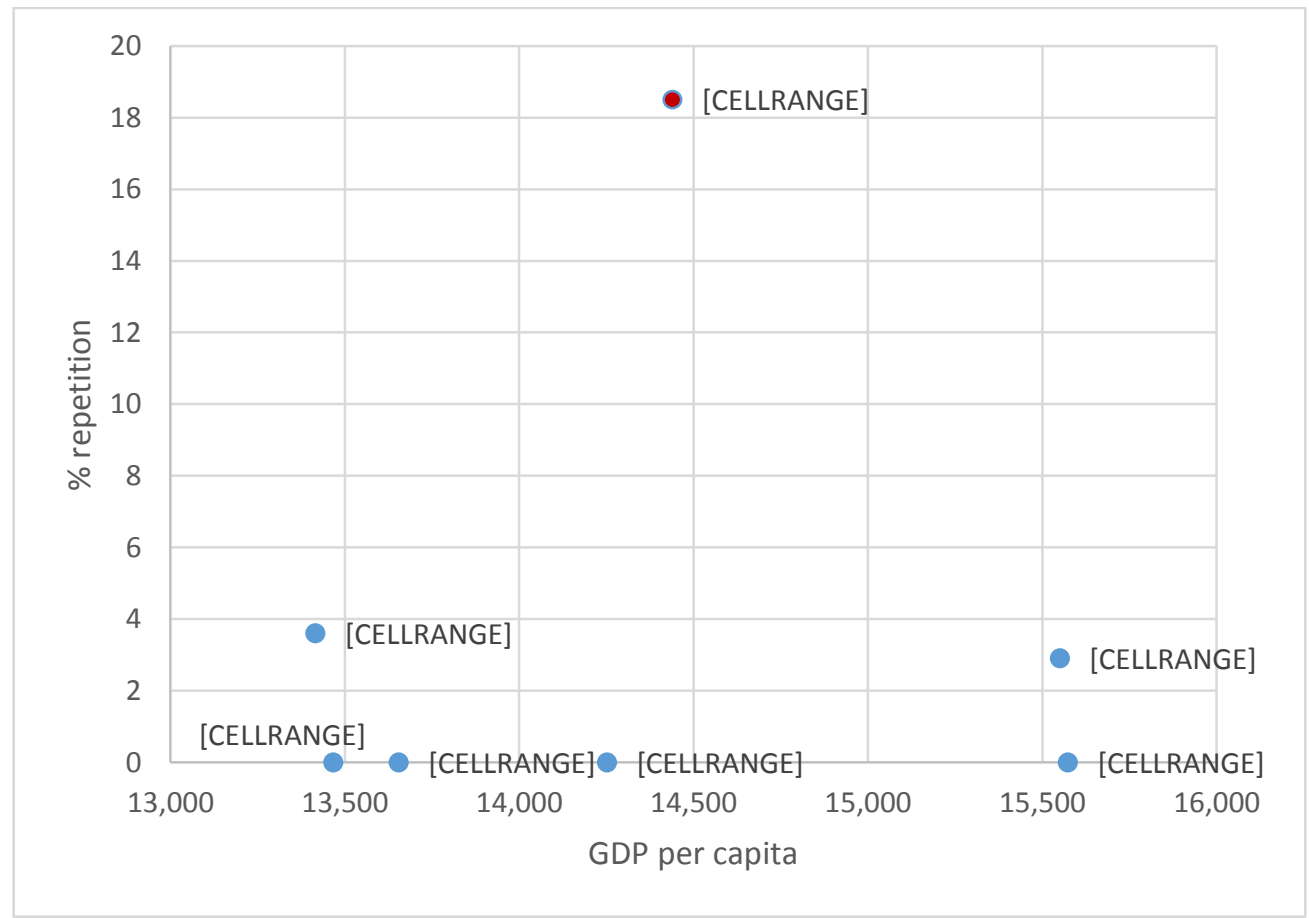

Source: UIS, latest available data. 
Figure 3.20. Repetition Rate in Primary Compared to Selected African Countries

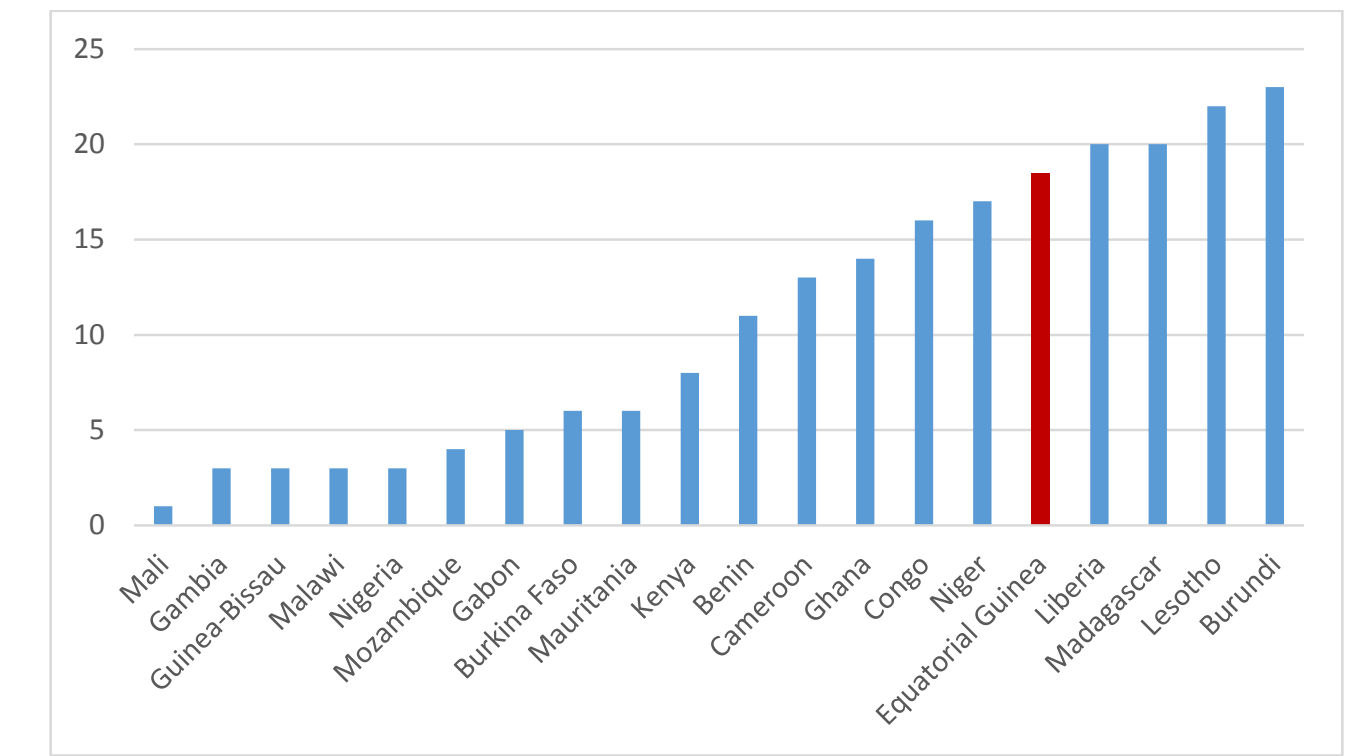

Source: UIS, latest available data.

The most commonly cited reason for failing a grade is that the child has not demonstrated a sufficient knowledge of the intended curriculum for that grade. This highlights the importance of measuring and monitoring student achievement levels, both in the classroom as part of the teacher's formative assessments, and at the systemic level through standardized testing. Little information is available about both of these dimensions of assessment. It is also important to recognize that grade repetition has a structural component, and acts as a filter for a system where access to higher levels of schooling may be restricted. This is not to say that children are being unfairly held back, but one potential way to improve student flows in lower levels is to continue to improve the supply of schooling in higher levels.

The high repetition rate in grade 1 helps explain the bunching up of students in this grade level. In most countries, a decline by grade across the basic education system (demonstrated earlier in Figure 3.6) would be a result of school dropout. Unfortunately, school dropout rates in EQG are difficult to estimate on the basis of administrative data (like the Anuarios), ${ }^{29}$ and in household surveys like DHS. ${ }^{30}$

Dropout rates in EQG are highest at the beginning of each school level (see Figure 3.21). For example, roughly 8-10 percent of students enrolled in primary grade 1, ESBA 1 and Bachillerato 1 in 2010-11 did not continue their schooling in 2011-12, based on the Anuario estimation. This is not an unusual result. In grade 1, children with physical or other problems may struggle to

\footnotetext{
${ }^{29}$ There is an inherent difficulty of measuring dropout rates on the basis of administrative data. In some grades the dropout rates are actually negative, which means that more children entered the following grade in 2011-12 than were enrolled in the previous grade in the previous year. When dropout is more likely to take place between school years, rather than during the school year, it can only be estimated rather than measured directly. This is a common problem faced by data collection staff such as MEC/PRODEGE.

${ }^{30}$ The 2011 ESDGE-I (DHS) is missing two variables that are useful for measuring dropout accurately, and are often available in DHS data collections. One is a summary variable that includes a category for dropout, as well as when the dropout took place (last year, two or more years ago, and so on). Another is a summary of the child's educational status in the previous year, which can be useful to measure year-on-year dropout.
} 
learn, and eventually drop out before completing the grade. In higher levels the transition to a more demanding curriculum - and in many cases a very different school environment (that is, much larger, multiple teachers, and so on) — can be difficult for some children. The usual sequence is to repeat the grade, perhaps several times, before eventually leaving. Students are also dropping out after other grades in the primary and (especially) secondary sequence, but these rates appear to be generally lower than those in the first year of each cycle.

Figure 3.21. Dropout Rates by Grade, 2010-11/2011-12

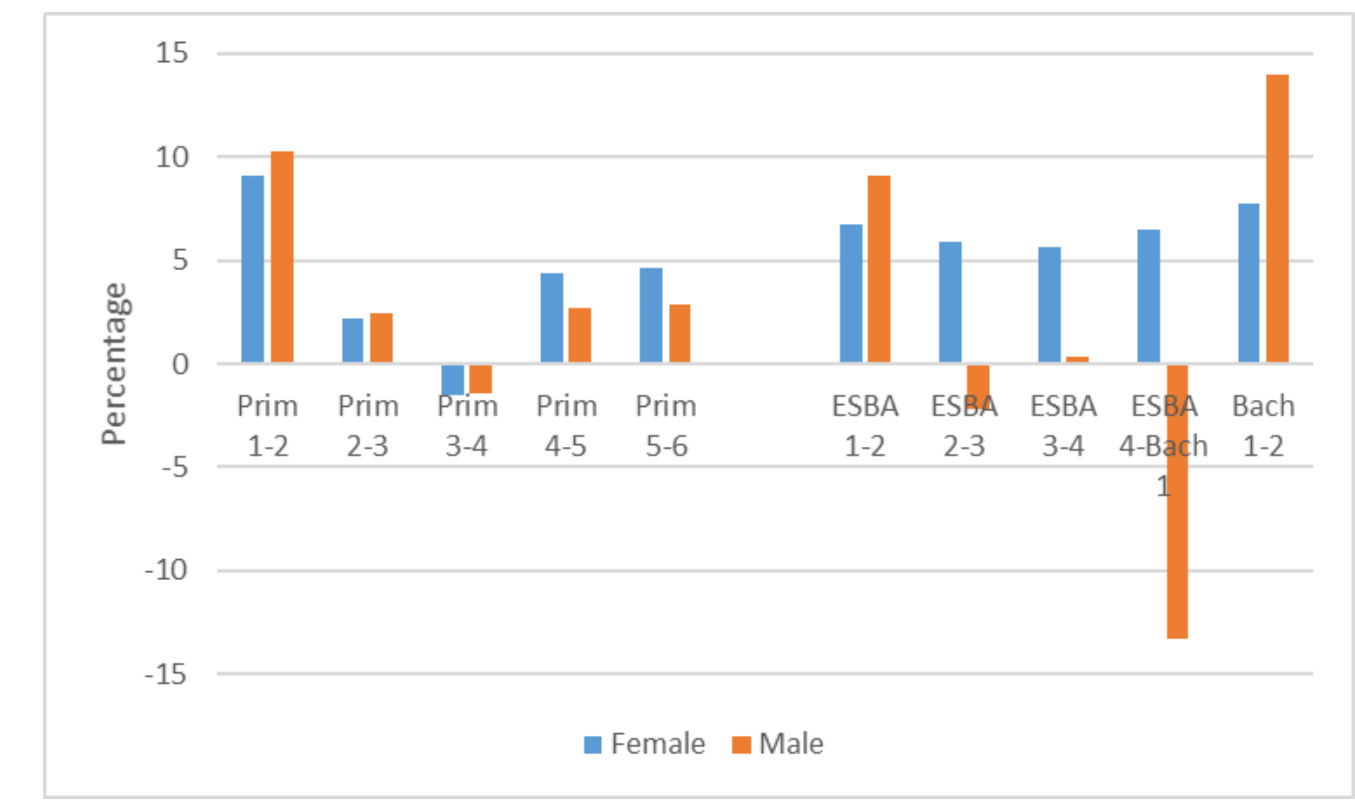

Source: PRODEGE/MEC, 2010-12 Anuarios.

The main reasons for dropout during the school year were sickness, lack of a teacher, and lack of money to pay for studies (see Table 3.5). In about 40 percent of the cases the dropout is not actually dropout, but is transferring to another school.

Table 3.5. Summary of Reasons for Leaving School during the 2003-04 School Year

\begin{tabular}{|l|r|r|r|r|r|r|}
\cline { 2 - 7 } \multicolumn{1}{c|}{} & \multicolumn{7}{c|}{ Grade } \\
\cline { 2 - 7 } \multicolumn{1}{c|}{} & \multicolumn{1}{c|}{ st } & 2nd & \multicolumn{1}{l|}{ 3rd } & 4th & 5th & \multicolumn{1}{l|}{ Total } \\
\hline Illness & 622 & 536 & 505 & 432 & 753 & 2848 \\
\hline Lack of mentoring & 384 & 219 & 142 & 154 & 68 & 967 \\
\hline Lack of resources & 103 & 55 & 73 & 59 & 67 & 357 \\
\hline Work & 34 & 35 & 10 & 60 & 144 & 283 \\
\hline Transfer to other center & 1233 & 684 & 402 & 647 & 284 & 3250 \\
\hline $\begin{array}{l}\text { Distance to closest } \\
\text { school }\end{array}$ & 69 & 35 & 65 & 7 & 11 & 187 \\
\hline Death & 46 & 54 & 13 & 25 & 8 & 146 \\
\hline School conditions & 29 & 11 & 31 & 0 & 0 & 71 \\
\hline Teacher conditions & 21 & 43 & 3 & 90 & 17 & 174 \\
\hline Other & 42 & 29 & 49 & 20 & 52 & 192 \\
\hline Total dropouts & 2583 & 1701 & 1293 & 1494 & 1404 & 8475 \\
\hline
\end{tabular}

Source: MEC, Office of Education Planning. 
In sum, large numbers of students are repeating the earliest grades, often multiple times, before eventually dropping out, and as a result enrollment is heavily tilted towards the earlier grades in primary. There is clearly dropout taking place throughout the primary and secondary system, both during and in between school years. Also, there is some evidence about when this is happening (that is, grade 1, ESBA 1, and so on). Current (2011-12) enrollment rates are near or above 95 percent for most of the basic school age sequence, and only fall below 90 percent (on average) at age 16 (see Figure 3.22). In other words, very few children are leaving the system before the age of 16 . The fairly steep decline between ages 15-18 is not an unusual finding, as children of this age have more opportunities to work and begin families. These pressures are especially pronounced for girls, who are significantly more likely to terminate their schooling at this stage than boys (details provided below) and for students from poor and rural backgrounds. However, it should be observed that about 75 percent of all 18-year-olds are still in school at the time of the 2011 DHS, so there is no evidence of a massive desertion from the system in late adolescence.

Figure 3.22. Current School Enrollment Rates by Age, 2011 DHS

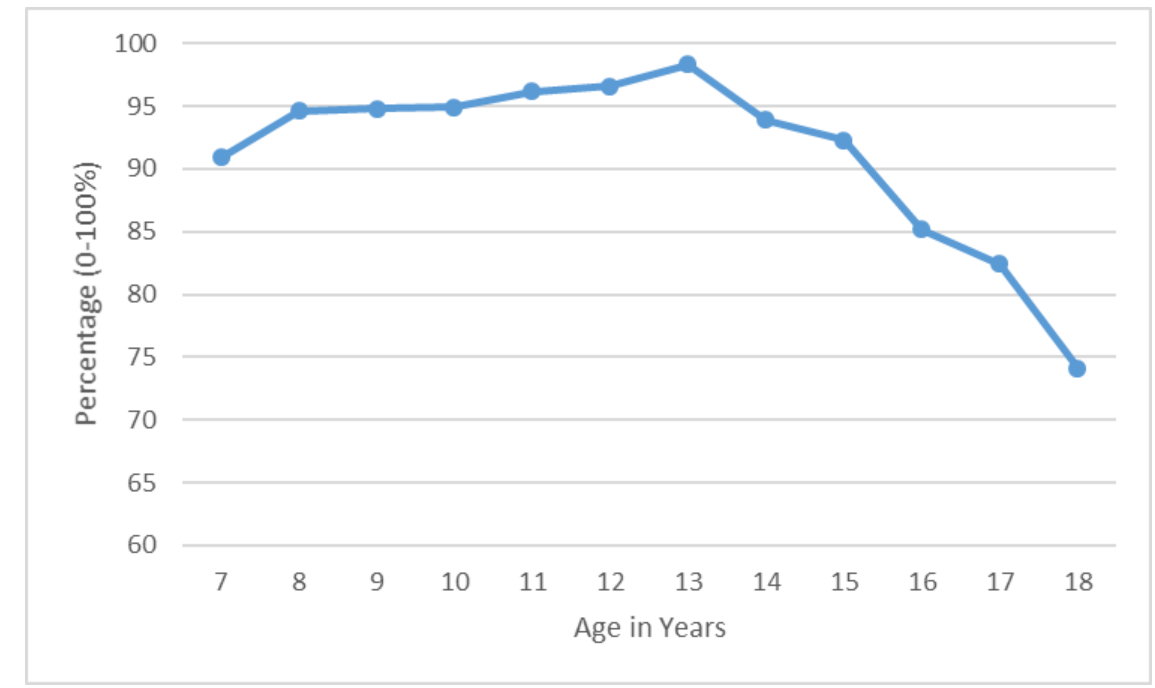

Source: EDSGE-I (DHS), 2011.

\subsubsection{Equity Comparisons: Gender, Socioeconomic Status (SES), and Location}

This section provides comparisons by gender, SES, and location to identify significant differences - often referred to as gaps-in key outcomes. The equity review is a necessary piece of any sector diagnostic, primarily because it helps identify areas of emphasis from a policy and planning standpoint.

\section{Gender}

Gender equity is a focus in EQG policy discussions, and in goals related to EFA and Educación Para Todos. Preschool enrollment is evenly divided by gender, with roughly equal numbers of boys and girls enrolled in each level. There is little difference in enrollment by gender from age 7 to 16; however, at age 16 boys' enrollment surpasses that of girls (see Figure 3.23). For the 1721 age range the average male advantage in attendance is just over 10 percentage points. 
Figure 3.23. Current Enrollment Rates by Gender, 2011 DHS

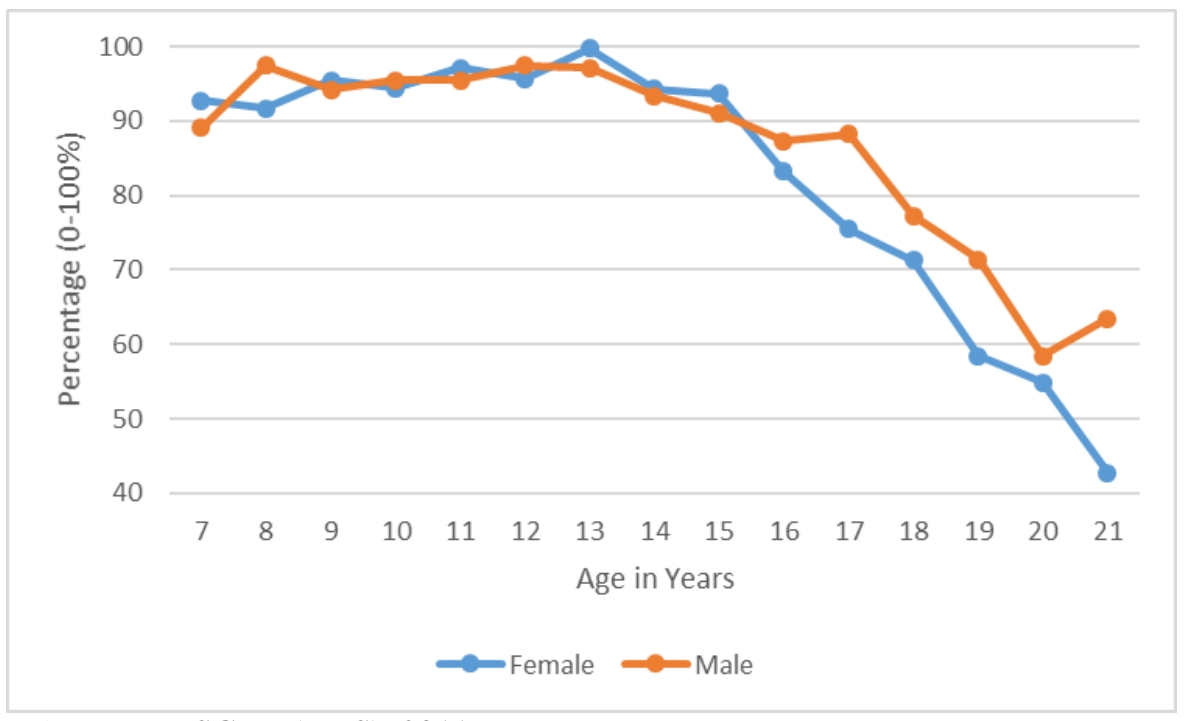

Source: EDSGE-I (DHS), 2011.

However, the time girls spend in school is marginally more efficient as they are less likely than boys to repeat grades (see Figure 3.24). Boys are more likely to repeat in all grades of the basic (primary plus ESBA) sequence, except for the last grade of ESBA (4). The differences are generally significant, but not enormous: in most grades girls are 2-3 percent less likely to repeat. These differences can add up over time, and predict girls completing more grades of education for the same amount of time spent in the system.

Figure 3.24. Grade Repetition Rates by Gender and Grade, 2014-15

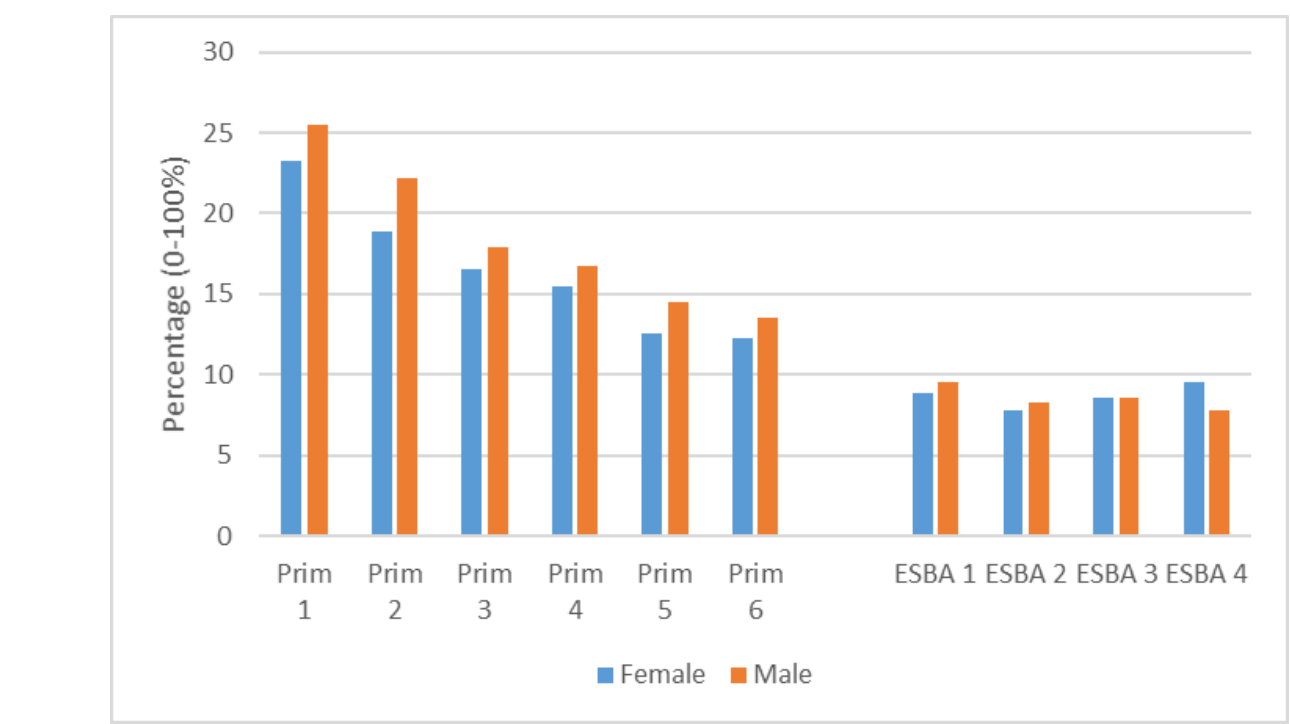

Source: PRODEGE/MEC, 2014-15 Anuario.

Between the ages of 7 and 18, girls complete more years of education than boys: for 7-12year-olds the difference is only 0.08 of one year, but for the 13-18-year-old cohort the female advantage is nearly one-half of a year of education (Figure 3.25). However, for the 19-25-year- 
old cohort it is males who have significantly higher levels of education (9.1 years versus only 8.1 years for females). A somewhat similar pattern occurs for ESBA completion. Through the age of 18 , boys and girls have similar rates of EBSA completion. But after age 18 the completion rates diverge substantially, except for age 22 (see Figure 3.26). ${ }^{31}$ For primary completion (Figure E6 in Appendix E), the pattern is somewhat different. Girls are more likely to complete primary schooling between the ages of 12 and 17, but from 18 onward boys have a marginally higher rate of completion.

Figure 3.25. Grade Attainment by Gender and Age Cohort, 2011 DHS

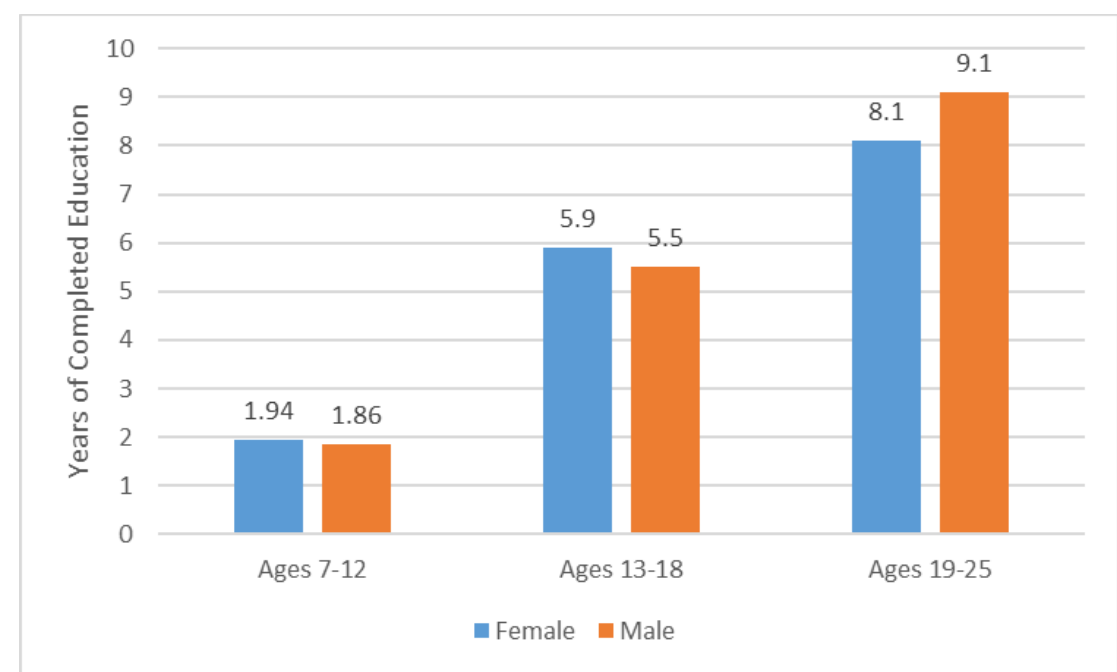

Source: EDSGE-I (DHS), 2011.

Figure 3.26. ESBA Completion Rate by Gender and Age, 2011 DHS

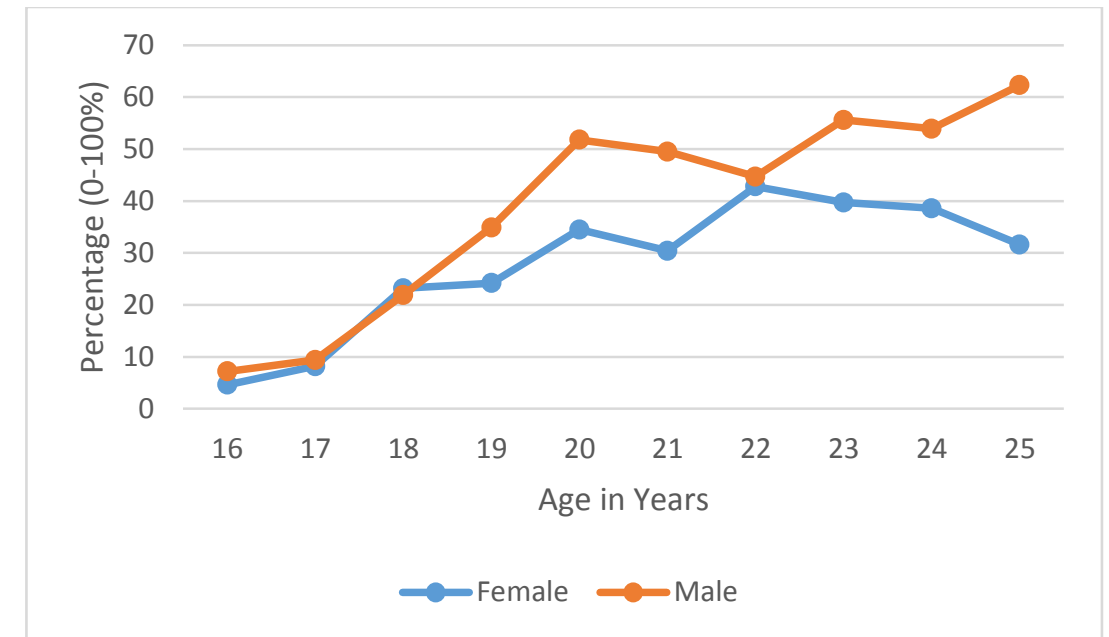

Source: EDSGE-I (DHS), 2011.

Overall, the comparisons by gender confirm the importance of gender equity as a goal in the EQG education system. However, it is important to clarify what this means in terms of what is needed, and when. For most of the basic school sequence-meaning preschool, primary, and

\footnotetext{
${ }^{31}$ The equal results for males and females at age 22 in Figure 3.18 is not consistent with the longer trend, and is probably a result of statistical error. 'Jumps' of this kind are not unusual in data summaries that drill down into more specific categories, such as age by gender, because these more specific comparisons are based on fewer cases.
} 
ESBA — girls are equally likely to be in school as boys, and they actually perform marginally better than boys (based on repetition rates and attainment). However, significant gender gaps favoring boys begin to appear at around the age of 17, driven by females exiting the system. In other words, the critical period for girls is in late adolescence. The main reasons for girls leaving school at this time are likely related to pregnancy and starting their own families, work demands at home to take care of other family members, or a household aversion to continuing the educational investment for girls, especially as the direct and indirect costs increase by educational level. These are not easy situations to address, but they do serve as a reminder of the inter-sectoral nature of addressing problems like dropout among older children.

\section{Socioeconomic Status (SES) Comparisons}

In the age of EFA, education systems around the world have made a priority of reaching the hardest-to-reach children (and communities), and as a result there is steady progress being made in enrolling all children in school. Nevertheless, in most countries there are still gaps between the wealthiest and poorest children, especially in the post-primary cycle. Furthermore, even when most children are in school, outcomes like attainment efficiency and achievement are likely to vary significantly by social class.

School enrollment rates at the time of the 2011 DHS were fairly equal between the poorest (Q1), average (Q3), and wealthiest (Q5) children between the ages of 7 and 14, although Q5 children are significantly more likely to be in school. However, at ages 15-16 enrollment across quintiles begins to diverge substantially (see Figure 3.27). For example, 90 percent of 18year-olds from Quintile 5 are in school in 2011, compared with only about 50 percent of 18-yearolds from Quintile 1 families.

Figure 3.27. Current Enrollment by SES Quintile, 2011 DHS $^{32}$

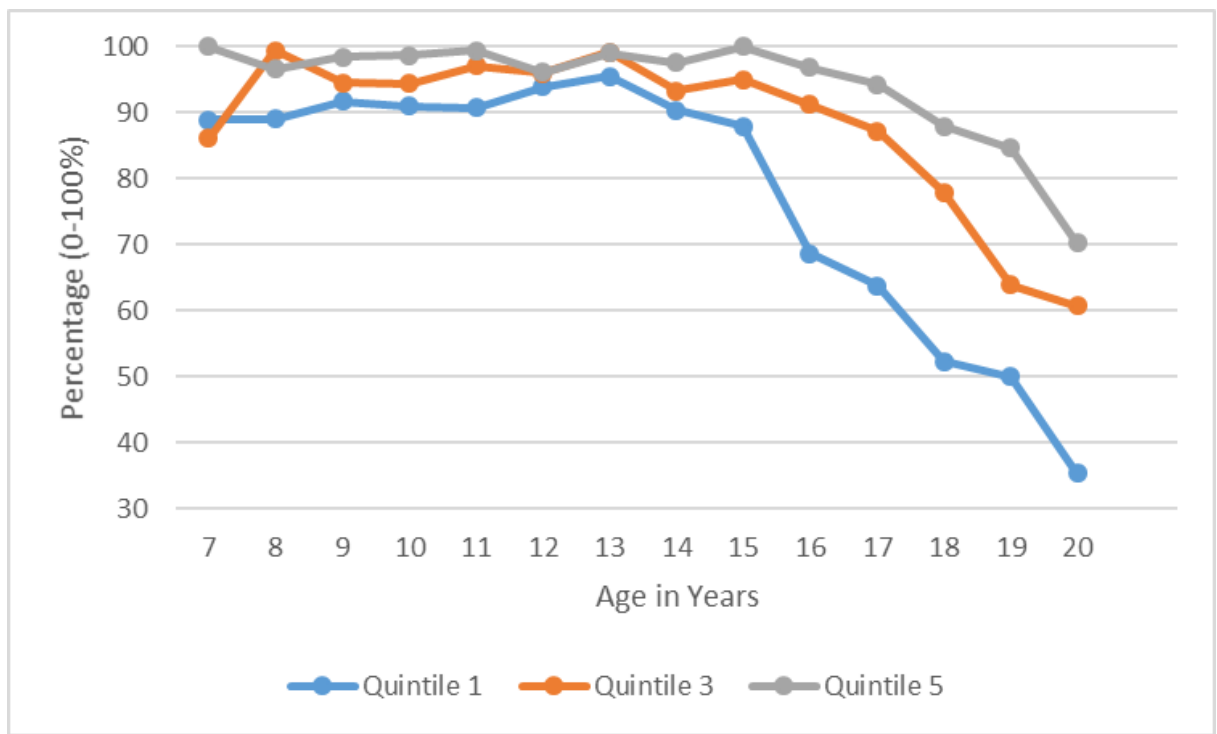

Source: EDSGE-I (DHS), 2011.

\footnotetext{
${ }^{32}$ Unfortunately, comparisons by social class are only possible with survey data, since administrative sources (like the Anuarios) do not have this kind of information.
} 
Similarly, children from wealthier households have higher grade attainment than poorer children. Among 7-12-year-olds, Quintile 5 children have completed 2.6 years of school, on average, versus only 1.5 years for Quintile 1 children (and 1.7 for Quintile 2) (see Figure 3.28). This advantage is likely attributable to beginning primary school at an earlier age, and repeating fewer times.

Figure 3.28. Grade Attainment by SES Quintile and Age Group, 2011 DHS

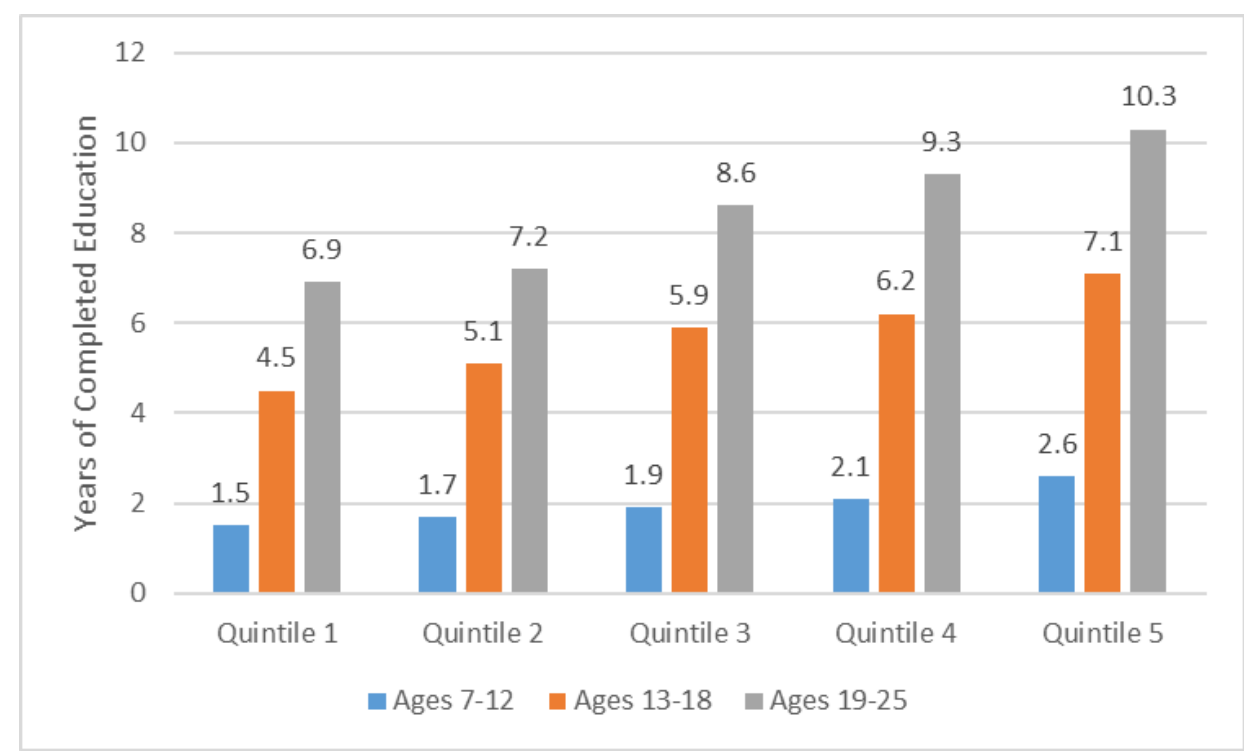

Source: EDSGE-I (DHS), 2011.

Owing to the cumulative impact of starting school earlier, repeating less often, and staying longer, Quintile 5 persons aged 19-25 have over 10 years of completed education, compared with less than 7 years for Quintile 1. Among 13-18-year-olds, the difference is also quite large (7.1 years for Q5 versus 4.5 years in Q1) (see Figure 3.29). These are very significant differences that potentially have long-lasting consequences in labor market and other outcomes.

Figure 3.29. ESBA Completion Rates by Age and SES Quintile, 2011 DHS

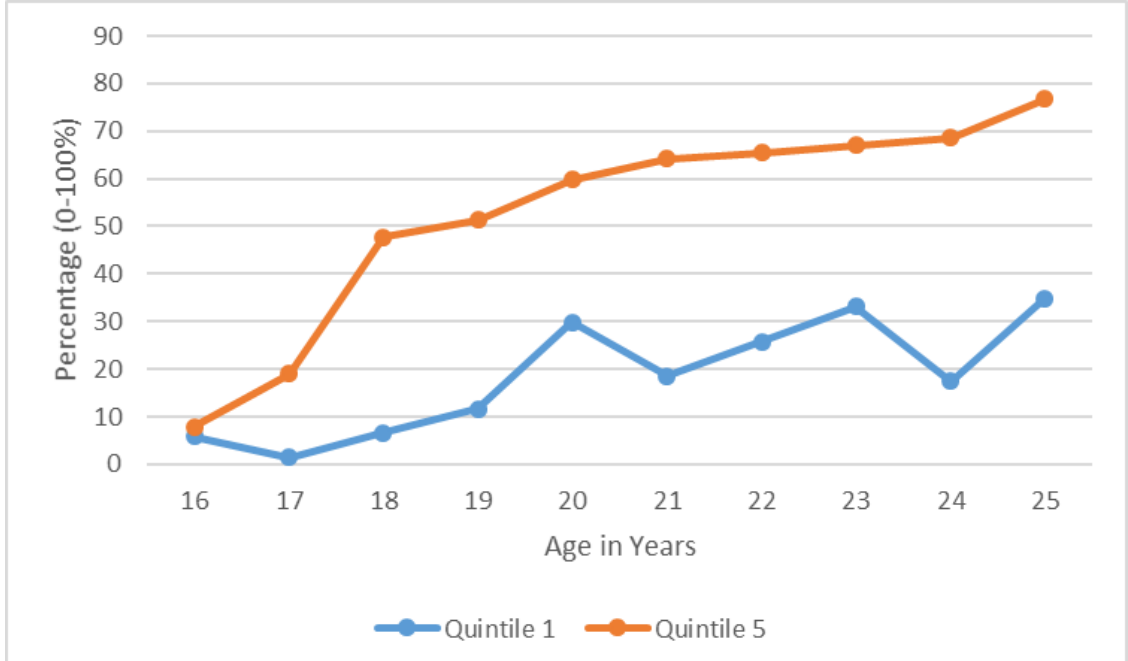

Source: EDSGE-I (DHS), 2011. 
Grade attainment varies significantly across four location types, although the gaps are not as large as for SES. The highest grade attainment levels are found in urban areas of the Insular region, followed closely by urban areas on the continent. Not surprisingly, rural locations have lower educational attainment, especially on the continent. The differences are largest among the older (19-25) cohort: for example, urban Insular grade attainment is nearly three years higher than the rural continent average (9.8 years versus 7.1). However, among 13-18-year-olds the differences are about half as large, which suggests that some progress had been made (at the time of the 2011 DHS) in reducing the gaps by location strata (see Figure 3.30).

Figure 3.30. Grade Attainment by Community Type and Age, 2011 DHS

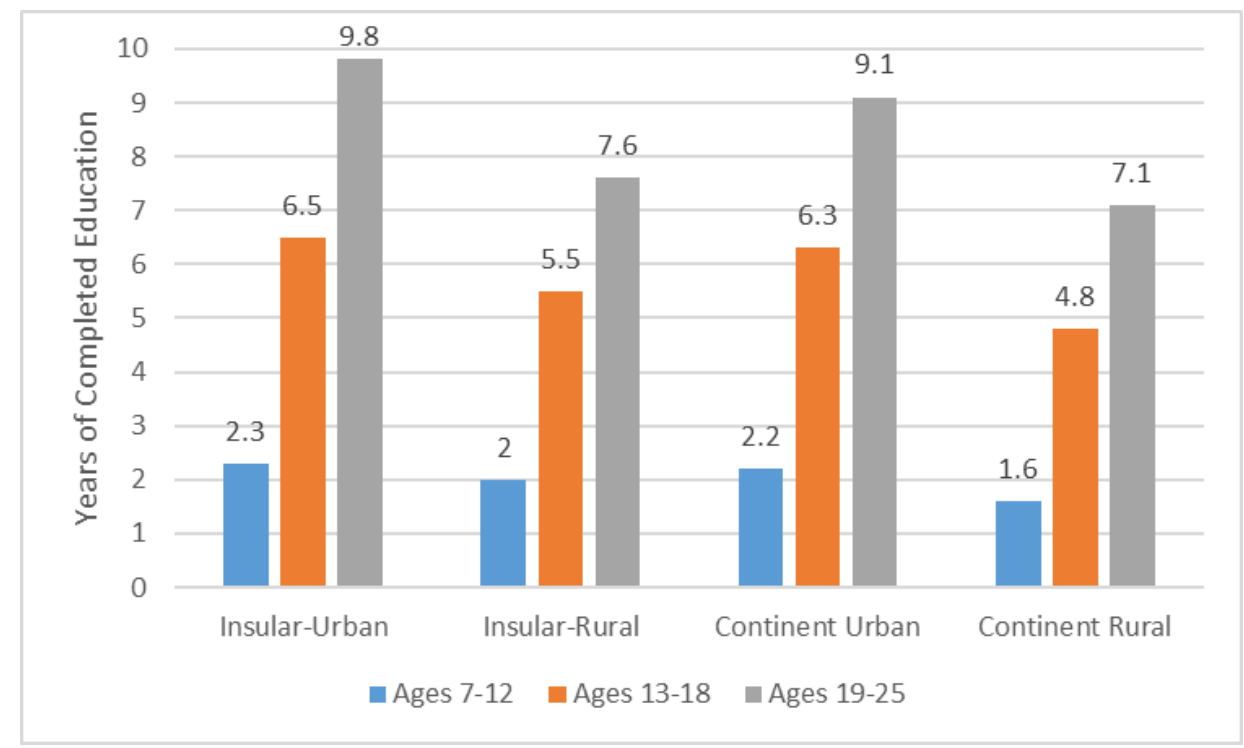

Source: EDSGE-I (DHS), 2011.

The results for the regional comparisons highlight two, somewhat distinct education systems in the country, divided mainly by rural and urban locations. The Litoral and Bioko Norte provinces not only are dominant in terms of total primary enrollments (nearly 75 percent of the total,), but they are more efficient (that is, less repetition and higher grade attainment) and there are more opportunities for post-primary study. The remaining provinces, mainly in the continental region, are smaller with relatively low efficiency and fewer opportunities to continue studies into late adolescence. These differences between predominantly urban and rural zones are not unusual, but they do need to be taken into account when discussing sectoral challenges.

Multivariate analysis provides some insight into the kinds of factors that are correlated with education outcomes in EQG. Below are the main findings (see Appendix F for details).

- Controlling for other variables, girls are more likely to be enrolled in secondary school (ages 13-20), and more likely to complete primary school (ages 13-18) than boys of the same age. However, there are no differences by gender for school attendance (across all levels), secondary completion, or grade attainment. 
- Girls' schooling is more negatively affected by marriage and child rearing, which helps explain why their attendance declines more than boys' in late adolescence. There is also an intersection between poverty and gender, as the poorest girls are much less likely to continue their schooling than the poorest boys.

- Overall, the results for SES confirm that wealthier households have better education outcomes. The disparities by social class are, in some cases, quite large: Quintile 5 girls are 40 percent more likely to be enrolled in secondary than Quintile 1 girls, while Quintile 5 boys have 3.5 more years of completed education than Quintile 1.

- There is little evidence of a tradeoff between the number of children in the household and education outcomes (often referred to as 'quantity versus quality').

- Individuals who are not children of the household head tend to fare worse in education. This is especially true for household members who are not related to the head, or are siblings of the household head.

- Household head and mother education are strong and significant predictors of education outcomes. For example, individuals in households where the head has completed university are 17 percent more likely to be enrolled in secondary compared with household heads with primary education only.

- There are fairly modest differences between urban and rural locations when controlling for variables like SES and household head education levels. This is a reminder of the importance of controlling for multiple factors to determine the 'direct' or specific effect of individual variables.

\section{Part B. Education Diagnostic by Topic}

Part B is divided into several sections that provide a more detailed overview of education finance, school infrastructure, school quality, and data and research, plus an additional section providing a spotlight on higher education and technical and vocational training.

Within each section the focus is on recent data from the Anuarios, supplemented with additional qualitative information obtained during interviews and site visits. When necessary, trends and comparisons based on Anuario data from different years are incorporated.

\subsection{Education Finance}

A key determinant of education sector performance is the availability of resources. This relationship is not necessarily automatic: some countries are able to get better results with fewer resources than other countries, which highlights the importance of priorities and execution. Nevertheless, there is little question that education outcomes are affected by how much money is available to spend on school buildings, materials, and teacher salaries, among many other things.

Unfortunately, there is very little actual data on education finance in EQG, at least in the recent period (that is, last 10 years). The data that are available are combined with more general 
observations about public sector finance challenges. These initial findings will feed into a more complete summary as part of the PER that the World Bank is developing.

\subsubsection{Education Expenditure Estimates}

The best estimates of current education expenditures come from the most recent (2015) budget execution summary, which was compiled as part of the 2016 Budget Law. These figures show an amount of CFAF 37.6 billion for the Ministry of Education and Science, equal to 5.2 percent of the total current public expenditure in 2015, including other constitutional branches such as the senate, the house of deputies and the judiciary branch. Focusing solely on the total expenditure of the 26 ministries existing in 2015, the education budget equaled 9.7 percent of the total, scoring fourth in size after the budget allocated to the ministries of defense, finance, and health (see Table 4.1).

Table 4.1. Equatorial Guinea Current Expenditure (2015)

\begin{tabular}{|c|c|c|}
\hline TOTAL GASTOS CORRIENTES MINISTERIOS & FCA & $\begin{array}{l}\% \text { del gasto } \\
\text { MINISTERIOS }\end{array}$ \\
\hline DEFENSA NACIONAL & $81,183,666,000$ & $21.02 \%$ \\
\hline HACIENDA Y PRESUPUESTOS & $52,844,046,000$ & $13.68 \%$ \\
\hline SANIDAD Y BIENESTAR SOCIAL & $47,331,392,000$ & $12.25 \%$ \\
\hline EDUCACION & $37,634,148,000$ & $9.74 \%$ \\
\hline JEFATURA DE ESTADO & $26,604,231,000$ & $6.89 \%$ \\
\hline ASUNTOS EXTERIORES Y COOP. & $21,777,385,000$ & $5.64 \%$ \\
\hline MINAS INDUSTRIA Y ENERGIA & $19,097,703,000$ & $4.94 \%$ \\
\hline JUVENTUD Y DEPORTES & $17,144,045,000$ & $4.44 \%$ \\
\hline PRESIDENCIA DE GOBIERNO & $16,661,898,000$ & $4.31 \%$ \\
\hline INTERIOR Y CORPORACIONES & $12,783,385,000$ & $3.31 \%$ \\
\hline AGRICULTURA Y BOSQUES & $10,768,080,000$ & $2.79 \%$ \\
\hline SEGURIDAD NACIONAL & $5,983,836,000$ & $1.55 \%$ \\
\hline ECONOMIA Y PLANIFICACION & $4,416,905,000$ & $1.14 \%$ \\
\hline INFORMACION, PRENSA Y RADIO & $4,214,247,000$ & $1.09 \%$ \\
\hline OBRAS PUBLICAS E INF & $3,568,396,000$ & $0.92 \%$ \\
\hline JUSTICIA, CULTO E INSTITUC. & $3,465,518,000$ & $0.90 \%$ \\
\hline COMERCIO Y PROMOCION EMP & $3,094,834,000$ & $0.80 \%$ \\
\hline PESCA Y MEDIO AMBIENTE & $2,931,937,000$ & $0.76 \%$ \\
\hline CULTURA Y TURISMO & 2,703,999,000 & $0.70 \%$ \\
\hline FUNCION PUBLICA Y REFORMA & $2,702,893,000$ & $0.70 \%$ \\
\hline ASUNTOS SOCIALES Y GENERO & $2,525,231,000$ & $0.65 \%$ \\
\hline TRABAJO Y SEGURIDAD SOCIAL & $2,353,524,000$ & $0.61 \%$ \\
\hline TRANSPORTE Y TECNOLOGIA & $2,288,213,000$ & $0.59 \%$ \\
\hline AVIACION CIVIL & $2,179,717,000$ & $0.56 \%$ \\
\hline TOTAL GASTOS MINISTERIOS & $386,259,229,000$ & \\
\hline SENADO & $6,619,620,000$ & \\
\hline CAMARA DE LOS DIPUTADOS & $5,689,032,000$ & \\
\hline PODER JUDICIAL Y FISCALIA & $2,573,267,000$ & \\
\hline TRIBUNAL CONSTITUCIONAL & $490,632,000$ & \\
\hline TOTAL ORGANOS CONSTITUCIONALES & $15,372,551,000$ & \\
\hline OBLIGACIONES DIVERSAS (sin inv.) & $313,881,000,000$ & \\
\hline TOTAL DE GASTOS CORRIENTES & $715,512,780,000$ & \\
\hline
\end{tabular}

Source: Ministry of Finance. Budget Law 2016. 
Since 2014, another category, institutional projects, ${ }^{33}$ was added to the current expenditure framework. This makes it possible to observe the preferences in the internal distribution of MEC resources as a proxy for the allocation of priorities. The total amount of this category is small compared to total spending. For 2014, the MEC resources primarily supported secondary and primary education, as well as goals from the Plan Nacional de Desarrollo Económico y Social (PNDES) Horizonte 2020. For 2015, technical and professional education and the support for goals of the PNDES increased in relevance and participation to the detriment of primary and secondary education. These institutional projects are complementary resources to other ongoing operations, ${ }^{34}$ but the figures do provide some insight into how the MEC defines priorities. It is noticeable that the total number of institutional projects has declined after the crisis.

Table 4.2. Institutional Projects MEC 2014-2015 and 2016 Projection

\begin{tabular}{|l|r|r|rr|r|r|}
\hline \multirow{2}{*}{ PROYECTOS INSTITUCIONALES } & \multicolumn{2}{c|}{$\mathbf{2 0 1 4}$} & \multicolumn{2}{c|}{$\mathbf{2 0 1 5}$} & \multicolumn{2}{c|}{$\mathbf{2 0 1 6}$ proyc. } \\
\cline { 2 - 6 } & \multicolumn{1}{c|}{ Total } & \% de total & \multicolumn{1}{c|}{ Total } & \% de total & Total & \% de total \\
\hline Total & $\mathbf{8 , 9 3 0}$ & $\mathbf{1 0 0 \%}$ & $\mathbf{8 , 0 0 0}$ & $\mathbf{1 0 0 \%}$ & $\mathbf{8 , 0 0 0}$ & $\mathbf{1 0 0 \%}$ \\
Subsector Educación Primaria & 1,786 & $\mathbf{2 0 \%}$ & 1,200 & $15 \%$ & 1,200 & $15 \%$ \\
Subsector Educación Secundaria cientifica & 1,965 & $22 \%$ & 1,300 & $16 \%$ & 1,300 & $16 \%$ \\
Subsector educacion tecnica profesional & 1,607 & $18 \%$ & 2,560 & $32 \%$ & 2,560 & $32 \%$ \\
Subsector educacion superior & 804 & $9 \%$ & 640 & $8 \%$ & 640 & $8 \%$ \\
Fondo para el desarrollo Social - sector educacion & 982 & $11 \%$ & 300 & $4 \%$ & 300 & $4 \%$ \\
Plan Nacional Horizonte 2020 - sector educativo & 1,786 & $20 \%$ & 2,000 & $25 \%$ & 2,000 & $25 \%$ \\
\hline
\end{tabular}

Source: Ministry of Finance. Budget Law 2016.

Another tool that can provide insights and estimates of the size and composition of public expenditure is called BOOST, which makes it possible to track total government current and investment expenditures from 2007 to 2015. Despite the fact that it is impossible to isolate the sole education expenditure from the rest of the institutions and categories, it is possible to estimate some of the transfers and subventions expenditure that are directly governed by the MEC, such as its institutional projects, scholarships and school incentives, support for catholic schools, and transfers to UNGE. The two largest spending categories are for UNGE and scholarships, followed by relatively smaller amounts for support for religious schools and institutional projects and programs (see Figure 4.1). The totals are fairly flat until 2014, when there was a marked increase in spending, followed by a deceleration (or even some decline) in 2015.

\footnotetext{
${ }^{33}$ The institutional projects are conceptually a category of investments, but for the convenience of the institutional resource allocation and disbursement processes, they are presented in a way that is more associated with current expenditures since public investment normally goes through GE Proyectos with which not many public entities have a fluid collaboration. The figures presented before for the 2015 current expenditure already included these institutional projects.

${ }^{34}$ Examples include the support of the African Development Bank for strengthening of the institutional capacity in the Technical Education Directorate of the MEC for designing the curriculum of each of the technical and professional education families, the reinforcement of infrastructure in public technical education centers and other secondary centers, support for the Cuban mission, support for public transport pilot program in Bata and Malabo, and the printing and distribution of school textbooks.
} 
Figure 4.1. MEC Institutional Projects, Transfers, and Subsidies 2007-2015

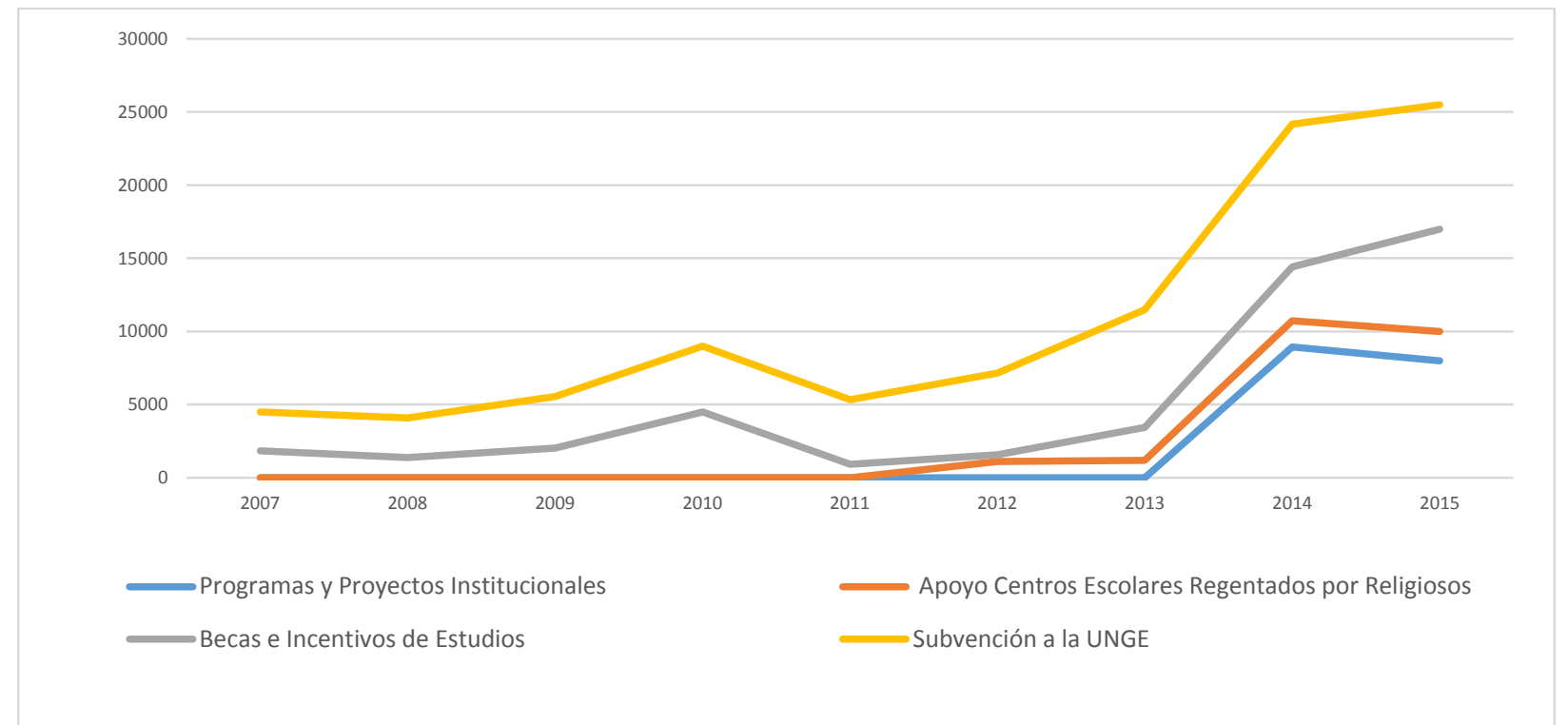

Source: BOOST Tool World Bank, 2016.

Note: blue line: institutional programs and projects; gray line: scholarships and incentives; orange line: support for religious schools; yellow: subsidy to UNGE.

BOOST also makes it possible to monitor transfers and subsidies that are not governed by the MEC but are clearly related to the education sector. These refer to public education centers governed by the ministries of agriculture, finance, foreign affairs, mines, justice, economy, health, and public works; the national library and cultural centers under the ministry of culture management; international scholarships under the ministry of foreign affairs management; and nursery schools and the national committee for children under management of the ministry of social affairs and gender equality. There is consistently low spending on preschool and the National Committee for Children's Rights, while vocational education centers have received large increases in funding in recent years (see Figure 4.2). These are under the control of line ministries of the given topic but not governed under the MEC standards. 
Figure 4.2. Education-related Transfers and Subventions to Other Line Ministries 2007-2015

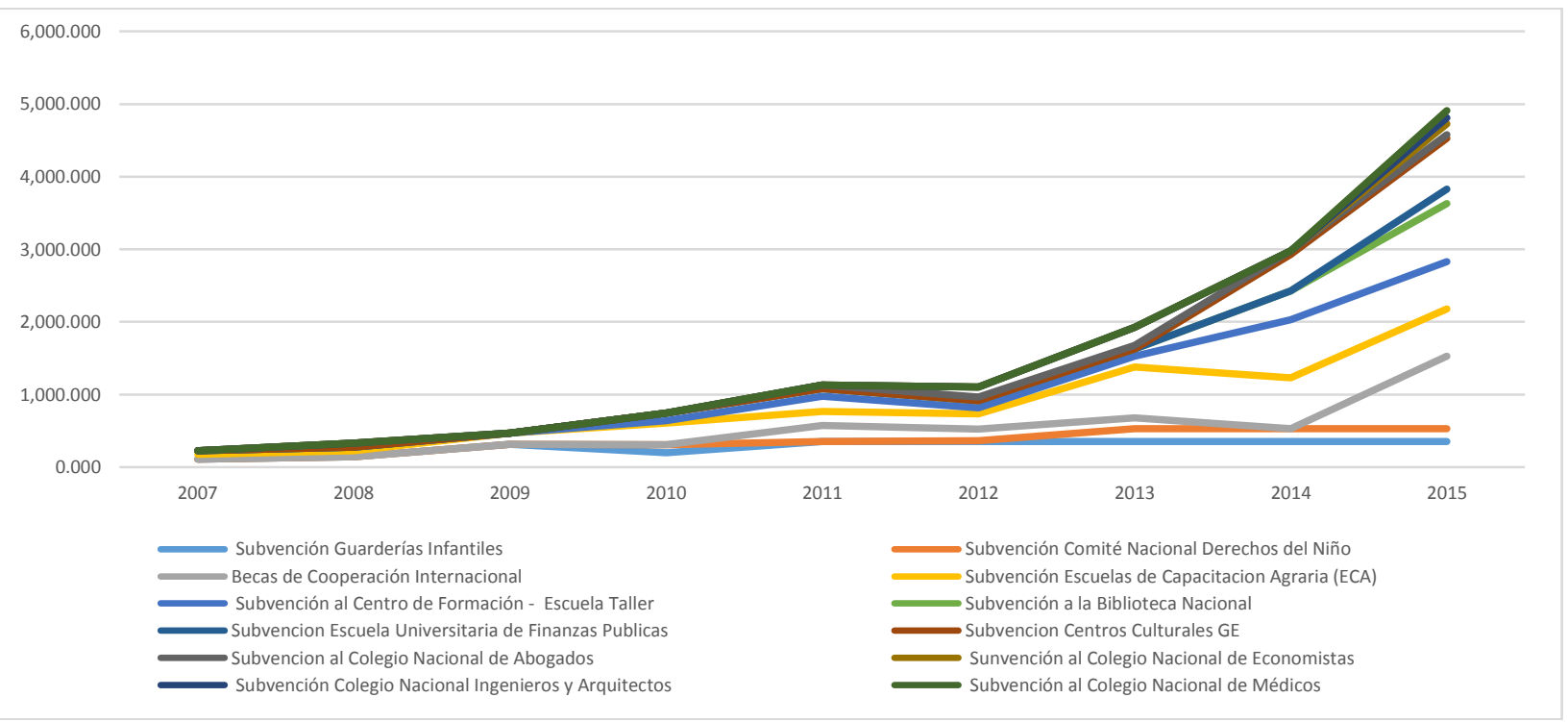

Source: BOOST Tool World Bank, 2016.

The final source of information on government education expenditures - and government priorities in the education sector and efficiency - is the public investment program database elaborated with support of the Public Investment Management and Monitoring (PIMM) RAS team. The RAS team analysis from 2016 covers the bulk of public investment projects and/or contracts recorded in official records from 2008 to 2015. They show that the total share of the capital budget dedicated to the major education program of the PNDES sums to CFAF 735.7 billion, representing 3.7 percent of the total public investment obligations. It also shows a level of financial disbursement of 49 percent, far behind the overall 67 percent (see Table 4.3). 
Table 4.3. Public Investment Program Associated with PNDES Programs, 2008-2015

\begin{tabular}{lcccc}
\hline \multicolumn{1}{c}{ PROGRAMAS PENDES } & Costo Total & $\begin{array}{c}\text { \% de costo } \\
\text { total }\end{array}$ & $\begin{array}{c}\text { Total pagos de } \\
\text { ejecucion } \\
\text { financiera }\end{array}$ \\
\hline Infraestructuras para Guinea Ecuatorial & $10,647,351$ & $53.49 \%$ & $7,554,833$ & $71 \%$ \\
Administración Moderna & $2,840,790$ & $14.27 \%$ & $1,803,502$ & $63 \%$ \\
Electricidad para Todos & $1,214,464$ & $6.10 \%$ & 612,212 & $50 \%$ \\
Agua para Todos & $1,138,007$ & $5.72 \%$ & 839,042 & $74 \%$ \\
Guinea Ecuatorial Modelo Ecológico & 865,582 & $4.35 \%$ & 580,049 & $67 \%$ \\
Guinea Ecuatorial Potencia Energética & 801,478 & $4.03 \%$ & 451,867 & $56 \%$ \\
Educación para Todos & 735,702 & $3.70 \%$ & 357,454 & $49 \%$ \\
Salud para todos & 719,522 & $3.61 \%$ & 497,447 & $69 \%$ \\
Un techo para todos & 637,249 & $3.20 \%$ & 447,405 & $70 \%$ \\
Guinea Ecuatorial Centro de Negocios de Referenci: & 178,778 & $0.90 \%$ & 145,631 & $81 \%$ \\
Guinea Ecuatorial País Numérico & 74,836 & $0.38 \%$ & 54,204 & $72 \%$ \\
Empleo para todos & 29,086 & $0.15 \%$ & 18,458 & $63 \%$ \\
Seguridad Alimentaria & 19,497 & $0.10 \%$ & 14,317 & $73 \%$ \\
Un plan de desarrollo para todos & 3,075 & $0.02 \%$ & 1,000 & $33 \%$ \\
\hline Grand Total & $19,905,417$ & $100 \%$ & $13,377,421$ & $67 \%$ \\
\hline SOurce: Ming
\end{tabular}

Source: Ministry of Economy, Planning and Public Investments; Ministry of Finance; GE Proyectos. 2016.

Of the total capital amount for education, 64 percent is devoted to new infrastructure in higher education, concentrated in three large projects: the construction of new campuses for UNGE in Malabo and Bata and the inception of the new American University of Djibloho (the new city in the continental region under construction, expected to be, in the future, the political capital of EQG). It was estimated by the PIMM RAS team that another 21 percent was directed toward the expansion and improvement of facilities in preschool. For primary and secondary education, it is virtually impossible to identify which share goes to each level with the information available.

\subsubsection{Is Equatorial Guinea Spending Enough and Well on Education? And Why?}

Compared to other Africa countries and countries with similar GDP per capita, EQG spends significantly less on education. As a reference, African countries devoted 4.8 percent of their GDP and 17.2 percent of their total government expenditure to education in $2015,{ }^{35}$ while Organization for Economic Co-operation and Development (OECD) countries spend an average of 5.2 percent of their GDP on education and 11.3 percent of their total public spending on education. ${ }^{36}$ Spending only 2.3 percent of their GDP and 5.2 percent of their total government expenditure on education, EQG lags behind (see Figure 4.3 and Figure 4.4).

\footnotetext{
${ }^{35}$ UNESCO Institute for Statistics, most recent year available.

${ }^{36}$ OECD 2016.
} 
Figure 4.3. Public Spending on Education as a Percentage of GDP (selected African countries)

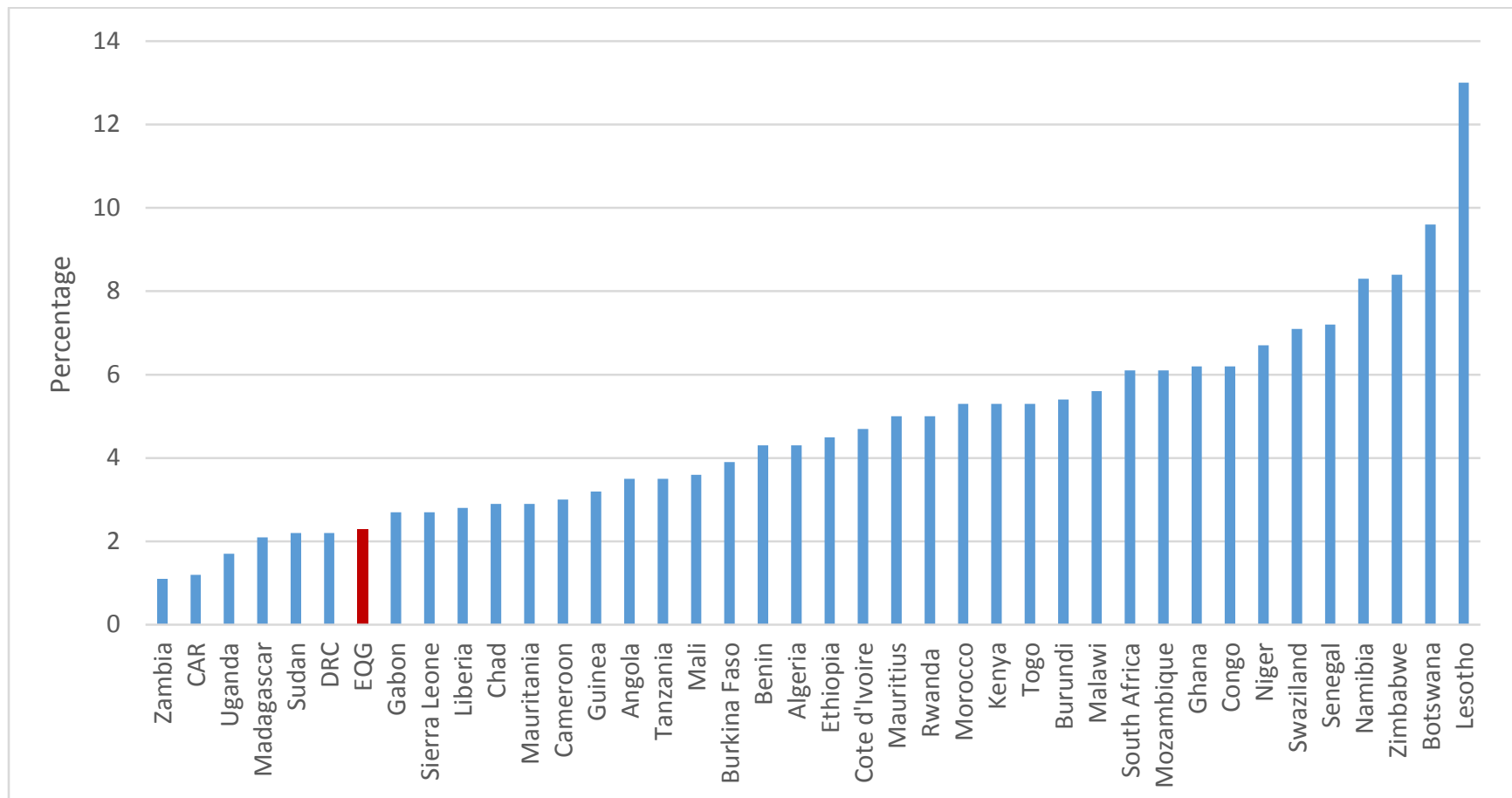

Source: UIS.

Figure 4.4. Share of Education of Total Public Spending (selected African countries)

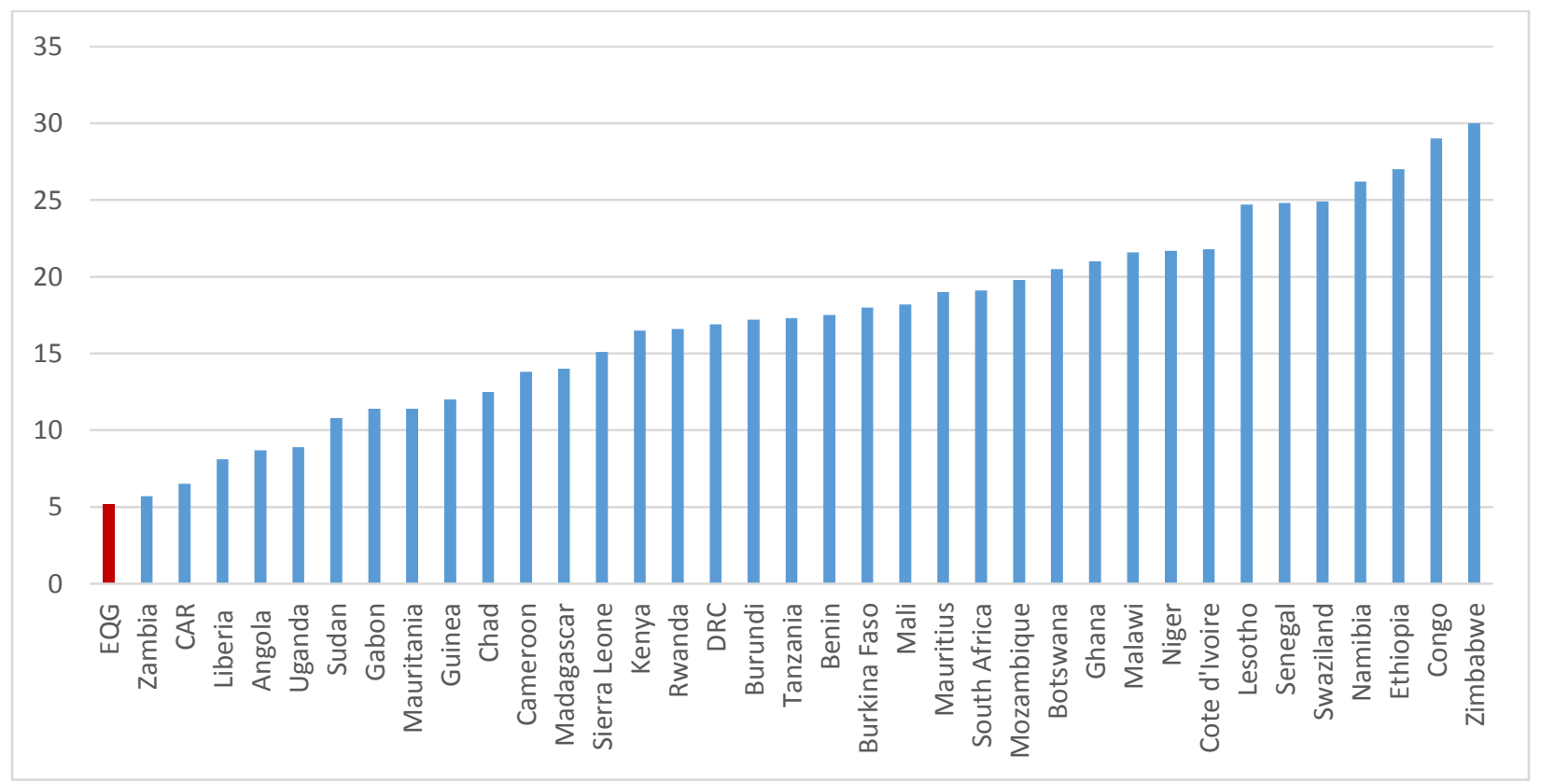

Source: UIS.

EQG appears to be similar to other African natural resource-rich countries that have poor education, health, and poverty outcomes despite their wealth (see Box 4.1). 


\section{Box 4.1. Poor Human Capital Outcomes in Resource-rich Sub-Saharan African Countries}

While natural resources can support economic growth and boost well-being in a country, SSA resource-rich countries tend to overlook human capital development, rather than channeling their resources productively to eradicate poverty and enhance shared prosperity.

Natural resource wealth leads to higher national incomes but does little to reduce poverty levels. Compared to other countries at the same level of income, resource-rich countries have done less to reduce poverty. After adjusting for GNI per capita, poverty rates are higher in the resource-rich countries.

Resource-rich countries underspend on education relative to their wealth. The percentage of GDP devoted to education and health in oil-rich SSA countries is less than half the amount allocated by nonresource-rich countries in the region.

Natural resource wealth in SSA is associated with poor education and health outcomes. Oil-rich SSA countries score lower on the United Nation's Human Development Index (HDI), which combines national income, life expectancy, education attainment, and school participation, than other countries. Controlling for national income, education outcomes are systematically worse in oil-rich SSA countries compared to nonresource-rich SSA African countries, and outcomes are worse for the poorest in resource-rich SSA countries.

Source: World Bank 2015.

Beyond country comparisons, it is important to have a detailed assessment of what is needed in education in the country, what is available in terms of resources, and what is actually executed and spent. This diagnostic does not have enough information to address these issues systematically, which means that a definitive review of the adequacy of social sector spending in EQG will have to wait on a more complete analysis, such as that contemplated as part of the World Bank's PER.

What we do know about education finance does raise some concerns. First, there is the quantitative summary based on what data are available. Importantly, the amount of resources for education (and other sectors) in EQG has increased enormously in the last 15 years, and as a result, spending levels are much higher than in previous decades. Nevertheless, the share of total government spending and GDP devoted to education appears to be low and at times highly concentrated in infrastructure. There are also reasons to be concerned about the priorities in spending, such as the share devoted to higher education (both in terms of current and capital spending).

Second, given the problems that have been referenced in this section (and others) it is easy to conclude that EQG is not spending enough on education, ${ }^{37}$ but it is still necessary to understand the underlying reason(s) for underinvestment. One possible reason for underinvestment in education is related to competing government priorities. The PNDES review also shows that the country has undertaken massive investments in infrastructure (roads, ports, and so on). These are expensive undertakings, and other sectors may suffer as a result. This requires a rebalancing of priorities or a sequential strategy where spending is shifted to other sectors as advances are made in others. These are questions that cannot be addressed in this short review, in part because they require an understanding of the government's global spending strategy.

\footnotetext{
${ }^{37}$ This conclusion is clearly shared by others, as evidenced by Recommendation Number 3 (of six) in the PNDES review (2014) of the Plan Nacional implementation: Invertir masivamente en educación y sanidad and by the World Bank PER conducted in 2010: "public education financing is insufficient and far below the regional desired levels".
} 
There is also some evidence that the education sector is underperforming in terms of spending execution. This issue was referenced on several occasions during interviews with social sector stakeholders, both inside and outside the government. For example, one highranking official emphasized the need for capacity building in public sector management. He noted that ministry line officials are not preparing adequate spending plans. The plans lack details related to spending targets, expected outcomes, and other specifics. As a result, they "cannot defend their numbers," which in turn leads to actual disbursements that fall short of what is requested. An international technical advisor also made reference to the problem of line ministries receiving less than what is potentially available, but for a somewhat different reason: there is a tendency among ministry staff to view the returning of money (that is, not using all that is allocated) as a form of efficiency that, in turn, is looked on favorably by senior leadership.

Failing to take advantage of the full complement of potential financing is a serious problem from a public management standpoint and highlights the need for technical capacity building in this area. This is not a new concern; indeed, the first two recommendations of the PNDES review are related to public management capacity. ${ }^{38}$ This is an area where there is clearly potential for World Bank assistance and again highlights the importance of completing a detailed PER to better understand the current situation with public administration and resource use and devise strategies to improve capacity.

Further qualitative evidence is also troubling. One issue is the vulnerability of social sector spending to variations in the price of oil, including both the amount and composition of education spending. One MEC official referred to the recent downturn in oil prices as a 'threat' to the education sector, meaning that budgets may be reduced. This has apparently not happened overall so far, but nonetheless is a concern, in particular when we consider that funds for the institutional projects have already been declining. It is also fairly noticeable and worrisome that scholarships and transfers to UNGE, very likely regressive, were relatively protected during the recent downturn in contrast to other spending (as shown in Figure 4.1), revealing lack of focus on protecting the poor. The withdrawal of Hess Corporation financing for education after 2019 is another reminder of the potential fragility of spending in the country given the economy's close association with the oil industry.

Finally, in relation to the composition and quality of public spending, there are concerns that the education system is not able to provide the kind of basic conditions that are needed to build a quality system. Too little may be spent on infrastructure for primary and secondary education, particularly maintenance of this infrastructure, as well as on teachers and quality inputs. This will be further analyzed in the following sections.

\subsection{School Infrastructure}

This section provides an abbreviated summary of school infrastructure, focusing on three general areas: the evolution of schools, classrooms, and enrollments; the shares of public and private

\footnotetext{
${ }^{38}$ These recommendations are: organize a transformational agenda 2015-2020 and strengthen the capacity of the Agencia Nacional Guinea Ecuatorial (ANGE) 2020 and reform and strengthen the capacities of the Administration of public management.
} 
schooling supply; and physical conditions of schools. All of the data come from existing Anuarios, as there is no other source of data on school infrastructure.

The main findings in this section include the following:

- During the 2008-2015 (Anuario) period, the number of primary schools has remained fairly stable, while secondary school supply has increased significantly. Primary and secondary classrooms have also increased, mainly because of the growth of private schooling.

- Private school enrollment is larger than public school enrollment at both the primary and secondary level. There is a need for additional information to be able to compare the relative cost-effectiveness of these different schooling modalities and also the need for a strong quality assurance framework in private schools.

- In terms of physical conditions, there is not much evidence of improvement during 20082015. Concerns about physical conditions are widespread, with references to deficiencies both in the physical infrastructure as well as maintenance.

\subsubsection{Schools, Classrooms, and Enrollment}

The total number of primary schools has stayed relatively stable across 2008-2015. This most likely reflects the fact that almost all communities in the country now have access to a primary school. By contrast, the number of secondary schools has increased significantly between 2010 and 2015, from 110 to 140 schools (see Figure 4.5 and Figure 4.6).

Figure 4.5. Number of Primary Schools by Sector, 2008-2015

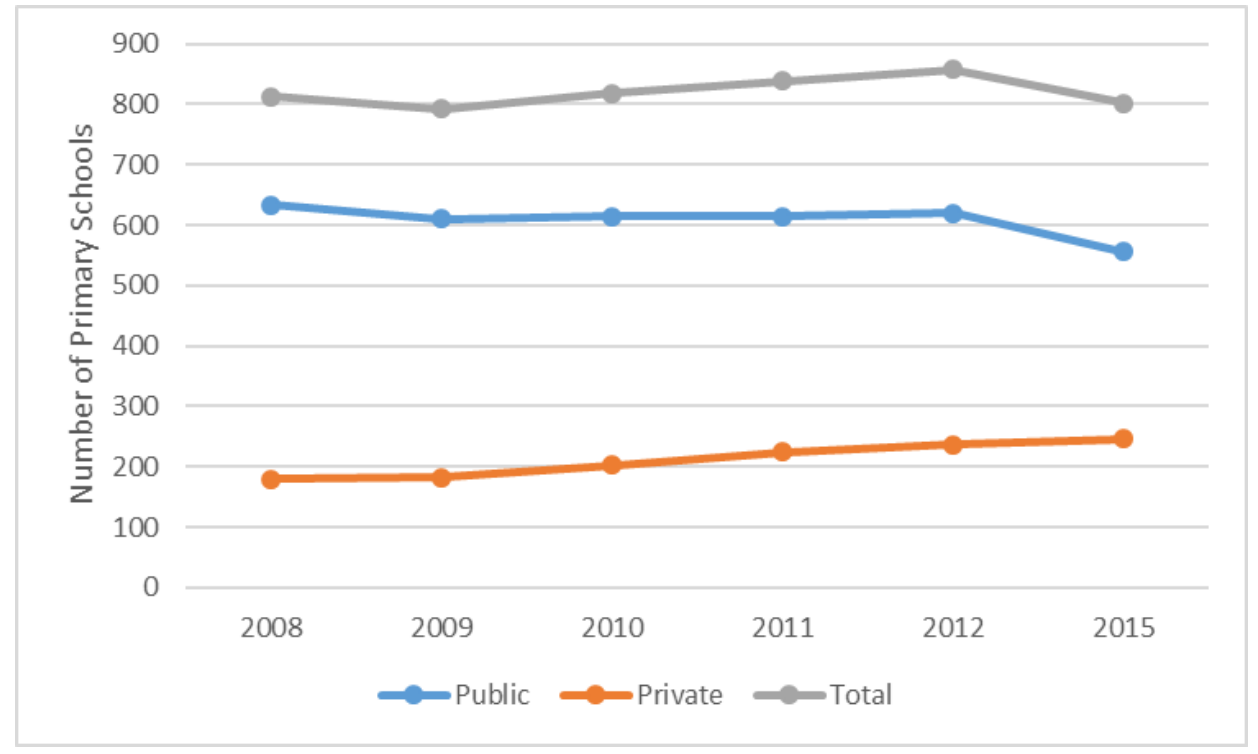

Source: PRODEGE/MEC, 2007-08 through 2014-15 Anuarios. 
Figure 4.6. Number of Secondary Schools by Sector, 2008-2015

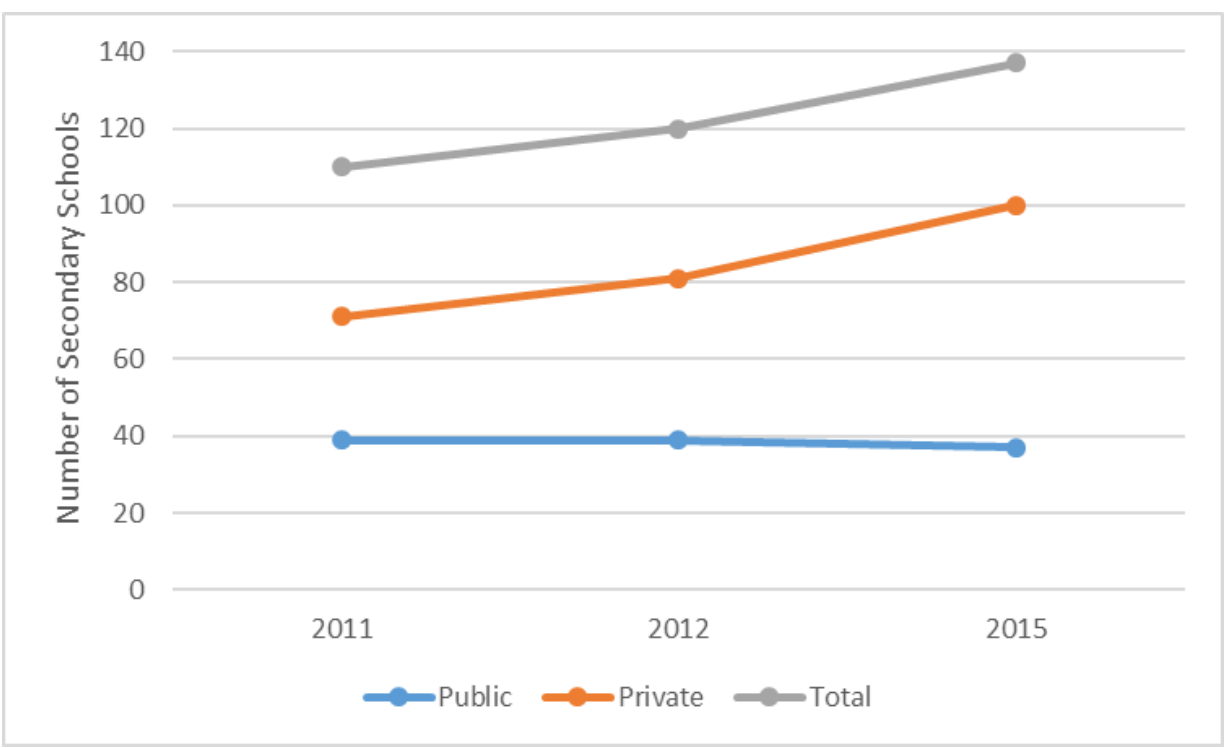

Source: PRODEGE/MEC, 2007-08 through 2014-15 Anuarios.

Note: Data on primary schools, classrooms, and conditions are available going back to the first Anuario (2007-08), but for secondary schools, this information is only available since 2010-11.

The stability in total numbers of primary schools is somewhat misleading, however, since there are significant changes taking place within the system. Primary schooling is becoming increasingly urban, which likely reflects the more general urbanization trend in the country (see Error! Reference source not found. and Figure E8 in Appendix E.

Figure 4.7. Number of Primary Schools by Urban/Rural, 2008-2015

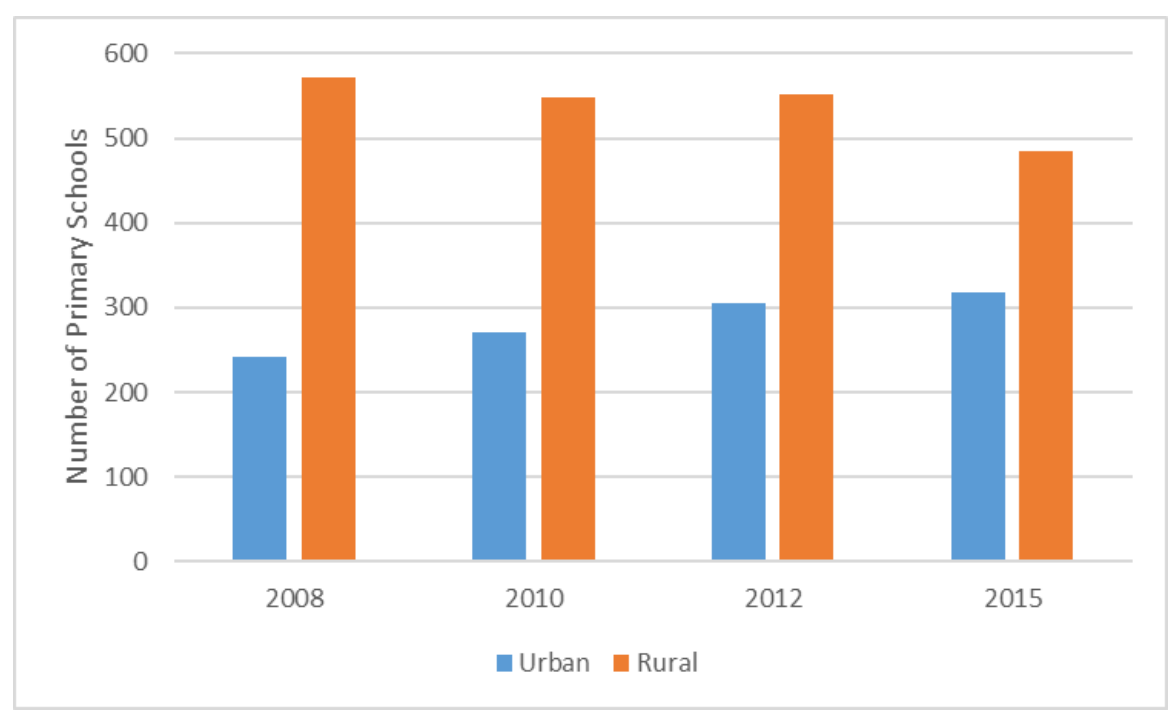

Source: PRODEGE/MEC, 2007-08 through 2014-15 Anuarios.

\subsubsection{Public Versus Private School Provision}

Education in EQG is also more and more private, as evidenced by the growing number of private primary and secondary schools over the past several years (Figures 4.5 and 4.6). Primary school 
enrollment has increased dramatically in private schools ${ }^{39}$ compared to public schools (Figure 4.8), and the number of private secondary school classrooms nearly doubled between 2010 and 2015, compared with minimal growth in public school classrooms at this level (Figure 4.9). In 2015 private education accounted for 56 percent of preschool enrollment, 59 percent of primary enrollment, and 64 percent of secondary enrollment. ${ }^{40}$

Figure 4.8. Total Primary Enrollment by Sector, 2008-2015

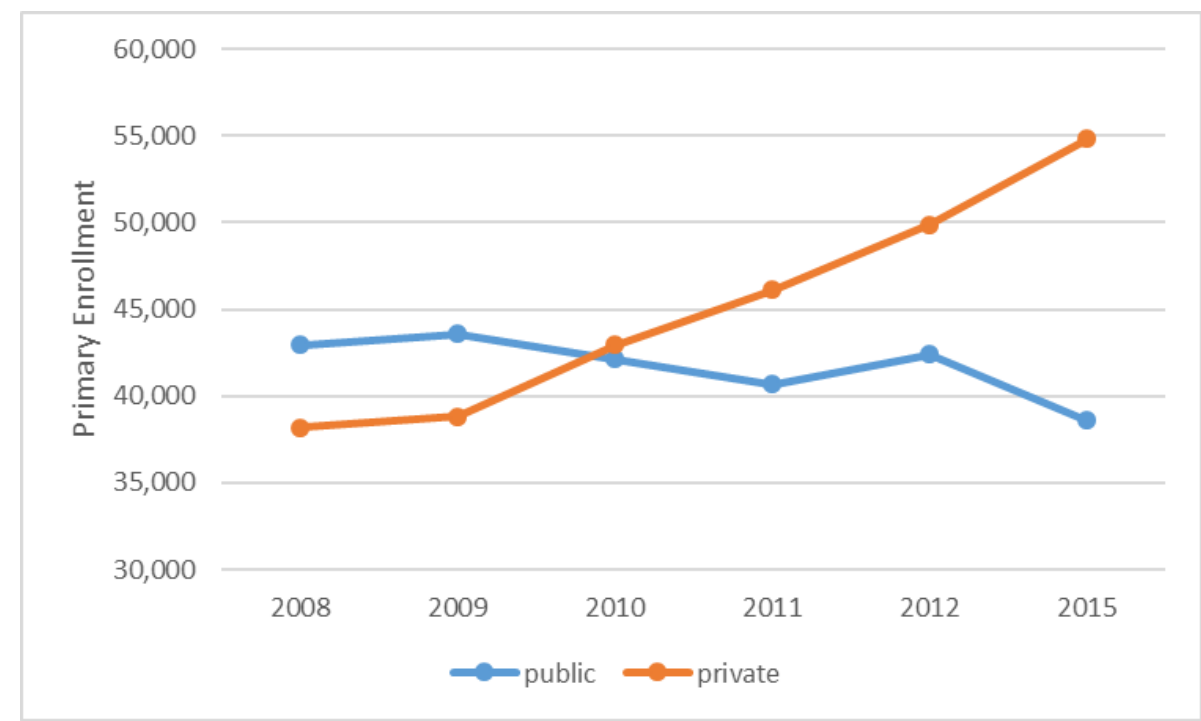

Source: PRODEGE/MEC, 2007-08 through 2014-15 Anuarios.

Figure 4.9. Number of Secondary Classrooms by Sector, 2011-2015

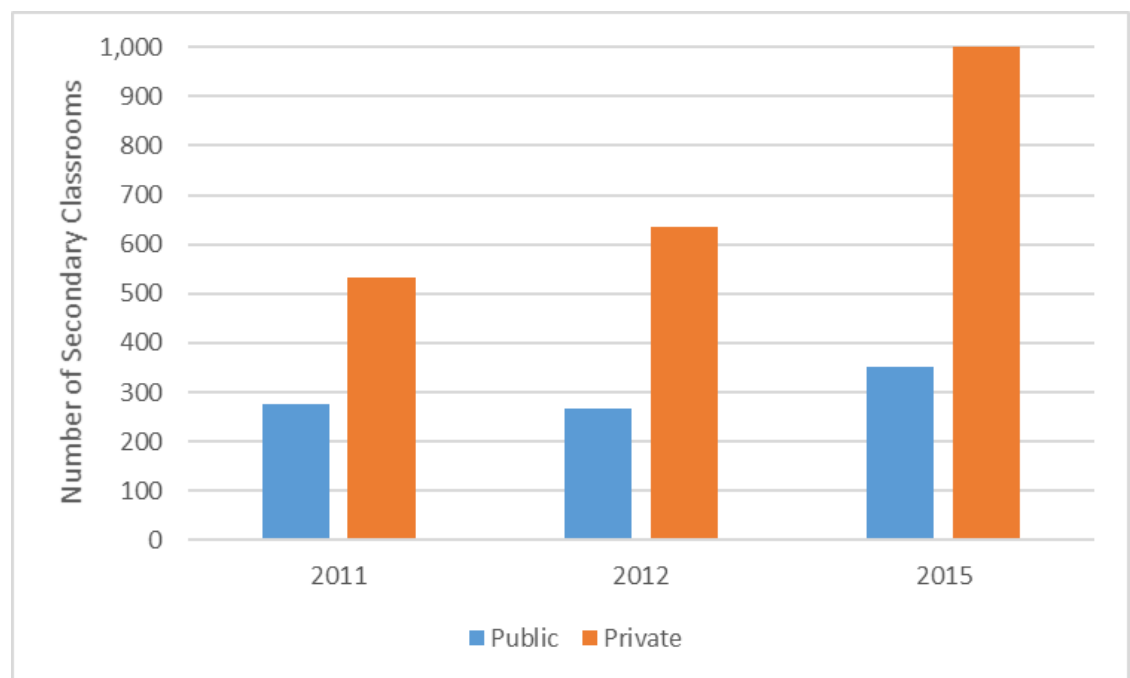

Source: PRODEGE/MEC, 2011-15 Anuarios.

A large presence of private schools at the secondary level is not unusual in developing countries. However, a large — and growing-private school sector in primary schooling is somewhat unusual. Some caution is required in interpreting this trend. First, there are very few 'pure'

\footnotetext{
${ }^{39}$ These can be fully private, subsidized private, faith-based, or other.

${ }^{40}$ UNESCO UIS.
} 
private schools in EQG, that is, schools that do not receive any support from the government. At the time of the 2010-11 Anuario, only about 8 percent of primary schools and 4 percent of secondary schools were classified as private receiving no public support. By contrast, about 45 percent of primary schools and 51 percent of secondary were classified as private receiving public support. This means that relatively few students are attending purely private schools (probably religious schools), and a fairly large share are enrolled in private schools that have teachers on the public payroll. It also means that the government is increasing the supply of schooling by contracting more teachers.

The growing trend toward private schooling is likely part of the urbanization trend already demonstrated and may also be related to rising incomes and an ability of more families to pay for an alternative schooling option-perhaps something that is closer to their homes or that they perceive to be higher quality. While this diagnostic does not have any information on the quality of private schools, qualitative evidence suggests that the cost of private school is significantly higher than public school. Anecdotal evidence shows costs of private schools between 380,0001,000,000 CFA (USD 645-1700) compared to public schools which are considered free, but do imply expenses for families up to approximately 8,000-15,000 CFA (USD 14-25).

The large and growing share of private schooling - especially at the primary level-could be seen as a way to increase supply (and possibly quality), but could also be seen as a symptom of problems in the public school sector. Box 4.2 provides more information on how private schools can contribute to enhanced quality and access and some key elements of effective regulation of private schools. However, it is important to recognize that private schools are not necessarily of better quality, even if they cost more for families, and this is also why an effective quality assurance and incentive framework is needed. Also, the fact that public school spaces are not expanding - or are actually declining in primary (Figure 4.5) - does raise some questions about the government's commitment to public education, particularly since the crisis. Again, this discussion is complicated by the fact that most private schools are supported by the public sector, and they appear to be part of the same support structure (that is, inspectors and so on). But this is a somewhat unique arrangement that needs to be carefully considered and research is needed to compare the relative cost-effectiveness of these different schooling modalities. 


\section{Box 4.2 The potential of private schools and requirements for effective regulation}

Private schools - schools that are not operated, owned, and financed by the government - have grown significantly in recent years. In Sub-Saharan Africa, over 14 percent of primary and 19 percent of secondary students are enrolled in private schools, whether for profit, non-profit, or faith-based. Between 1991 and 2003, enrollment in private primary school in Sub-Saharan Africa grew by 113 percent, compared with a 52 percent increase in enrollment in public primary schools.

How private schools can contribute to enhanced quality and access

Reaching education goals in the coming years will require increased supply and quality of schooling and private schools have the potential to play an important role. However, to do so, private schools must be able to reach traditionally underserved children to expand access and implement effective monitoring and support measures to ensure quality. Evidence suggests that the growth of private education markets has enabled access to education for millions more children around the world and that many governments have successfully improved both access and quality by increasing oversight and cooperation with private education providers.

Key elements of effective regulation of private schools

Government must provide oversight for the whole education system to ensure that the country's objectives for school access, quality, and equity are met, irrespective of type of service provider. The combination of increased levels of school autonomy and accountability has been found to positively impact student performance. Raising school accountability requires strengthening the quality assurance mechanisms that are in place between the government and school providers. This can involve:

- Government sets standards regarding what students need to learn, including deadlines.

- For meeting these standards students are required to take standardized examinations; results are disaggregated by school, socioeconomic status, gender, etc.

- Schools are required to report on the use of public funds as a condition for continued funding.

- Government or external agency perform inspection of schools as determined by school need.

- Schools produce school improvement plans.

- School performance leads to rewards and escalating sanctions.

Accountability is also important between the parents and school providers. This can involve:

- Ensuring that information on school performance is made available and letting families respond to that information through open enrollment policies

- Giving parents more direct influence over what takes place in the school. For example, parents and students can be involved in the school inspection and school improvement planning processes.

Source: Author's elaboration based on The World Bank (2014): "Framework Paper on what matters most for engaging the private sector in education" - Systems Approach for Better Education Results (SABER) Working Paper Series. 


\subsubsection{School Conditions}

The average number of students per classroom has declined during 2008-2015, especially in the Insular region (see Figure 4.10). This is an indirect measure of classroom crowding that is also declining at the secondary level (not shown).

Figure 4.10. Average Primary Students per Classroom by Region, 2008-2015

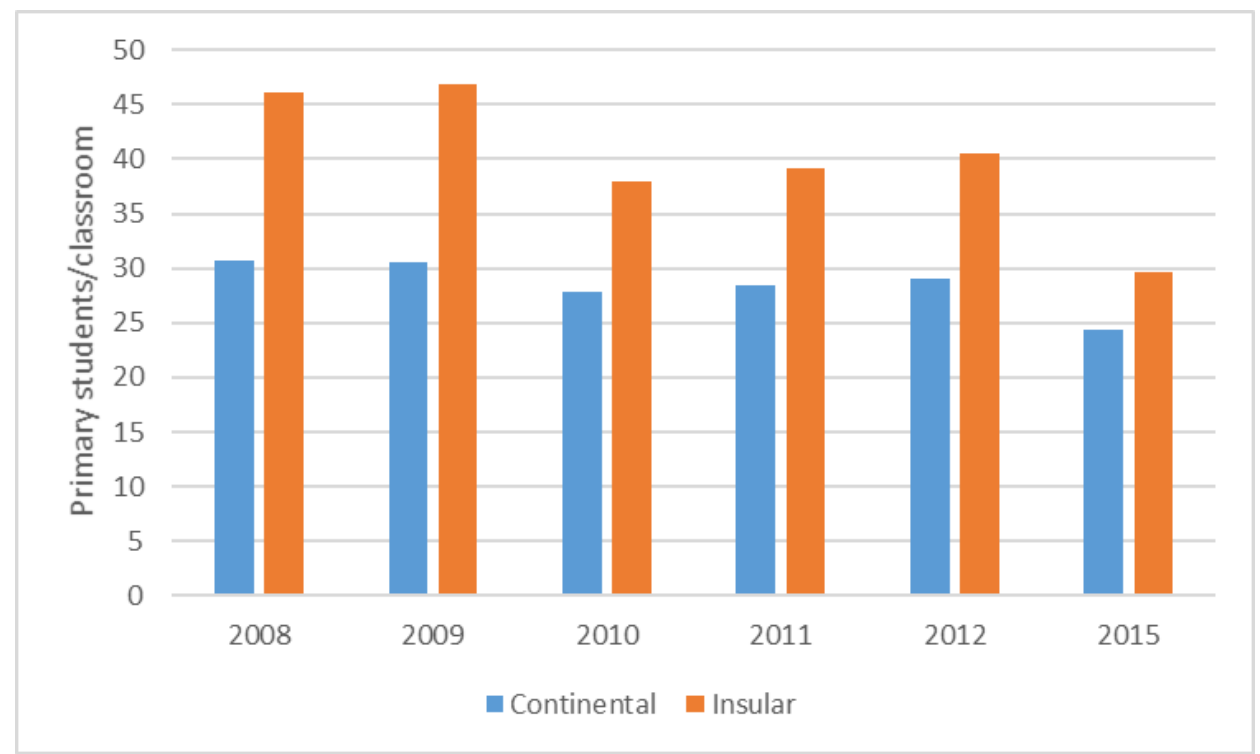

Source: PRODEGE/MEC, 2007-08 through 2014-15 Anuarios.

Data from the Anuarios suggest that primary classroom and school conditions have not improved much during 2008-2015, although these are a fairly limited set of variables. ${ }^{41}$ The percentage of primary schools with water and electricity has not changed much during 20082015. Primary schools in the Insular region were much more likely to have electricity in 2015 than in 2008 (about 75 percent versus 55 percent-gray line in Figure 4.11). But the other averages are fairly flat or, in the case of electricity in continental primary schools, the percentage has even declined (Figure 4.11).

\footnotetext{
${ }^{41}$ This topic was referenced repeatedly during interviews in Malabo and field visits to schools. A number of interview subjects made reference to infrastructure deficiencies, especially in terms of the conditions of bathrooms, water, student desks and chairs, and so on. Only a few schools were visited as part of the field visits, but in several cases, it was found that the schools were seriously lacking proper physical infrastructure. One secondary schoolwith hundreds of students in attendance-did not have functioning toilets. Serious problems were also evident with basic physical conditions of classrooms (roofs, walls) and school grounds.
} 
Figure 4.11. Primary School Conditions by Region, 2008-2015

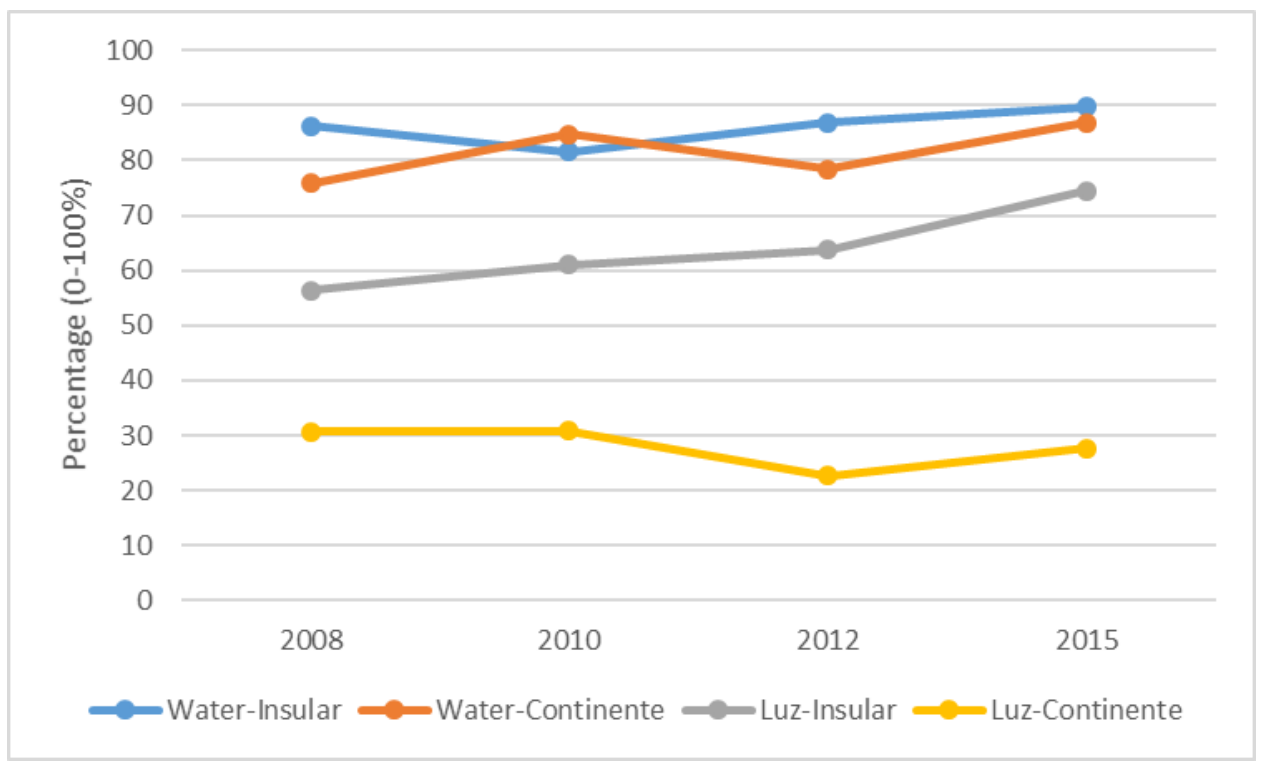

Source: PRODEGE/MEC, 2007-08 and 2014-15 Anuarios.

Finally, there are also weaknesses in school maintenance. School cleaning and other basic maintenance services, which are provided (in cities) on a contractual basis to cleaning services, appear to be unresponsive to schools' needs, and the quality of services is often poor. Some school directors also noted a lack of parental involvement in the school, which potentially affects school maintenance.

Overall, the results for infrastructure are somewhat mixed. It is not possible to gauge the full extent of the government's commitment to increasing facilities in the 'oil boom' years (before the Anuarios began), although at this point it appears that relatively few communities are lacking a primary school. Secondary school supply is clearly increasing, which is a necessary step in improving overall sector performance. It is important to hear more from the government about how it views the growing share of private schooling and how committed it remains to ensuring access to public primary schooling during this crisis. Finally, there are widespread concerns about the physical conditions in schools, which in at least some cases require urgent attention.

\subsection{School Quality}

School quality is important enough to warrant its own separate diagnostic, but this section provides a condensed review based on existing data and interviews. A good place to begin is with the government's recognition of the importance of this topic. References to school quality deficiencies were common throughout the interview portion of the diagnostic, as well as in site visits and meetings with school directors and inspectors. This not only confirms this topic is an important one, but also, more significantly, it signals a government openness to addressing school quality.

One of the challenges of reviewing school quality is deciding what constitutes the best measures of quality. Discussions with MEC officials about school quality tend to focus on basic inputs, teacher training levels, and outcomes like grade repetition and the results from the Selectividad 
test at the end of Bachillerato Year 2. All of these measures are certainly relevant to quality, and part of the reason they are commonly referenced is that most are available through the Anuario summaries. Nevertheless, these are a somewhat limited set of measures when it comes to understanding the quality of the teaching and learning environment in EQG, which is critical for identifying systemic strengths and weaknesses. So the summary in this section will focus on the data that are available but make reference to the kinds of quality indicators that are needed to delve deeper.

The main points in this section for quality include the following:

- Schools in EQG lack the kinds of basic inputs that are necessary to guarantee quality, such as textbooks for every student.

- There is a general consensus, or at least perception, that teacher salaries are low, and this has a range of negative consequences related to teacher recruitment, absenteeism, charging of extra fees, and teacher migration to the private sector.

- There is certainly evidence that teacher preparation levels are improving, due, in large part, to training programs put in place by PRODEGE.

- Assessing the state of school quality on the basis of outcomes is challenging, and most discussions refer to grade repetition and dropout rates or results of the Selectividad endof-cycle test in secondary. Evidence based on classroom observations, research, and student testing is not widely available and is mainly concentrated in the PRODEGE I period. What evidence is available, however, does suggest deficiencies in the teaching and learning environment and student achievement that is below the expected minimum level.

- The evidence on community participation in EQG suggests that the links between schools and parents are quite weak. During the school visits, school directors and teachers complained about what they perceived as a lack of interest on the part of parents.

\subsubsection{School Inputs}

Deficiencies in teacher salaries, learning materials, and physical conditions suggest that the system is not guaranteeing a basic level of quality. There is a general consensus that teacher salaries are low, which in turn has implications for pre-service training levels and the quality of teacher work. Learning materials are not available to all students. For example, textbooks are sold to students rather than provided free of charge, and as a result, not all students have their own textbooks. In most primary grades, the ratio of students to textbooks is above 3.0 and in some cases much higher (see Table 4.4). The textbook purchases are organized through the school, which takes a count of the number of students who are able to purchase the textbooks and then requests this number. The price is lower than it would be if textbooks were purchased privately, and the cost-recovery mechanism is clearly designed to aid sustainability of the text provision system. Nevertheless, large numbers of students do not have their own textbooks, which likely means sharing, borrowing, or going without this important input. 
Table 4.4. Student to Textbook Ratio by Grade and Subject, 2014-15

\begin{tabular}{|c|c|c|c|c|c|c|c|}
\hline Subject & Average & $1^{\text {st }}$ grade & $2^{\text {nd }}$ grade & $3^{\text {rd }}$ grade & $4^{\text {th }}$ grade & $5^{\text {th }}$ grade & $6^{\text {th }}$ grade \\
\hline A Globalized World I & 1.8 & 2.9 & 4.0 & 4.0 & 0.0 & 0.0 & 0.0 \\
\hline A Globalized World II & 5.8 & 21.0 & 2.0 & 12.0 & 0.0 & 0.0 & 0.0 \\
\hline A Globalized World III (I \& II) & 4.3 & 1.0 & 14.0 & 1.8 & 5.0 & 1.0 & 3.0 \\
\hline Math & 5.6 & 0.0 & 2.0 & 20.0 & 3.4 & 4.1 & 4.2 \\
\hline Language and literature & 2.0 & 0.0 & 0.0 & 0.0 & 3.5 & 4.0 & 4.6 \\
\hline Social Science & 2.3 & 0.0 & 0.0 & 0.0 & 3.7 & 4.5 & 5.5 \\
\hline Natural Sciences & 2.2 & 0.0 & 0.0 & 0.0 & 3.6 & 4.4 & 5.0 \\
\hline Religion & 96.4 & 190.0 & 182.0 & 196.0 & 5.0 & 5.9 & 5.3 \\
\hline
\end{tabular}

Source: PRODEGE/MEC, Anuario 2014-15, Table 6.4.2. (shading in original table).

\subsubsection{Teachers}

Teachers are a key driver of quality and a critical resource that must be developed and supported. There are a number of teacher training initiatives in place that are intended to upgrade teacher capacity levels. PRODEGE has been especially active in this area.

There has been significant improvement in the education profile of the average primary school teacher. In 2007-08, about 30 percent of primary teachers had diplomados, while 34 percent had only completed elemental secondary education. In 2014-15, the diplomado share had increased to 42 percent, while the elemental secondary share had declined to just 15 percent (see Figure 4.12). This is consistent with ongoing efforts to upgrade teacher education levels.

Figure 4.12. Teacher Training Summary by Level, 2008-2015

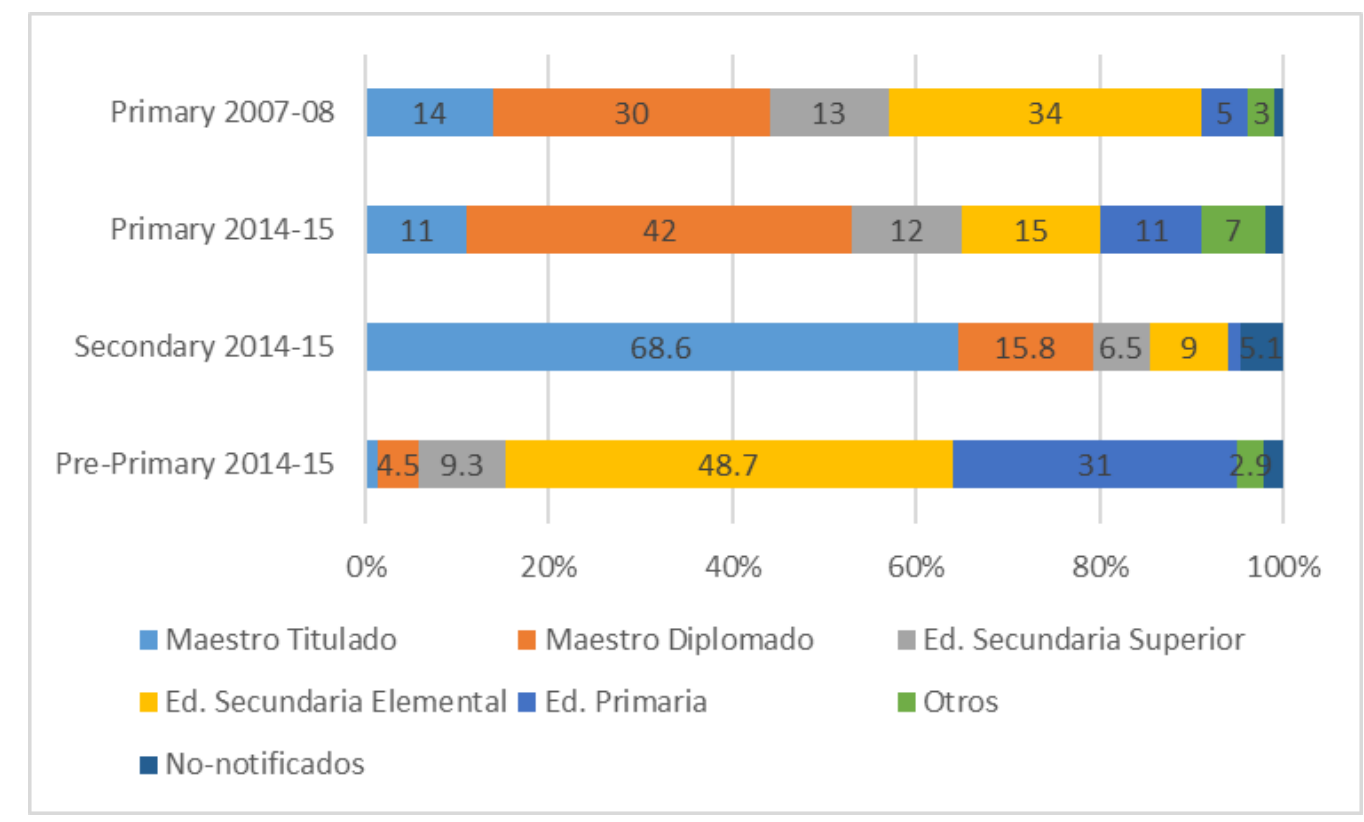

Source: PRODEGE/MEC Anuarios, 2007-08, 2014-15.

Before-and-after comparisons of teacher education in preprimary and secondary are not possible because of the focus of the Anuarios on primary education (until 2010-11). As of 2014-15, almost half of preprimary teachers have elemental secondary education, and 31 percent only have primary education. At the secondary level, the results are very different and show that roughly two-thirds (68.6 percent) are maestros titulados (university graduates), with relatively 
smaller shares of diplomado and secondary education. There has also been improvement in teacher education levels at the secondary level, since the share of non-titulados/diplomados in 2010-11 was about 40 percent compared with about 17 percent.

Education profiles in primary and secondary are improving, although at the primary level this appears to be mainly a result of in-service upgrades in education rather than bettereducated individuals entering the profession. However, relatively few teachers in primary have university education, and even at the secondary level, this proportion-while improvingis less than 70 percent. Also, a lot of work is required to significantly upgrade teacher education levels in preprimary education, which is dominated by individuals with lower secondary and primary education.

Current actions to improve the quality of teachers are framed under the ProFad initiative (Programa de Formación, Actualización, y Acreditación Docente en Servicio) with the support of PRODEGE. This training program is expected to be in place for more than two years and implemented at the district level with the support of the inspectorate. ${ }^{42}$ Given teachers' low performance, the program will create a leveling course before starting the accreditation program itself. $^{43}$

Teacher gender balance is getting closer to 50-50 parity in primary school, but preschool and secondary are far from even. Male teachers are more common at the primary level, but the ratio of men to women has declined somewhat between 2007-08 and 2014-15. This is definitely not the case in the other schooling levels. More than 90 percent of preprimary teachers are female, while almost the same percentage are males in secondary education (see Figure 4.13). This kind of gender specialization by level is not unusual for preprimary, but the lack of female teachers in secondary education is a significant limitation.

\footnotetext{
${ }^{42}$ The strategy started with a general assessment test during the first semester of 2016 for in-service preschool and primary teachers who had not completed more than ESBA education level. Out of the 2,274 teachers who participated in the test elaborated over the areas of linguistics, mathematics, natural science, and social science, only 10 teachers scored 70 percent or higher, largely confirming concerns about teacher capacity and knowledge of the basic secondary education curriculum. The majority of teachers (65 percent) scored between 22 and 49 percent correct (PRODEGE, quarterly reports, June 2016).

${ }^{43}$ Specifically, the next phase of ProFad will include a leveling course for about 800 to 1,000 teachers based on the secondary education curriculum. The objective of this leveling course is to reach the minimum standard needed to formally enroll in ProFad's accreditation course. In parallel, during the second semester of 2016, PRODEGE has been hiring and training an estimated 40 tutors who in turn will be trained by PRODEGE specialists to undertake the forthcoming accreditation courses in 2017. It is not clear yet what would be the extent of these courses in terms of how many teachers can be trained and what would drive the targeting and prioritization of them.
} 
Figure 4.13. Teacher Gender by Level, 2008-2015

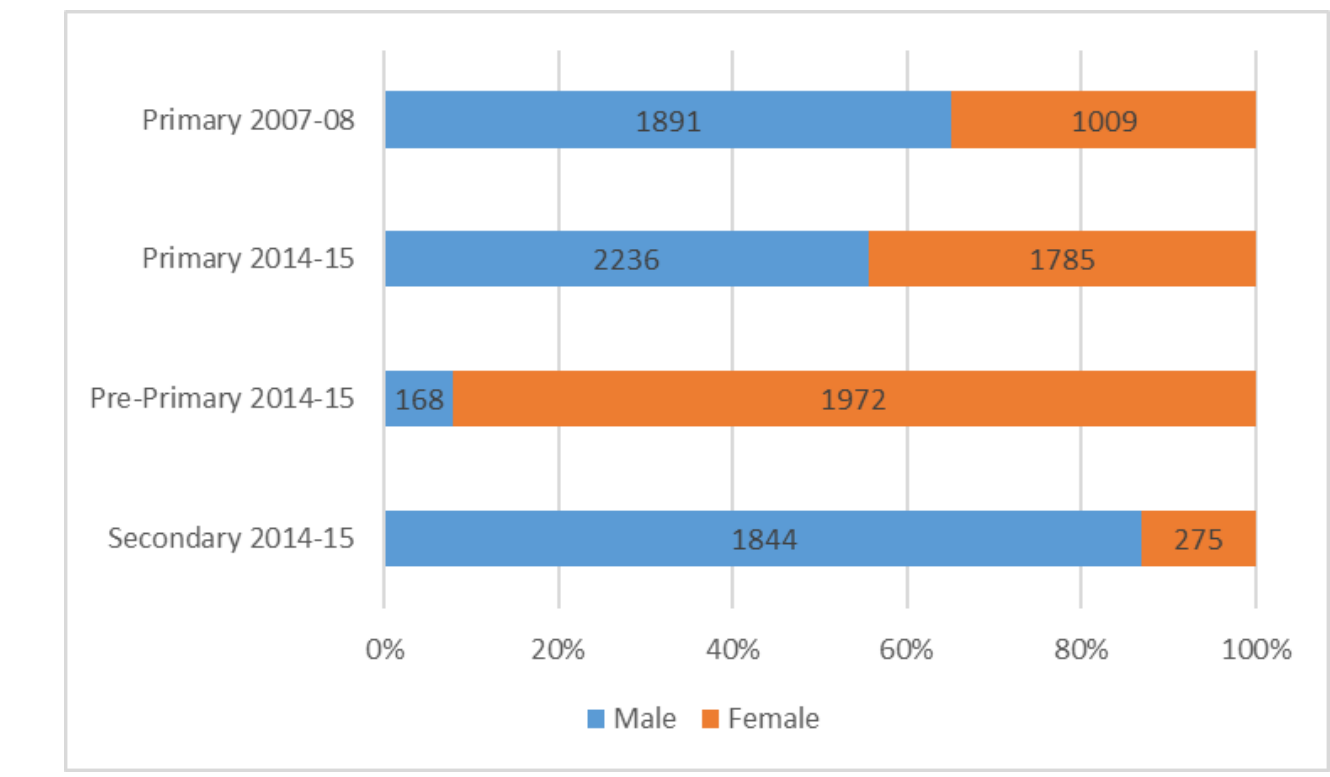

Source: PRODEGE/MEC Anuarios, 2007-08, 2014-15.

There are relatively similar age groups by schooling level. The most common age bracket is 2640 years, followed by 41-60 years. Relatively few teachers are 25 years or younger, and the same is true for over 60 years (Figure 4.14).

Figure 4.14. Teacher Age by Level, 2010-2015

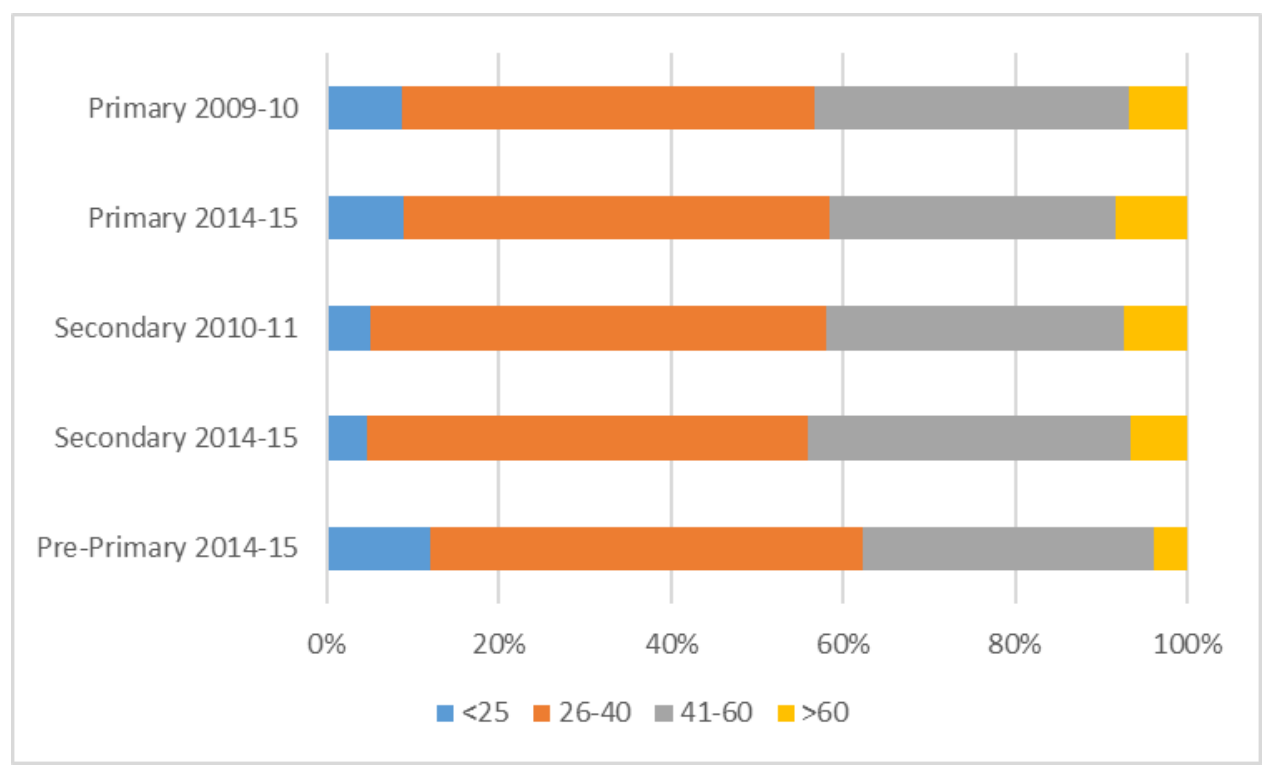

Source: PRODEGE/MEC Anuarios, 2010-11, 2014-15.

Teachers can be hired under four contract types. The three most common categories are 'Nombrado', followed by contract teachers hired by the government and school, respectively. In preprimary, the most common form is state-contracted teachers, while in primary it is Nombrado and secondary it is school-contracted. The proportion of school-contracted in secondary is probably due to the high proportion of private schools at this level. The last category includes 
volunteers (see Figure 4.15). During the fieldwork this category was referred to with some suspicion, since teachers who are reported as volunteers may actually be earning money by charging students.

Figure 4.15. Teacher Contract Status by Level, 2014-15

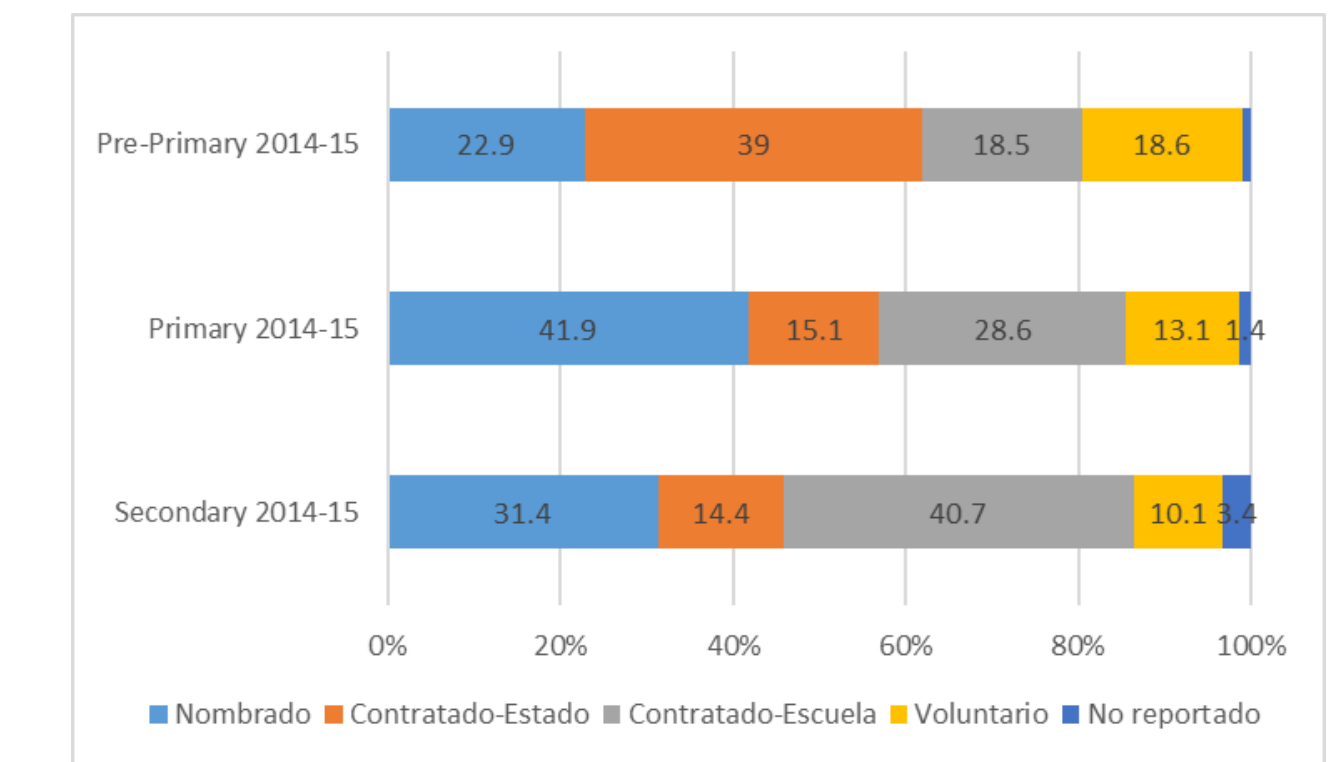

Source: PRODEGE/MEC Anuario, 2014-15.

There are serious concerns about the quality of teachers, based on discussions with MEC leaders and other education stakeholders. One of the main concerns is low teacher salaries. As noted earlier, there is a general consensus in the education sector (government, international partners, and so on) that teacher salaries are low. Unfortunately, for this diagnostic, it is not possible to update Razquin's (2006) earlier summary of teacher salaries or extend this to include comparisons of teacher salaries against other public and private professions. There is also no information on teacher salaries by level to compare primary with secondary and so on. An updated, detailed salary analysis is an important pending activity that will hopefully be included as part of the PER.

In the absence of a definitive summary of teacher salaries, some basic examples and comparisons can be provided to give some context on this critical issue. Based on interviews with the MEC and ANGE officials, it was estimated that a teacher appointed in the state payroll with an education level of primary school enters the profession with a remuneration of around CFAF 150,000 (or approximately US\$240), a teacher with a Diplomado receives CFAF 220,000 (US\$350), and a teacher with a Licenciado degree receives CFAF 250,000 (or US\$400). By contrast, non-managerial public officials appointed in the state payroll have basic salaries starting at around CFAF 100,000 for auxiliary personnel, about CFAF 155,000 for technical degrees, and CFAF 200,000 for Licenciado degree public officials.

In comparison with other developing countries, these examples of teacher salary figures do not appear to be very low. But some details are still missing, such as the evolution of the pay scale, the degree to which salaries are improving in recent years, and how these figures compare with changes in the cost of living or with private sector positions for similar levels of education. 
The comparison with other public officials is certainly useful and suggests that the teacher profession is not undervalued compared to other (non-managerial) public postings, but it may simply be that teachers are 'less underpaid'.

The number of references to low teacher salaries during the interview phase of this diagnostic strongly suggests there is at least a perception of a problem; a more detailed review is required to have the final word. Assuming this is an issue, the problems associated with low teacher salaries are manifested in two ways.

First, there is little demand to enter the profession. Education is not a popular field at the university level, although this is not unusual. But compared with many countries where there is a surplus of teachers who have been trained, there does not appear to be a high demand for entering the profession in EQG. Only 12 percent of the total university enrollment in 2015 was for the education faculty, compared to more than 30 percent registered in 2006.

Second, low salaries have a range of consequences at the school and classroom level. These kinds of problems - which are based on interviews and anecdotes rather than systematic dataare the most troubling from a quality standpoint. They include the following:

- Substitutes. A number of teachers obtain full-time 'substitutes' who replace them as teachers at the school but allow them to remain in the system, perhaps even in other (private) schools. These substitutes, in theory, are supposed to have the necessary qualifications, but in reality they may not always be suitable for the post.

- Absenteeism. Teacher absenteeism and a lack of interest in their work are other commonly cited problems. In a recent study on child labor, ${ }^{44}$ a large sample of young people expressed a number of concerns about the quality of education in the country, including about teachers who have limited patience to explain the material and are frequently absent. However, these same students observed that teacher salaries are very low, which helps explain the low quality and a reluctance to enter the field of teaching. More recently, in a series of workshops conducted by PRODEGE, it was identified that neither school principals nor academic department coordinators are supervising this issue of absenteeism (quarterly report June 2016 - PRODEGE).

- Extra charges. There were a number of references in the interviews to teachers demanding extra payments from students for various things. This may help explain the expansion of the private sector, as teachers are able to obtain more payments from students and their families. Also, the previously cited child labor study noted that some young people from the interior regions of the country complained about surcharges for textbooks.

There is little information about actual teaching quality in the country. Bivini Mangue's (2015) review notes the problematic school administration process of placing new and inexperienced teachers in the earliest grades (primer ciclo) and reserving the more 'prestigious' higher grades for teachers with more experience. PRODEGE conducted a number of research

\footnotetext{
${ }^{44}$ Corbo 2014.
} 
studies on teaching, ${ }^{45}$ which provide a wealth of information about teachers, including their opinions, challenges facing the sector, and activities in the classroom. However, this appears to be virtually the only source of information of this kind.

Overall, the PRODEGE studies found that classes in EQG tend to be teacher dominated, with a heavy reliance on dictation and copying and less use of problem solving and studentinitiated dialog. This emphasis on 'traditional teaching' served as a motivator for PRODEGE's focus on active and participative teaching methods as part of their training, which is ongoing.

In sum, the recent focus on teacher training - especially within PRODEGE-is a reflection of well-grounded concerns about teacher training levels, capacity, and their work in the classroom. However, there are likely to be limitations to training efforts that focus on in-service teachers, which is returned to later on in the discussion of the PRODEGE experience. Making the teaching profession more attractive is another key issue, which likely means raising salaries. Improving the teaching and learning environment is also necessary, which includes addressing basic deficiencies related to materials (textbooks and other materials) and infrastructure, as well as community involvement (see section 4.3.4 below).

\subsubsection{Student Outcomes}

Discussions of school quality in EQG on the basis of actual outcomes tend to focus on two sets of results. First, there are the grade repetition and dropout rates, which are very high across the basic education sequence, especially in the earliest grades. Second, the results on the Prueba de Selectividad, applied at the end of the Bachillerato sequence, are also referenced as a measure for how the system is performing.

Both sets of results have some utility for measuring quality and monitoring progress, but they also have some limitations. Measures of student flow (repetition, dropout, and so on) are certainly relevant, but they are only indirect measures of what students are actually learning and what kinds of skills they are obtaining. Repetition and dropout are often attributed to low achievement, but as discussed in earlier sections, there are other, systemic factors that can affect student flow measures.

The Selectividad provides information on actual student competencies at the end of the basic education sequence (high school), but the problem is that this information is only applicable to a reduced set of students. A series of filters are in place, beginning with the 'natural' filtering - dropout and repetition - that takes place between grades 1 and 12. And even among grade 12 students, not all are allowed to take the Selectividad exam. An additional filter is implemented that restricts the eligible Grade 12 population.

The Selectividad acts as a form of entrance exam for the national university, which is consistent with the low pass rates. In 2015, only 18.8 percent (or 501) of the 2,683 students who took the exam received a passing score. The pass rate was higher in the Continental region

\footnotetext{
${ }^{45}$ These took place mainly during 2008-2011 (PRODEGE I) and include a diagnostic study of teaching in the country (PRODEGE 2009) and other studies on the impact of PRODEGE-led training related to active and participative teaching methods (PRODEGE 2011), among other studies.
} 
(21.3 percent) compared with the Insular region (14.9 percent). In 2016, 9.3 percent (or 314) of the 3,387 students who took the test succeeded, with the same average for the two regions. There were no significant differences between male and female performance.

Pass rates on the Selectividad have declined since 2013-14. The pass rate was 54 percent in 2013-14, 18.7 percent in 2014-15, and 9.3 percent in 2015-16 (see Table 4.5). The underlying reasons for this are a matter of national debate, with some factions pointing to the UNGE as responsible by raising the standard of the test and designing it without regard for the current curriculum and others pointing to the overall system quality.

Table 4.5. Selectivity Test Results, 2011-2016

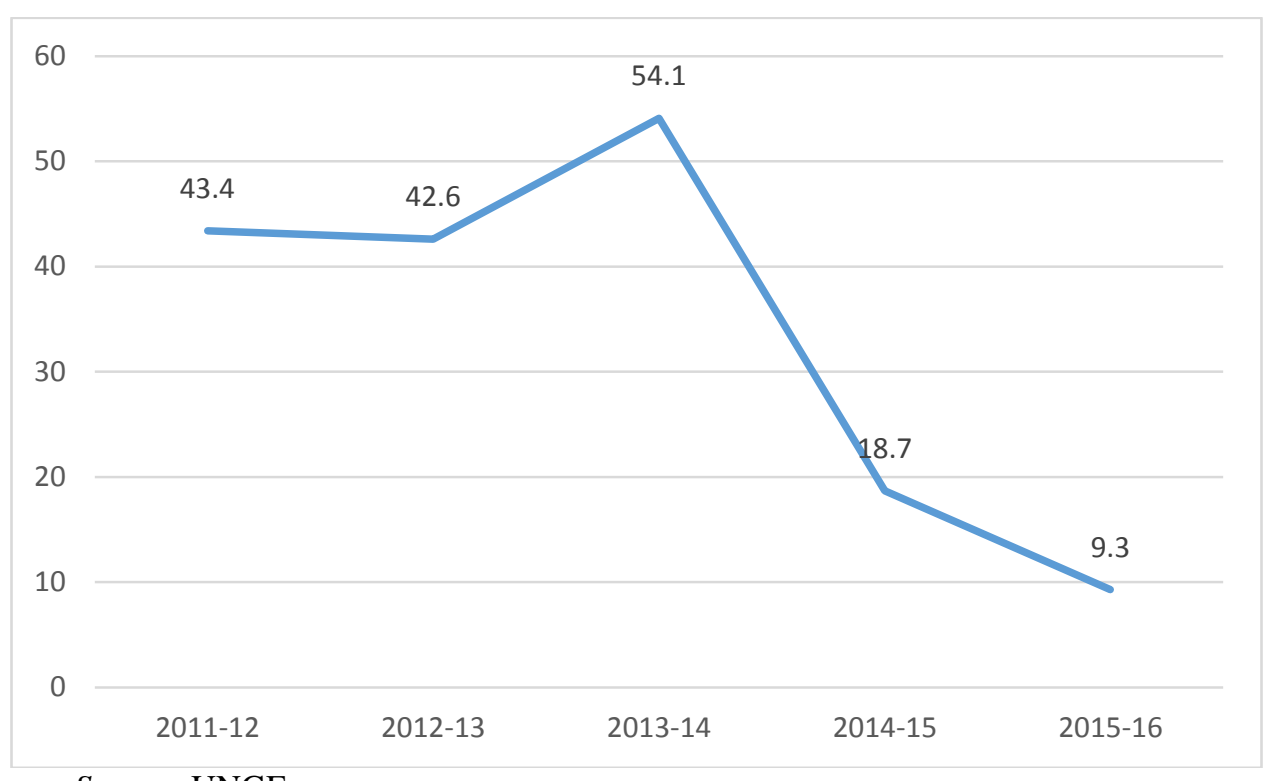

Source: UNGE.

The numbers of students who take the Selectividad has been declining in recent years (from 6,089 in 2013-14 to 3,387 in 2015-16). In conversations with MEC personnel, there was general agreement that too many students had been allowed to take the test in 2014-15 and that the results would likely improve in 2015-16 with a more restrictive filtering system in place. One school director noted that the admissions the previous year had indeed been too generous and that in his school, they would only allow students with zero subject failures to take the exam. However, even with an apparently more restrictive filtering process in place, the pass rates have not improved.

The Selectividad serves a purpose as an entrance exam for higher education, but otherwise the results are of limited utility for monitoring quality in the education system. What is needed instead are assessments of student achievement levels at different grades, beginning with very basic skills in the earliest grades. This kind of information is increasingly available throughout the developing world, beginning with Early Grade Reading Assessment (EGRA) and Early Grade Math Assessment (EGMA) that help identify basic reading and mathematics skills 
among young students, complemented by end-of-cycle standardized tests in grades 3, 6, 9, and so on that are used to monitor systemic progress on the basis of student achievement levels. ${ }^{46}$

Collecting data on student achievement outcomes is not the only 'outcomes-based' approach to monitoring system performance. Data can also be collected on teaching outcomes to give a better idea of the teaching and learning environment itself. In many countries (including EQG), this type of monitoring is carried out, in theory, by the inspection system. But it is also important to have information on what students can actually do, which is where test-based outcome monitoring comes in.

The literature review for this diagnostic only identified a couple of data collections where information on student achievement levels in EQG was measured using standardized tests. This information again comes from the PRODEGE I period, when program staff applied standardized tests to monitor the impact of teacher training activities and the implementation of the Escuela Activa model. The samples were created as program evaluation samples rather than being nationally representative, but the results still provide useful information about student achievement levels in early grades.

The results from the PRODEGE studies (2008-2011) largely confirm the kinds of concerns about school quality that have been detailed throughout this diagnostic. Standardized tests (applied individually or 'one on one', like an interview) were used to measure student skills in language and mathematics across a cohort of students who were in grade 1 in 2008, followed up in 2009 and 2010, and then in a separate group of grade 1 students in 2011. The results show that reading and writing skills were very low. For example,

- At the time of the 2011 test application in grade 1, 60 percent of the students were classified as Low Achievement (Dominio Bajo) in the Common Words reading section, meaning that they were unable to read any words or could only read part of a single word;

- In 2011, more than 70 percent of grade 1 students were classified as Low Achievement in the other (non-reading) test components;

- At the end of grade 1, relatively few students were able to write more than five words. This average was somewhat higher among older children (sobre-edad) compared with children of the correct age for their grade;

- The results in mathematics were also low, as less than 10 percent of grade 1 students achieved a 'High Achievement' level; and

- Students who had been exposed to Escuela Activa generally had better results in language, but the results in mathematics were similar. The apparent effect in language is an important result given the emphasis of the teacher training in recent years on this methodology. But it is important to note that the positive impacts were relatively small and that overall achievement levels in early grades were still quite low.

\footnotetext{
${ }^{46}$ See Clarke (2011) for a review of different kinds of assessment activities.
} 
High repetition and dropout rates, low pass rates on the Selectividad exam, and low scores on standardized tests applied during PRODEGE testing all point to the same conclusion: students are not reaching the expected, or minimum, learning levels on the official curriculum. This is not an unusual result - even in industrialized countries - and it is important to put these kinds of findings into the proper perspective. Simply stated, what they suggest is that the system is not performing as well as it should be. This does not mean that teachers or students or parents "are to blame." It simply means that more work is needed to improve quality, and based on some initial results from PRODEGE, there already has been some improvement.

\subsubsection{Community Participation}

Community participation is a potentially important aspect of the schooling environment. Parents and community members can help schools with basic repairs and maintenance, as well as participate in school activities, help their children with homework, and even work alongside teachers and school directors to make decisions about school management. Making parents and community members genuine partners in the schooling process is a considerable challenge, even as part of interventions (like school grants) that explicitly require parents to take on management and advisory roles. Nevertheless, some amount of parental and community engagement in the school is necessary.

The evidence on community participation in EQG suggests that the links between schools and parents are quite weak. During the school visits, school directors and teachers complained about what they perceived as a lack of interest on the part of parents. Most schools have parental associations in place (Asociación de Padres), but they appear to have limited involvement in the school after the initial enrollment phase when textbooks are purchased, fees are paid, and children are formally entered into school.

There is some data to support the qualitative evidence on weak community engagement obtained during the field visits. PRODEGE's (2011) study on teacher quality cites data from the first Anuario data collection (not presented in Anuario report). They show that most teachers (about 80 percent) report that parents participate in the initial enrollment of their children and come to the school when asked. But the other indicators show far less involvement: parents participate in activities related to security, maintenance, and school management in only about 30 percent of schools (according to teachers). In a separate PRODEGE study on the impact of the teacher training, a survey of teachers in 2010 found that only about 20 percent reported that parents regularly helped clean the school or contribute resources. ${ }^{47}$

One of the goals of the teacher training efforts organized by PRODEGE is to stimulate more involvement of the community in the school, as well as more involvement of teachers in the community itself. The results from the initial PRODEGE surveys show some limited impact along these lines, although the authors note that in comparison with classroom aspects, the community participation indicators did not change much as a result of the trainings.

These kinds of results are, again, not unusual in the developing world. Poor parents, or parents with low levels of education, may not feel comfortable engaging with the school. They may have

\footnotetext{
${ }^{47}$ PRODEGE 2011.
} 
limited time to do so or not have much to contribute. Also, school personnel often see parents as simply a supply of labor for school cleaning or maintenance but are not interested in their participation in other aspects of school. These are not easy attitudes to change (on both sides), but it does seem clear that more can be done in EQG to stimulate community involvement in the school, which in turn has the potential to help improve quality. Once again, the initial steps taken as part of PRODEGE provide some useful experiences to build on. (Appendix G outlines lessons learned from the PRODEGE project.)

\subsection{Data and Research}

This section focuses on data availability, capacity, and future data and research needs. Data and research capacity are critical to help inform stronger education systems for evidence-based decision making in education. For instance, without data it is impossible to accurately assess infrastructure needs and deploy teachers where they are needed.

\subsubsection{PRODEGE/MEC Anuario}

The PRODEGE-MEC statistical summary (Anuario) has provided an increasingly sophisticated system that now covers preprimary, primary, and secondary (plus Technical and Vocational Education and Training [TVET] recently added in 2014-2015) education levels. However, based on interviews with the MEC and PRODEGE personnel, there are a number of challenges facing this system, especially since PRODEGE is scheduled to end in 2019. In terms of capacity building, despite increased capacity since the beginning of this process, there is still some technical assistance provided via PRODEGE in the form of international consultants. The goal is to slowly remove the assistance and ensure that the MEC team that is responsible for the Anuarios can independently complete the process, including data management functions and high-quality data collection. PRODEGE is in the process of developing a sustainability plan for the Anuario process that guarantees that the function continues into the post-PRODEGE period.

The largest problem is incomplete information from schools. The MEC staff observed that almost all schools are reporting information to the MEC, but that the information is not always complete (that is, missing entire sections), or it does not appear to be accurate. ${ }^{48}$ Moving forward, this issue of incomplete information is critical, since high levels of capacity in data management and analysis will not guarantee a quality product unless the data itself are accurate and complete.

In the future, other actors may play a role in the Anuario. The national statistics office (Instituto Nacional de Estatistica Guinea Ecuatorial, INEGE) has expressed an interest in being more involved in the work of the MEC Anuario, and INEGE is currently receiving technical assistance from the World Bank. In the past there have been some problems in relations between INEGE

\footnotetext{
48 One reason why schools may not be fully engaged in the Anuario reporting process is because of the temporary discontinuation of this function between 2012 and 2014, when PRODEGE scaled back support and the MEC did not continue the data collection process. The complications caused by the interruption of the data collection for two years are a reminder of how crucial it is to provide sustained support for initiatives to guarantee their institutionalization over the long term.
} 
and other entities working in the area of data and information, but it is important to note that INEGE is the entity responsible for statistics-related research and reporting across all ministry departments. Better coordination between INEGE and PRODEGE-MEC could therefore potentially be useful for both entities. Appendix $\mathrm{H}$ has more information on the PRODEGE/MEC Anuario.

Beyond the Anuarios, there is very limited information on education. The 2011 DHS (EDSGE-I) is the only household survey data source that is available, and the most recent census data are from 2001. It is not clear when the next sample-based survey is planned, but repeated references have already been made to the importance of obtaining updated population data when the latest census data are made public. Just having the data is one thing, but it is also necessary that census and other information be provided to entities like PRODEGE-MEC in a timely and effective manner (that is, providing the kinds of specific population data that are needed and not just the standard age category summaries).

\subsubsection{Education Research}

In EQG, there is very little original research in education to draw on. The main source is from the PRODEGE I period (2005-2011), which generated a large number of research studies, bulletins, and discussion papers. ${ }^{49}$ In recent years, there has been no additional research on education in the country, and it is not clear if PRODEGE II has new research undertakings planned. As a result, almost all of the information available comes from the Anuarios. These are certainly useful, but more is needed.

There are two main sources for original research in the country. The first is from education partners such as PRODEGE, United Nations Children's Fund (UNICEF), and other UN entities, which historically have provided the most data and information on education in the country. These partners must be encouraged to continue to serve this function, ideally in close coordination with the government to ensure that the research topics are timely and relevant and that government capacity can be developed by participating in the activities. This is a potentially expensive undertaking, but the country cannot continue to rely solely on the Anuario for education data. This is especially true for outcomes like student achievement, which require a separate data collection modality (that is, an assessment project).

The second potential source of original research is the university system. UNGE staff complained about a lack of resources for research. It is not clear what the capacity level is for undertaking research, even if resources are available. Nevertheless, this is another modality that should be considered as a means of generating new research on the education sector, especially qualitative data that focus on schooling processes.

\subsection{Spotlight on Higher Education and TVET}

\subsubsection{Higher Education}

\footnotetext{
49 This research is available on the PRODEGE website (http://www.prodegeguineaecuatorial.com/wp/es/), although the PRODEGE office also makes a CD-ROM available with a more complete summary of documents.
} 
The higher education system in EQG is still relatively new and mainly consists of the offerings at UNGE. Higher education is a stated priority of the national government and the MEC. In terms of financing, the 2006 diagnostic showed that higher education received a relatively large share of total education spending and more recent analysis in 2016 from the PIMM RAS showed the concentration of public investment in higher education infrastructure expansion (see Figure 4.1).

UNGES' academic structure has had historically two branches: faculties offering Bachelor's degrees in four years (licenciatura) and university schools offering technical education diplomas in three years. In 2015, UNGE had 4 faculties and 2 university schools in Malabo and 2 faculties and 2 university schools in Bata. According to the total enrollment in 2015, the most popular faculties and schools among the students were the faculty of Social Science ( 27 percent of the enrollment); the school of administration (17 percent); the school of agriculture, fishery, and forestry (13 percent); and the schools of education of Malabo and Bata, accounting for another 12 percent of the enrollment. (Appendix $J$ includes more information on the university programs, students, and staffing.)

It is not possible to plot the evolution of enrollments for 2006-2015; however, a relatively simple comparison of snapshots of the two years (2006 and 2015) provides some interesting insights on the sense of the academic structure evolution. Compared to the 2006 figures, total enrollment has increased more than fivefold, going from 1,466 students in 2006 to 7,971 students enrolled in 2015. Between 2006 and 2015, there was a steep decline of enrollment in the education school. However, in 2006, the education school accounted for 37 percent of enrollment; in 2015 it accounted for only 12 percent. ${ }^{50}$

Based on interviews at UNGE, a number of challenges and issues were identified. The main concerns are related to budgets and resources. One person noted the gap between national priorities and goals in higher education and actual resources for implementing these goals. The university system lacks teaching materials and adequate infrastructure, including quality Internet. There are also limited resources available for scholarships, although it is not clear to what extent these scholarships target poor students or are based on ability. They are likely favoring wealthier students. There are also very few resources for research, and as a result, there are not many research projects taking place.

Another problem is the absence of a program for training teachers at the university level. As mentioned repeatedly, the low salaries in education provide a strong disincentive for entering this field, which is notable, at the university level, by a lack of interest in this career.

\subsubsection{Technical Education (Professional and Vocational Training)}

Technical education and vocational training is divided into two categories by the MEC: programs that are controlled and supervised by the MEC and that comply with its legal standards and programs that, despite being formally established in the country, are not ruled by the MEC's rules and regulations or supervision and are not complying with the MEC standards and

\footnotetext{
${ }^{50}$ All the other programs' shares remained relatively stable, with the exception of the faculty of letters and social science that has increased its participation from 12 percent in 2006 to 27 percent in 2015.
} 
regulations. The MEC has 27 families of programs with around 130 titles and grades governed by the actual norms and regulations. There are two levels of technical education: a basic twoyear cycle and a more advanced two-year cycle. Appendix I includes more information on the professional and vocational training.

As is the case with university education, professional and technical education is concentrated in Malabo, with 60 percent of the enrollment in 2015 and 55 percent in 2014. Unlike university education, technical and professional education is dominated by female students. This female dominance is more evident in some specific programs such as administrative studies and support for business administration, nursery, and secretarial studies for the basic cycle. For the advanced cycle administrative duties, human resources and finance and banking are the most representative.

In another contrast with the higher education offered by UNGE, technical and professional education is driven mainly by the private sector. In the basic cycle, 22 percent and 33 percent of the total enrollment is represented by private offer for the basic cycle in 2014-15 and 201314 , respectively. The advanced cycle is driven almost entirely by private institutions, including 95 percent of students.

Vocational training aims at developing skills oriented toward the labor market and in close coordination with specific private sector needs and performances. As is the pattern for technical education, vocational training presents an even more markedly female enrollment of 72 and 81 percent for 2014-15 and 2013-14, respectively.

However, the programs do not seem to be well matched with economic opportunities. Very few programs aim to develop skills for agriculture and fishery, two of the sectors the government has identified as potential engines of the economy to help balance with the oil sector. Also, skills are not abundant in the construction sector, which is not coping with the needs of the secondlargest source of GDP growth during the past years.

\section{Part C: Policy Options}

The GoEG has articulated clear goals for education. These include (a) ensuring universal coverage in preschool and primary education, and a 98 percent gross enrollment rate in secondary education; (b) improving the quality of education, including adequate teacher preparation; (c) eliminating gender discrepancies at all levels; and (d) improved and expanded professional, technical, and higher education adapted to the necessities of the labor market. These goals are well focused on the key target groups and strategic areas in the country.

The following policy recommendations provide options to reach the government's four goals as well as an additional goal of improved education financing, taking into consideration the current economic crisis in the country. The recommendations attempt to reflect promising solutions to maintain access to education and basic school functioning, especially for poor children, while improving school quality and systems data.

Increasing enrollment in preschool, primary, and secondary education 
The main reasons for dropout during the school year were identified as child sickness, lack of a teacher, and lack of money to pay for studies. In a situation of economic crisis, where enrollment may already be decreasing, the ability to pay for school or related expenses (school supplies, transportation, clothes, etc.) is likely to diminish. Some options to reduce dropout and keep poor children in school include cash transfers (either unconditional or conditioned on school attendance), school feeding, and transportation subsidies. According to the information in this diagnostic there is no such program in EQG so it could be difficult to begin to implement such an intervention, unless started on a small scale with a focus on children most at risk. Adolescent girls could be a target of these transfers to maintain their attendance in secondary school.

\section{Comprehensive approach to reduce grade repetition}

Addressing the problem of high repetition rates in primary school requires a comprehensive approach. This would consist of several aspects: (i) expansion of pre-primary, (ii) enforcement of age requirements in primary; and (iii) a clear threshold for repetition rates coupled with personalized attention to the weakest students.

Ensuring access to quality preschool is the best way to prepare young people for primary school, which in turn can reduce repetition and dropout rates. There is a significant geographic disparity in preschool access in EQG with 75 percent of preschool enrollment in urban areas. Access in rural areas could be expanded through the creation of community-based preschools, expansion of public provision, or the addition of private preschools, provided there is sufficient monitoring and oversight by the MEC.

Early entry into primary, before the official entry age of seven, is fairly common. According to the 2014-15 Anuarios, nearly one-third of grade 1 entrants in 2014-15 were below seven years of age at the national level and 42 percent in the Insular zone. Enforcement of entry age requirements in primary would prevent younger children from joining too early, thereby allowing teachers to focus on ensuring learning and grade progression for the age-appropriate students in the class.

A clear threshold for repetition rates, coupled with personalized attention to the weakest students could allow the MEC to better limit repetition rates. For example, a threshold of 10 percent repetition could be held, with the rest of the children automatically progressing with additional attention for the weakest students to ensure they can learn and perform in the subsequent grade.

\section{Improving the quality of education}

\section{School grants to improve basic school conditions}

Learning materials (such as textbooks) and infrastructure deficiencies, including poorly resourced and dilapidated schools and classrooms, have been identified as key constraints limiting the country's ability to achieve a basic set of quality conditions for students to learn in EQG. One solution to these problems is the provision of school grants, that is, cash grants that 
are disbursed to schools to address priorities as defined by the school and local community. Activities like purchasing textbooks and other learning materials as well as improving physical conditions (and school maintenance) are commonly supported by school grants. The overarching goals of school grant programs are to improve school conditions for learning while also using the planning and execution process to improve school management capacity as well as strengthen the interface with parents and the community. School grants therefore have a lot of potential to address a range of needs in EQG schools, with the added advantage that the grant does not have to be a 'one size fits all' intervention. Grants can also be targeted to the regions and schools with greatest need and be made conditional on the achievement of simple education outcome/output indicators to increase school accountability for results.

\section{Teacher sector reform}

In the context of economic crisis in EQG, there is a risk of increased teacher absenteeism (for example, if teachers do not receive regular payment from the Government or seek other work to earn enough money) and diminished investment in teacher training due to limited financial resources. In such a situation, it is critical to ensure first, that teachers continue to show up at schools to teach children and, second, that the quality of teaching is as high as possible. According to a series of workshops conducted by PRODEGE in 2016, it was identified that neither school principals nor academic department coordinators are supervising the issue of absenteeism. It would be important, then, to ensure that such monitoring takes place. that public school teachers receive consistent payment, especially those working in areas most affected by the crisis, and that mechanisms are in place to replace teachers that are not showing up.

To ensure high quality teacher training, there is a need to ensure sufficient Government resources are allocated to pre- and in-service training. Indeed, training must be strengthened to better orient teachers to effective pedagogies (for example, child-centered rather than teacher-dominated) and classroom techniques. There is a particular need to ensure improved training of preschool teachers, who are currently the least trained, since research shows that quality preschool education can contribute to reducing grade 1 repetition, a significant problem in the country. An alternative teacher training program, such as a shorter condensed program, particularly for teachers in rural areas, could be developed to expand the number of teachers in the short term, with a path to certification planned over time.

Improving data collection, data quality, and analysis to improve the evidence-based policy planning process

Improving data collection, data quality, and analysis can be supported by three specific policy actions. First, a Service Delivery Indicator (SDI) study would be useful as a way to obtain more data on service delivery in EQG, especially given the lack of data and the potential effect of the economic crisis. A Service Delivery Indicator (SDI) study uses a set of education indicators to examine the effort and ability of staff and the availability of key inputs and resources that contribute to a functioning school. The surveys measure the performance and quality of education services using cutting-edge methodologies and a high degree of quality assurance and generate nationally representative indicators, disaggregated by rural and urban location, and public and private provider type. The survey instrument is nimble allowing for relatively rapid fieldwork and data analysis, making it more useful for decision making and policy discussions. 
This would provide data to shape policy decisions regarding teachers, learning materials, and other inputs needed to ensure school quality. Ideally, some of the key questions could eventually be integrated into the EMIS.

Second, learning assessment can provide up-to-date information on student achievement levels in different grades (and subjects), and also help create a 'culture of assessment' in the country, which can in turn facilitate more expansive quality monitoring and support activities later on. To fill the gap in learning assessment data in EQG, it is recommended that sample-based assessments take place at different grade levels to determine how well students in specific grades are able to answer questions taken from the official curriculum. For example, the Early Grade Reading Assessment (EGRA) and Early Grade Math Assessment (EGMA) could provide insight into how well the youngest children are learning while there is still time to adjust teaching methods and ensure they learn in subsequent years. Results can be used to inform and adapt the teacher training system improvements noted earlier.

Third, high quality support and monitoring is needed. Having a strong Education Management Information System (EMIS) in place provides a foundation for an effective overall monitoring system, with the added advantage of making schools comfortable with a system where data is collected on an annual basis. The Anuario process that was implemented as part of PRODEGE has served a critical function in a data-constrained environment and should be strengthened to guarantee that it continues to provide at least a minimum amount of annual information on all schools. The ultimate goal is a strong, two-way flow of information where schools are being constantly monitored to define their needs, this information is then processed at different levels, and then information flows back to the schools in the form of support intended to address their specific needs.

\section{Eliminating gender discrepancies in enrollment}

\section{Support for adolescent girls and early childhood development}

The critical period for girls' enrollment is in late adolescence. The main reasons for girls leaving school at this time are likely related to pregnancy and starting their own families, work demands at home to take care of other family members, or a household aversion to continuing the educational investment for girls, especially as the direct and indirect costs increase by educational level. To address this increase in girls' dropout rates in late adolescence in EQG, the most at-risk adolescent girls should be targeted with comprehensive programs including mentorship, financial assistance, childcare support, and sexual and reproductive health services. This would require collaboration across ministries of health, education, and so on. It would also be beneficial to remove the ban on pregnant teenage girls staying in school, if it is still in place.

Children of teenage mothers are at higher risk of illness, poor nutrition, and mortality than children of older mothers. At the same time, adolescent mothers are less likely to take preventive measures to ensure their children's health and nutrition, which can adversely affect cognitive and socioemotional development and learning and put children of teenage mothers at higher risk of poor development outcomes. Therefore, early childhood development support for these children is critical. This could be parenting counseling for adolescent mothers and other caregivers 
(perhaps delivered through the health system), subsidized access to childcare (ideally near the adolescent mother's school), and financial support.

\section{Education financing}

\section{Identification of priority spending needs and plans for execution}

To guarantee the necessary inputs for a quality education system, education financing must be of sufficient size and prioritized according to the greatest needs-rather than the current bias toward infrastructure and higher education. For example, there is the consistently low spending on preschool in EQG and yet preschool is critical for building the foundation of children's learning and preparing them to be successful in primary school. Given the conditions of economic crisis in EQG, it is essential to identify the most important budget lines to maintain basic education functioning and then ensure that the available money is actually disbursed. This requires identifying spending needs and laying out detailed plans for how these will be executed, with specific goals and targets.

Improved monitoring and evaluation of private schools and support for Strengthening Public Private Partnerships (PPPs)

Given that both primary and secondary education is becoming more private in EQG, it would be important to better monitor and evaluate the supply, quality, and cost of private education. Based on this information, there could be opportunities to strengthen Public Private Partnerships (PPPs), including, for example, better design of the subsidies provided by Government to private schools, such as tying the funding to specific process and performance results for private schools. 


\section{References}

Bivini Mangue, Santiago. 2015. “Informe Temático Sobre el Objetivo de Desarrollo del Milenio \#2: Lograr la Enseñanza Primaria Universal.” Malabo, EQG: UNICEF y PNUD.

Bolobo Ekobo, P. 2001. El estudio de perspectivas del sector forestal en Africa: La República de Guinea Ecuatorial: FOSA.

Clarke, Marguerite. 2011. "Framework for Building an Effective Student Assessment System." READ/SABER Working Paper, World Bank, Washington, DC.

Corbo, Gabriel. 2014. "Empleo Juvenil en Guinea Ecuatorial: la dinámica del mercado laboral y la educación.” Malabo, EQG: PNUD.

DHS (Demographic and Health Survey) 2011. Ministerio de Sanidad y Bienestar Social, Ministerio de Economía, Planificación e Inversiones Públicas, e ICF International. 2012. “Encuesta Demográfica y de Salud (EDSGE-I) 2011.” Calverton, Maryland, USA.

Dyombe, Marlène Evita. 2009. El sistema educativo en Guinea Ecuatorial, Educación y Futuro Digital. http://www.cmeyanchama.com/Documents/Guinee/marlene_Educacion_en_Guinea.pdf [downloaded June 24, 2016].

Freedom House. 2017. "Freedom in the World 2017.” www.freedomhouse.org.

Maroto Blanco, Jose Manuel. 2014. "La Ayuda Oficial al Desarrollo española en Guinea Ecuatorial: un análisis crítico.” Cuadernos Geográficos 53 (1): 1-27.

OECD (Organisation for Economic Co-operation and Development). 2016. "Education at a Glance.” OECD Indicators.

PNDES review (2014) of the Plan Nacional implementation: "Invertir masivamente en educación y sanidad." *This is cited above in spanish as a Ministry of Economia document

PRODEGE (Programa de Desarrollo Educativo de Guinea Ecuatorial). 2009. Docentes de la Educación Primaria en Guinea Ecuatorial: Características y Desafíos.

—. 2011. Cambios en el Desempeño Docente en Educación Primaria.

Razquin, Paula. 2006. "Informe de Situación del Sector Educación y Lineamientos para Fortalacer la Política Educativa." Malabo, EG: Banco Mundial.

Rodriguez, Juan Carlos. 2012. Evaluación del EMIS en Guinea Ecuatorial. UNESCO-IIEP. 
UNICEF (United Nations Children's Fund), and UNESCO (United Nations Educational, Scientific, and Cultural Organization). 2015. "Global Out of School Children Initiative Operational Manual.” New York: UNICEF.

UNESCO (United Nations Educational, Scientific, and Cultural Organization) Institute for Statistics. http://uis.unesco.org/en/home.

World Bank. 2004. World Development Indicators 2004.

—. 2010. Equatorial Guinea: Public Expenditure Review. World Bank.https://openknowledge.worldbank.org/handle/10986/3011 License: CC BY 3.0 IGO.

. 2014. What matters most for engaging the private sector in education: A Framework Paper. World Bank Systems Approach for Better Education Results (SABER) Working Paper Series.

- 2015. From Mines to Minds: Turning Sub-Saharan Africa's Mineral Wealth into Human Capital. 